\title{
Population Genetics of the Red Rock Lobster,
}

\section{Jasus edwardsii}

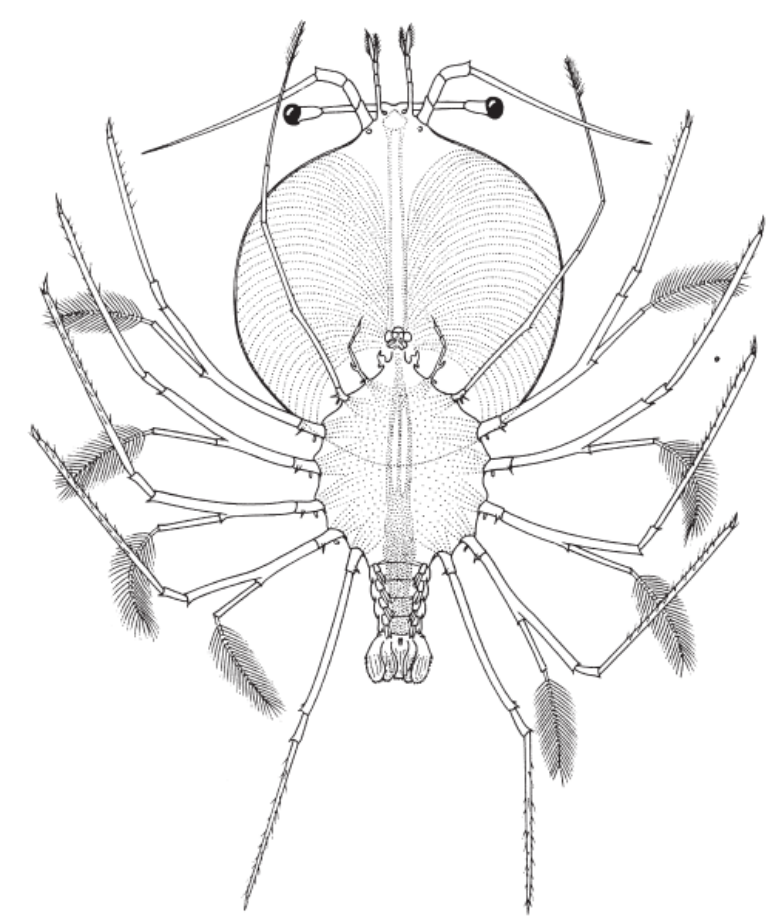

\section{Luke Thomas}

A thesis submitted to the Victoria University of Wellington in partial fulfilment of the requirements for the degree of Master of Science in Marine Biology.

Victoria University of Wellington 2012 
This thesis was conducted under the supervision of:

\section{Dr. James J Bell}

Victoria University of Wellington

Wellington, New Zealand 


\section{General Abstract}

Understanding patterns of gene flow across a species range is a vital component of an effective fisheries management strategy. The advent of highly polymorphic microsatellite markers has facilitated the detection of fine-scale patterns of genetic differentiation at levels below the resolving power of earlier techniques. This has triggered the wide-spread re-examination of population structure for a number of commercially targeted species. The aims of thesis were to re-investigate patterns of gene flow of the red rock lobster Jasus edwardsii throughout New Zealand and across the Tasman Sea using novel microsatellite markers. Jasus edwardsii is a keystone species of subtidal rocky reef system and supports lucrative export markets in both Australia and New Zealand. Eight highly polymorphic microsatellite markers were developed from 454 sequence data and screened across a Wellington south coast population to obtain basic diversity indices. All loci were polymorphic with the number of alleles per locus ranging from 6-39. Observed and expected heterozygosity ranged from $0.563-0.937$ and $0.583-0.961$, respectively. There were no significant deviations from Hardy-Weinberg equilibrium following standard Bonferroni corrections. The loci were used in a population analysis of $J$. edwardsii that spanned 10 degrees of latitude and stretched 3,500 km across the South Pacific. The analysis rejected the null-hypothesis of panmixia based on earlier mDNA analysis and revealed significant population structure $\left(F_{S T}=0.011, R_{S T}=0.028\right)$ at a wide range of scales. Stewart Island was determined to have the highest levels of genetic differentiation of all populations sampled suggesting a high degree of reproductive isolation and self-recruitment. This study also identified high levels of asymmetric gene flow from Australia to New Zealand indicating a historical sourcesink relationship between the two countries. Results from the genetic analysis were consistent with results from oceanographic dispersal models and it is likely that the genetic results reflect historical and contemporary patterns of Jasus edwardsii dispersal and recruitment throughout its range. 
Dedicated to my loving parents: Jenny and Nick 


\section{Acknowledgements}

There are a number of people that I would like to thank for helping both directly and indirectly with the production of this thesis. First and foremost I would like to acknowledge my parents. None of this would have been possible without their loving emotional and financial support and I dedicate this thesis to them.

To my brothers--thanks for listening and pretending to be interested in my research despite having little knowledge of or care for the subject matter. To mi novia--your emotional, physical and intellectual support over the last year and a half has been extraordinary. The quality of this thesis would have no doubt suffered if you were not by my side. Thanks for all the time you spent proof reading and making corrections.

I would also like to acknowledge my supervisor Dr. James Bell for his support along the way. Despite going on paternal leave for several months and supervising 20 some odd PhD students, he still found time for us to meet regularly and discuss the project. Thanks for all of your input and feedback.

The Kelburn Campus Postgraduate Crew (KCPC) also deserves recognition: Hayden “Hay-Dogs" Smith, Shaun "Wilko" Wilkinson, Paul "Porites" Fisher, Leighton "LT2" Thomas, Phil "Spider-Man" Sirvid and many others. Those coffee breaks made lonely times in the lab more bearable and played an integral role in the development of this thesis, thanks for the company. An additional shout out to my New Zealand partners in crime, Tyler "Canadian Seal Clubber" Eddy, Ian "Creasing" Geeson and Pelayo "Joto Maximo" Salinas for keeping things entertaining along the way. Additional thanks to Daryl Sykes and Malcolm Lawson of the Rock Lobster Industry Council for their role in sample collection. They were the ones that ultimately made this project possible. 


\title{
Publications from this Thesis
}

\section{Published Articles}

Luke Thomas and James J Bell (2011) Characterisation of polymorphic microsatellite markers for the red rock lobster Jasus edwardsii (Hutton 1875). Conservation Genetic Resources, Technical Notes: DOI 10.1007/s12686-011-9537-x

\begin{abstract}
Author contribution: LT designed the study, performed all of the laboratory work and molecular analysis and drafted the manuscript. JJB co-designed the study, edited the manuscript and obtained funding for the study. The New Zealand Rock Lobster Industry Council collected samples for the study.
\end{abstract}

Luke Thomas and James J Bell (submitted to Proceedings from the Royal Society) Ecological relevance of low genetic differentiation: consistency in connectivity patterns for a widely dispersing marine species.

Author contribution: LT designed the study, performed all laboratory work and molecular analysis and drafted initial manuscript. JJB co-designed the study, coauthored the manuscript and obtained funding for the study. Samples were collected by the New Zealand Rock Lobster Industry Council and the Southern Australian Rock Lobster Fishery.

\section{Conference Proceedings}

James J Bell and Luke Thomas (2011) where did that lobster come from? Trans-Tasman Rock Lobster Industry Conference (7th Lobster Congress); Marlborough Convention Centre-Blenheim, New Zealand

Author contribution: LT performed the laboratory work and molecular analysis. JJB developed the presentation. 


\section{Table of Contents}

\begin{tabular}{|c|c|}
\hline \multicolumn{2}{|r|}{ CKNOWLEDGEMENTS } \\
\hline \multicolumn{2}{|r|}{ 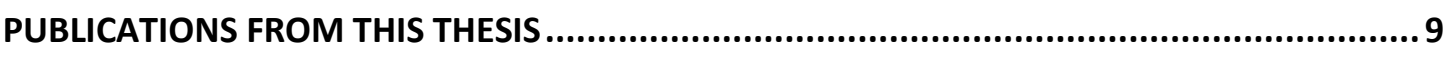 } \\
\hline \multicolumn{2}{|r|}{ 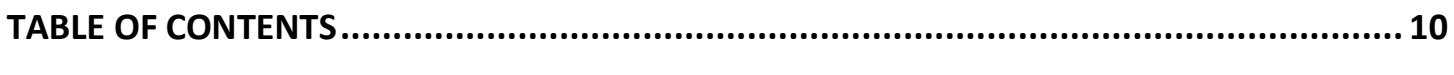 } \\
\hline \multicolumn{2}{|r|}{ 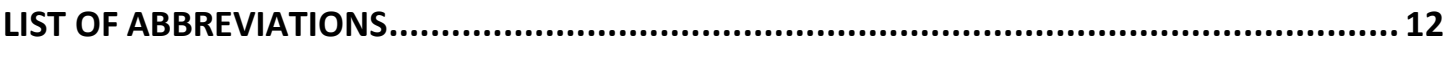 } \\
\hline \multicolumn{2}{|r|}{ 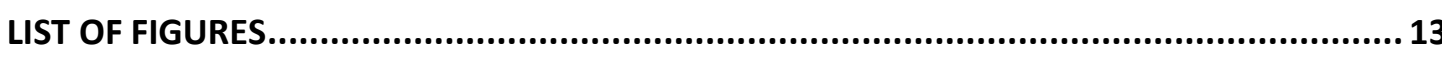 } \\
\hline \multicolumn{2}{|r|}{ 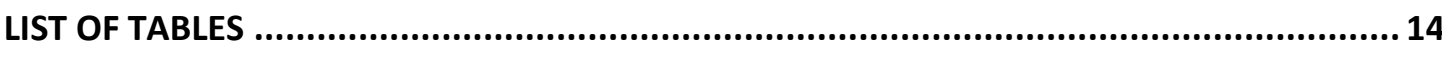 } \\
\hline \multicolumn{2}{|r|}{ 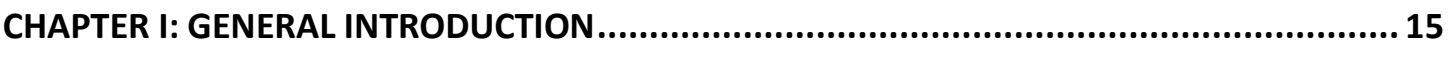 } \\
\hline 1.1 & 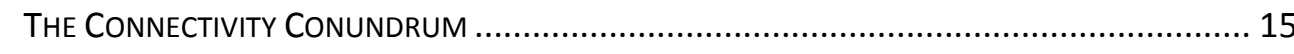 \\
\hline 1.2 & BIO-GEOGRAPHICAL COMPLEXITIES AND THE STOCK CONCEPT......... \\
\hline 1.3 & MICROSATELLITE LOCI .......................................... \\
\hline 1.4 & THE NEW ZEALAND ROCK LOBSTER FISHERY.......... \\
\hline 1.5 & JASUS EDWARDSII BIOLOGY .................... \\
\hline 1.6 & PREVIOUS GENETIC ANALYSI \\
\hline 1.7 & PhysiCAL PROCESSES AfFECTING GENE FLOW....... \\
\hline $1 . \varepsilon$ & OCEANOGRAPHIC MODELS.............................. \\
\hline & $\mathrm{AFSIS}$ \\
\hline 1.9 & \\
\hline
\end{tabular}

CHAPTER II: CHARACTERISATION OF POLYMORPHIC MICROSATELLITE MARKERS FOR THE RED ROCK LOBSTER JASUS EDWARDSII (HUTTON 1875).............................................. 37

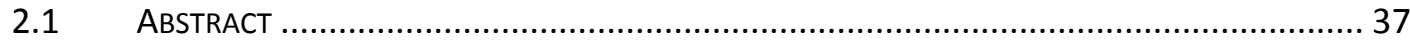

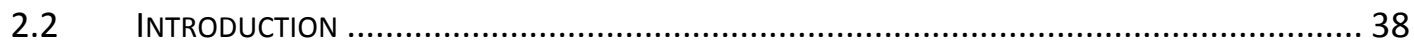

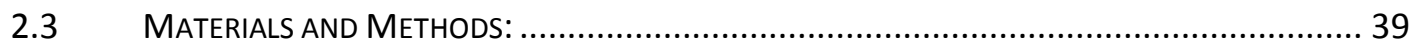

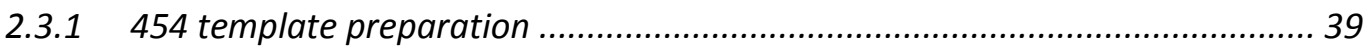

2.3.2 454 GS-FLX sequencing procedure (454 life sciences) ...................................... 39

2.3.3 Screening for Tandem Repeats............................................................... 41

2.3.4 DNA extraction for primer development ................................................... 41

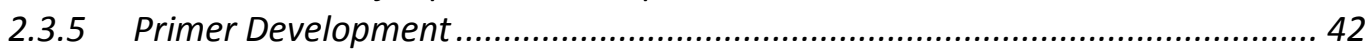

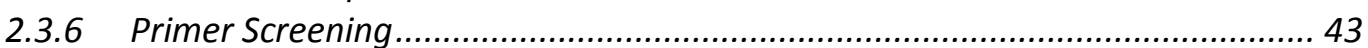

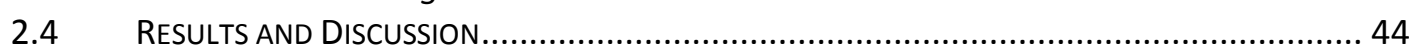

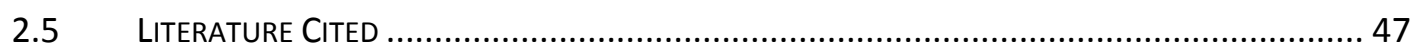

CHAPTER III: MICROSATELLITE ANALYSIS REVEALS ISOLATION OF STEWART ISLAND AND STRONG SOURCE-SINK RELATIONSHIP BETWEEN AUSTRALIA AND NEW ZEALAND ............50 50

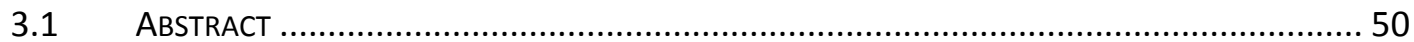

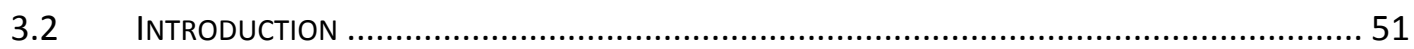

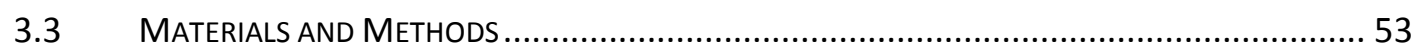

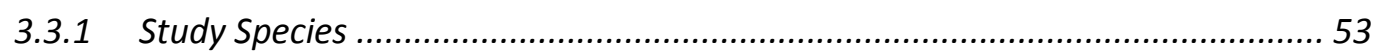

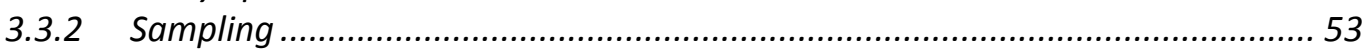

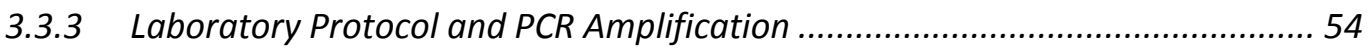

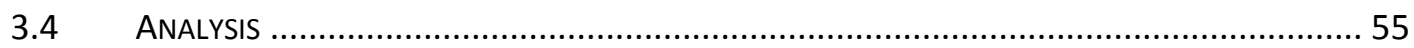

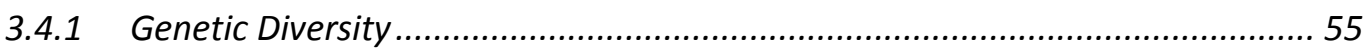

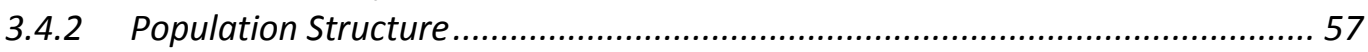

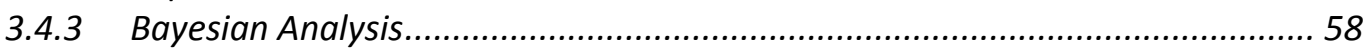

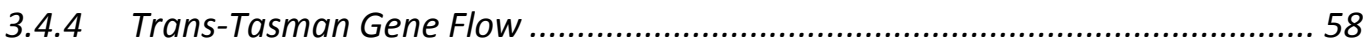




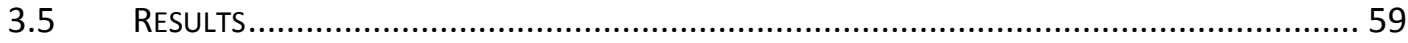

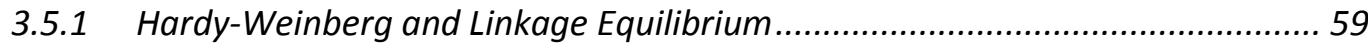

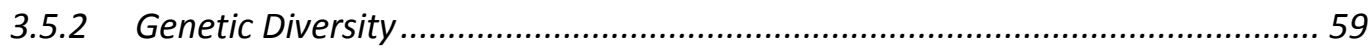

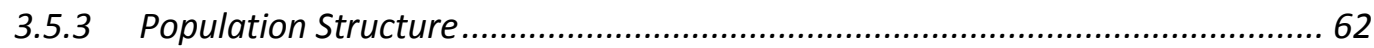

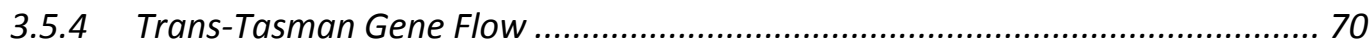

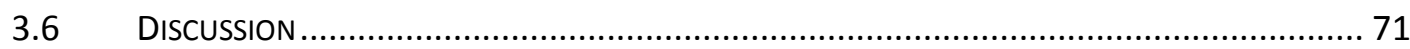

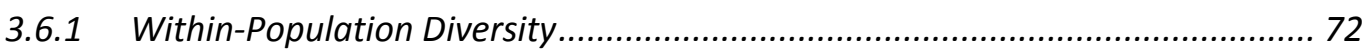

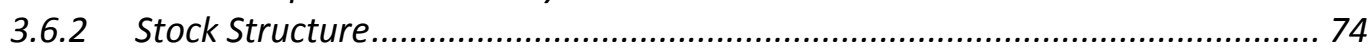

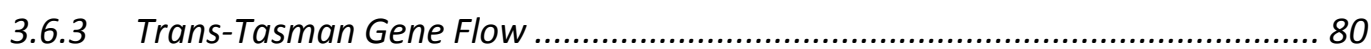

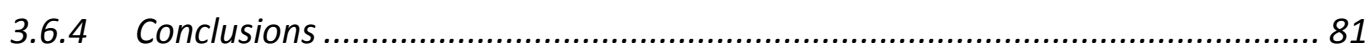

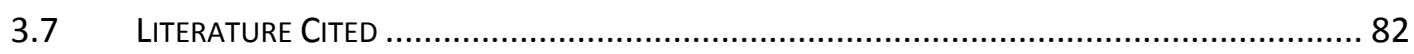

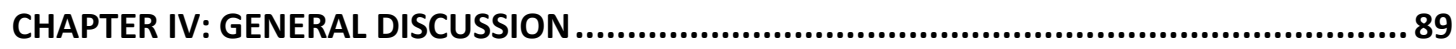

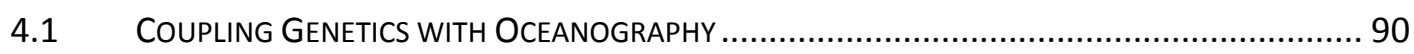

4.1.1 Patterns of Recruitment around New Zealand ................................................ 90

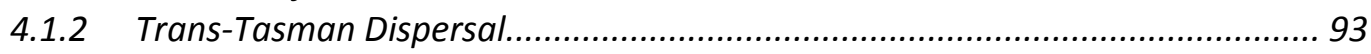

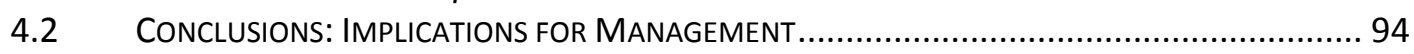

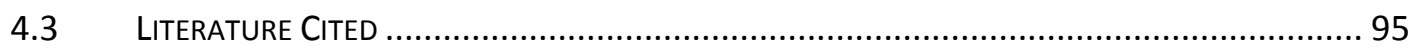




\section{List of Abbreviations}

$\begin{array}{ll}\text { BP } & \text { Base Pairs } \\ \text { CHI } & \text { Chatham Islands } \\ \text { CL } & \text { Carapace Length } \\ \text { CPUE } & \text { Catch per Unit Effort } \\ \text { DNA } & \text { Deoxyribonucleic acid } \\ \text { EAC } & \text { East Auckland Current } \\ \text { ECC } & \text { East Cape Current } \\ \text { EtOH } & \text { Ethanol } \\ \text { HG } & \text { Hauraki Gulf } \\ \text { HWE } & \text { Hardy Weinberg Equilibrium } \\ \text { IAM } & \text { Infinite Alleles Model } \\ \text { KAI } & \text { Kaikoura } \\ \text { mDNA } & \text { Mitochondrial Deoxyribonucleic acid } \\ \text { NRLMG } & \text { National Rock Lobster Management Group } \\ \text { NZRLIC } & \text { New Zealand Rock Lobster Industry Council } \\ \text { PCR } & \text { Polymerase Chain Reaction } \\ \text { PLD } & \text { Pelagic Larval Duration } \\ \text { QMS } & \text { Quota Management System } \\ \text { SA } & \text { South Australia } \\ \text { SI } & \text { Stewart Island } \\ \text { SMM } & \text { Stepwise Mutation Model } \\ \text { STC } & \text { Sub-Tropical Convergence } \\ \text { SWC } & \text { South West Coast } \\ \text { SZRLF } & \text { Southern Zone Rock Lobster Fishery } \\ \text { TAC } & \text { Total Allowable Catch } \\ \text { TACC } & \text { Total Allowable Commercial Catch } \\ \text { TD-PCR } & \text { Touchdown Polymerase Chain Reaction } \\ \text { TF } & \text { Tasman Front } \\ \text { WEL } & \text { Wellington } \\ & \end{array}$




\section{List of Figures}

FIGURE 1.1 The spectrum of population differentiation. Each circle represents a sub-population with varying degrees of population divergence ranging from $(D)$ panmixia to $(A)$ complete isolation Taken from Waples and Gaggiotti (2006)...............................................................................16

FIGURE 1.2 NZ Quota Management Areas for J. edwardsii.....................................................................21

FIGURE 1.3 Adult J. edwardsii: Total length $25.4 \mathrm{~cm}$. Taken from Kensler (1967)....................................23

FIGURE 1.4 The final developmental stage of J. edwardsii phyllosoma larvae. Total length is $43.5 \mathrm{~mm}$. Modified from Kittaka et al. (2005)...

FIGURE 1.5 Distinguishing features of J. edwardsii phyllosoma instars 13, 15 and 17; pl, pleopod; $u$, uropod; Is, lateral spine. Bar indicates $1 \mathrm{~mm}$. Notice instar 17 uropods and pleopods fully segmented and differentiated from the abdomen and are fringed with setae presumably for advanced swimming ability. Modified from Kittaka et al. (2005)

FIGURE 1.6 Prevailing currents of the waters surrounding New Zealand. Courtesy of Sebastian Hernandez.

FIGURE 2.1 Sequence lengths of 454 results from GS-FLX sequencing instrument produced by Genious Pro 5.1.4. Average length $(571 \mathrm{bp}$

FIGURE 2.2 Chromatograph images of primers as seen in GeneMarker v1.97. Microsatellites in blue are labelled with fluorochrome tag 6-FAM ${ }^{T M}$ and in green with HEX ${ }^{T M}$.

FIGURE 2.3 Allele discovery curves for each locus for the Wellington population. The curve for each locus reaches an asymptote when genetic diversity is completely sampled. Curves were generated using PopGenKit Package (Paquette 2011) in R 2.13.1..

FIGURE 3.1 Sample site locations where J. edwardsii was collected throughout New Zealand and on the Australian coast: HG, Hauraki Gulf; WEL, Wellington; KAl, Kaikoura; CHI, Chatham Islands; SWC, South West Coast; SI, Stewart Island; SA, South Australia..

FIGURE 3.2 Allele discovery curves for 9 microsatellite loci across 7 populations......................................62

FIGURE 3.3 UPGMA Cluster using Nei's (1972) minimum distance as implemented in TFPGA by bootstrap analysis with 10,000 pseudoreplicates.

FIGURE 3.4 Isolation by distance generated by IBWS 3.2.1. Pairwise genetic distances (Slatkin's linearized $F_{S T}$ (above) and $R_{S T}$ (below) plotted against the logarithm of minimum oceanographic distance between populations.

FIGURE 3.5 Structure 2.3.2 results with pre-defined clusters $K$ ranging from 2-7. Each individual in the data set is represented by a single vertical line, which is partitioned into $K$ segments that represent that individual's estimated membership fraction in each of the $K$ inferred clusters (Pritchard et al. 2000)...

FIGURE 3.6 Structure results with pre-defined cluster $K=2$ at corresponding sampled locations............68

FIGURE 3.7 Prevailing current systems of New Zealand. Courtesy of Sebastian Hernandez....................77 


\section{List of Tables}

TABLE 2.1 DNA extreaction protocol (adopted from Sambrook 1989)....................................................41

TABLE 2.2 Primer design conditions as used for Primer3 in Geneious Pro 5.1.4 (C).................................42

TABLE 2.3 PCR Reaction set-up: For each primer pair a reaction was set up as follows...........................43

TABLE 2.4 Touchdown (TD) PCR protocol (Korbie and Mattick 2008)..........................................................44

TABLE 2.5 Primer characteristics and sequences of microsatellite loci for J. edwardsii............................46

TABLE 3.1 Sampling locations where J. edwardsii was collected. .54

TABLE 3.2 Ho, observed heterozygosity; He, expected heterozygosity; Fis, Inbreeding coefficient; for 7 populations across 9 microsatellite loci (bold values: significant deviation from HWE)..... 60

TABLE 3.3 Ho, observed heterozygosity; He, expected heterozygosity; Na, number of alleles; Fis, inbreeding coefficient at 7 populations averaged across 8 microsatellite loci. 61

TABLE 3.4 Allele size variations at 8 microsatellite loci with mean number of alleles, number of private alleles and total number of alleles at 7 populations 8 microsatellite loci...

TABLE 3.5 Matrix of pairwise comparisons of population differentiation using $F_{S T}$ (below diagonal) and $R_{S T}$ (above diagonal) values at 7 populations using 8 microsatellite loci (bold values: significant $p<0.05)$...

TABLE 3.6 Assignment tests (Rannala and Mountain 1997) for (A) individuals from each sampling location (rows) assigned to each population (columns) and (B) clustering of populations based on AMOVA results. Numbers represent percentages of individuals assigned to each population and values in bold are correct assignments.

TABLE 3.7 Hierarchical analysis of molecular variance (AMOVA) among 3 different clustering situations: (A) 4 groups: SA, SI, HG and WEL/KAI/SWC/CHI, (B) 3 groups: $S A, S I$, and HG/WEL/KAI/SWC/CHI and (B) 2 groups; SA and New Zealand Populations.

TABLE 3.8 Maximum likelihood estimates of migration rate (M) and effective population size $\Theta$ ) of New Zealand and Australian Jasus edwardsii populations. Confidence intervals (90\%) are shown.

TABLE 3.9 Reported mean annual commercial catch and CPUE values for New Zealand CRA zones (Star 2011) and South Australia Southern Zone (Linnane et al. 2011) for the Jasus edwardsii fishery from 1990-2010 with standard deviations. Measurements of coastline were taken from Chiswell and Booth (2003) for CRA zones.

TABLE 4.1 Sinks: fate of phyllosoma hatched in each quota management area as predicted by Chiswell and Booth (2008) Table should be read as follows: $18 \%$ of phyllosoma released from CRA 1 metamorphosis in CRA 2.

TABLE 4.2 Sources of settlement (\% in each quota management area as predicted by Chiswell and Booth (2008). Table should be read as follows: CRA 1 receives 80 \% of recruits from CRA 9......91 


\section{Chapter I: General Introduction}

\subsection{The Connectivity Conundrum}

Most marine species, particularly benthic invertebrates, have a bipartite life cycle consisting of a sessile adult stage and a dispersing propagule stage (larvae, egg or spore). In some cases the dispersal stage can last for many months (Shanks et al. 2003), providing the opportunity for large-scale dispersal over vast oceanographic distances. The traditional view for most of the $20^{\text {th }}$ century was that the marine environment was a demographically open system characterized by high levels of larval exchange between populations at large spatial scales (Caley et al. 1996; see Levin 2006 for a review). This assumption was supported by: (1) the fact that a wide range of marine taxa exhibit a planktonic larval stage; (2) the abundance of larvae in offshore oceanic waters; and (3) the spatial and temporal scale of ocean currents (Levin 2006).

There is now mounting empirical evidence, however, suggesting that larval exchange in the marine environment often reflects that of a closed system and that larval retention to natal habitats is a more common process than originally believed (Swearer et al. 2002). The application of recent technological advances in genetics (Taylor and Hellberg 2003, Baums et al. 2005) and elemental signature analysis (Ruttenberg et al. 2005; Becker et al. 2007) have revealed complex patterns of spatial structure and show that there are numerous cases in which species do not form panmictic populations throughout their geographic range (Hilborn et al. 2003; Crivello et al. 2005; Ruzzante et al. 2006). Instead, they are composed of a number of demographically isolated units that may react independent of one another, particularly to fishing pressure. Although the marine environment appears to have few barriers to dispersal in comparison to freshwater or terrestrial systems (Waples 
1998; Palumbi 1994), physical oceanographic processes (e.g. topographical eddies, retention zones, coastal boundary layers) (Largier 2003) and larval behaviour (Fisher 2005; Gerlach et al. 2007) often act as barriers and prevent larval exchange between populations. The influence that these retention mechanisms have on population structure varies significantly across taxa and location, creating a wide range of population connectivity throughout the marine environment (Figure 1).

Figure 1 The spectrum of population differentiation. Each circle represents a sub-population with varying degrees of population divergence ranging from (D) panmixia to (A) complete isolation Taken from Waples and Gaggiotti (2006).

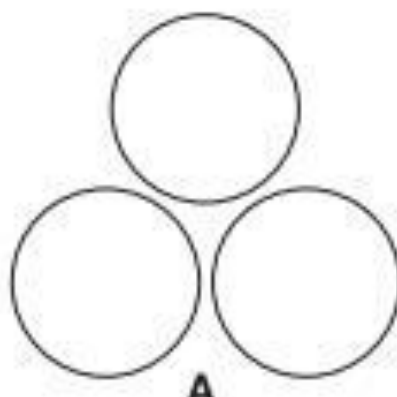

A

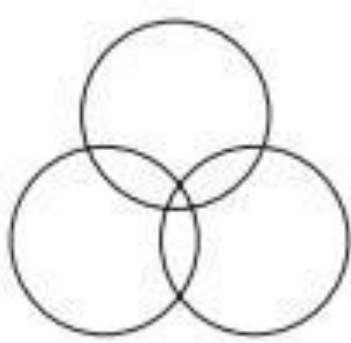

B

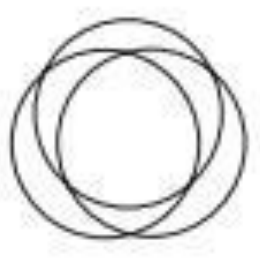

C

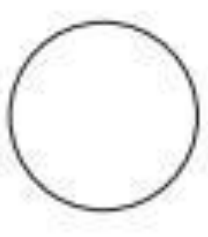

D

Isolation

Panmixia

1

$\because$

Divergence

\subsection{Bio-geographical Complexities and the Stock Concept}

The past several decades have been marked by the collapse of a number of commercial fisheries despite having management strategies in place (Baum et al. 2003; Hilborn et al. 2003; Worm et al; 2006; Pinsky et al. 2011). This suggests that previous strategies have either ignored or failed to accurately address important biological processes of the harvested species (Sale et al. 2005). It is now widely accepted that the foundation of an effective fishery management strategy must incorporate a comprehensive understanding of population dynamics (Grimes et al., 
1987; Hilborn et al. 2003) and processes that play fundamental roles in shaping population structure, such as larval dispersal and recruitment (Doherty 1981; Bohanak 1999).

A stock is the basic unit used in fisheries management and is best defined as an intraspecific group of randomly mating individuals with temporal and spatial integrity (Ihssen et al. 1981). A variety of techniques exist to help identify independent stocks for management and are fundamentally split into two groups: behavioural/ecological techniques such as mark-recapture, catch data, life history characteristics, parasite tags and morphology; and (2) molecular techniques, which include otolith microchemistry, stable isotopes and genetics. For a detailed account of each of these methods see Begg and Walman (1999). All of the techniques aim to identify discrete differences between populations and can range from a rather simple process to a highly technical one requiring complex statistical analyses (Begg and Walman 1999).

The stock identification process becomes extremely complicated when dealing with highly fecund species that have a dispersing larval stage (Waples 1998). The logistics behind physically tagging hundreds of thousands of microscopic larvae and monitoring them as they disperse over large expanses of oceans are extremely challenging if not impossible. Because larvae carry with them heritable genes, genetic markers can serve as a natural 'tag' that can be used to help understand population structure (Palumbi and Warner 2003). This has become an increasingly popular technique, offering insightful information into the biogeography and evolutionary divergence of a species (Shaklee and Bentzen 1998; Begg et al. 1999; Cowen and Srinivasan 2006).

Genetic techniques ultimately aim to use inherited markers (e.g. allozyme, mitochondrial DNA, nuclear DNA) to identify genotypes that characterize populations (Coyle 1988; DeYoung and Honeycutt 2005). Over time, evolutionary forces such as gene flow, genetic drift, mutation and selection drive genotypic divergence in populations that are expressed as variations in the frequencies of 
alleles (Lowe and Allendorf 2010). This variation is used to interpret how subpopulations across a species' range are connected by the exchange of genes (Palumbi 2003).

Marine resource management is often heavily weighted in politics, and there has been a consistent trend for governments to disregard bio-geographical properties of a targeted species in order to maximize short-term economic gain. The disregard for genetic structure in particular can have severe negative impacts on genetic diversity (Hauser et al. 2002) and consequently, the overall yield of the fishery (Ricker 1981). Genetic diversity directly influences the adaptability of a species at the DNA level and when greatly reduced, can seriously jeopardize the long-term sustainability of the stock (Hauser et al. 2002; Hutchings and Baum 2005). This is particularly relevant in the context of global climate change in a stochastic environment and should be a top priority of all management strategies.

\subsection{Microsatellite Loci}

The marine environment is generally characterised by relatively high levels of gene flow in comparison to freshwater or terrestrial systems (Ward et al. 1994; Waples 1998). Consequently estimates of genetic differentiation between populations are usually on far finer scales. This is particularly the case when dealing with highly dispersing marine organisms with long-lived larval stages. The ability to exchange genes over large oceanographic distances places them towards the 'open' end of the connectivity continuum, where genetic differentiation is at very low levels, often below the resolving power of traditional molecular techniques such as allozyme or mDNA analysis (Ward 2000). In order to detect differences that may hold biological significance, highly polymorphic microsatellites have become the tool of choice in modern stock identification studies for species that require high-resolution analysis (Ward 2000).

Microsatellite loci are highly polymorphic DNA loci that are widely distributed throughout the eukaryotic genome with an overall abundance in the order of $10^{4}-10^{5}$ 
(Shaklee and Bentzen 1998). The loci occur as simple sequence repeats (2-5 base pairs) and are normally less than 300 bp long (DeYoung and Honeycutt 2005). Microsatellite loci are generally considered to be selectively neutral (the majority appear in non protein-coding portions of DNA) and are characterised by high levels of mutation (slippage and proofreading errors), making microsatellite loci one of the most variable types of DNA sequences in the genome (Weber 1990; Ward 2000). This heightened degree of polymorphism (loci length variation) provides for far more variation than allozyme or mitochondrial DNA-based techniques and thus, enhances our ability to discriminate between individuals and populations on finer temporal and spatial scales (Ward et al. 1994; Carvalho and Hauser 1994, Begg et al. 1999; Chambers and MacAvoy 2000; Ward 2000). Furthermore, because the loci are selectively neutral, any variation between populations can be attributed to gene flow and genetic drift rather than local selection for specific genes.

An important consequence of the extremely high mutation rate of microsatellite loci is that their underlying mutation pattern cannot be ignored (Balloux and LugonMoulin, 2002). Two models have been developed that take different possible mutation patterns of the loci into account: the Infinite Allele Model (IAM; Kimura and Crow 1964) and the Stepwise Mutation Model (SMM; Kimura and Otha 1978). The IAM assumes that the probability of any allele mutating to any other allelic state (size) is the same, whereas the SMM has a memory of allele size and as a result determines alleles of different sizes to be less related than those of similar sizes and is thought to more accurately reflect the mutation pattern of microsatellite loci (Balloux and Lugon-Moulin, 2002).

Microsatellites markers have recently become an extremely popular tool to investigate patterns gene flow in the marine environment. Their highly polymorphic nature has facilitated the detection of fine-scale spatial genetic variation that has previously been gone undetected for a number of commercially targeted species (Bentzen et al. 1996; Ruzzante et al. 1998; Crivello et al. 2005; Machado-Schiaffino et al. 2010; Olsson et al. 2011). This has considerable implications for the future management of the fisheries they support. 


\subsection{The New Zealand Rock Lobster Fishery}

Jasus edwardsii was introduced into the New Zealand Quota Management System (QMS) in 1990 and now supports New Zealand's most lucrative seafood export market, worth approximately $\$ 230$ Million NZD annually (www.fish.govt.nz). It is not only a lifeline to the commercial fishing industry but also plays an important role in the customary fishing practices and history of the Maori. Furthermore, it is one of the most popular recreationally fished species in the country, with almost $10 \%$ of total allowable catch (TAC) being allocated to the recreational sector. The Commercial sector receives $78 \%$ (roughly $2,800,000 \mathrm{~kg}$ ) of the TAC, and the remaining catch is allocated to the customary sector. In addition to TAC, the fishery is also regulated by the provision of a minimum legal size, gear restrictions, season closures and the prohibition against catching incubating females ("berried") and soft shelled individuals ("softies") (NRLMG 2006 Annual Report).

Recorded commercial landings around the country have remained steadily below the total allowable commercial catch (TACC) over the last 10 years. In 2010, $2.9 \mathrm{M} \mathrm{kg}$ of rock lobster was landed nationally, a quota worth $\$ 770 \mathrm{M}$, only second to Hoki at $\$ 814$ M. $80 \%$ of this catch is shipped to Hong Kong where prices have almost doubled since 2006, from $\$ 52$ to $\$ 81$ per kg (Ministry of Fisheries 2010).

The fishery is divided into 10 stocks, or CRA zones (Figure 2), with each allocated a certain percentage of the annual TACC as set by the Ministry of Fisheries (The CRA zones are divided furthermore into 43 statistical zones for stock assessment purposes). CRA 10 is strictly an administrative zone and receives no commercial fishing pressure. While these zones are currently used for that management of J. edwardsii around New Zealand, they are not based on the biology of the species. Previous allozyme (Smith et al. 1980; Booth et al. 1990) and mDNA (Ovenden et al. 1992) analysis support the assumption of J. edwardsii forming a single panmictic population around the mainland of New Zealand (NRLMG Annual Report 2010). 


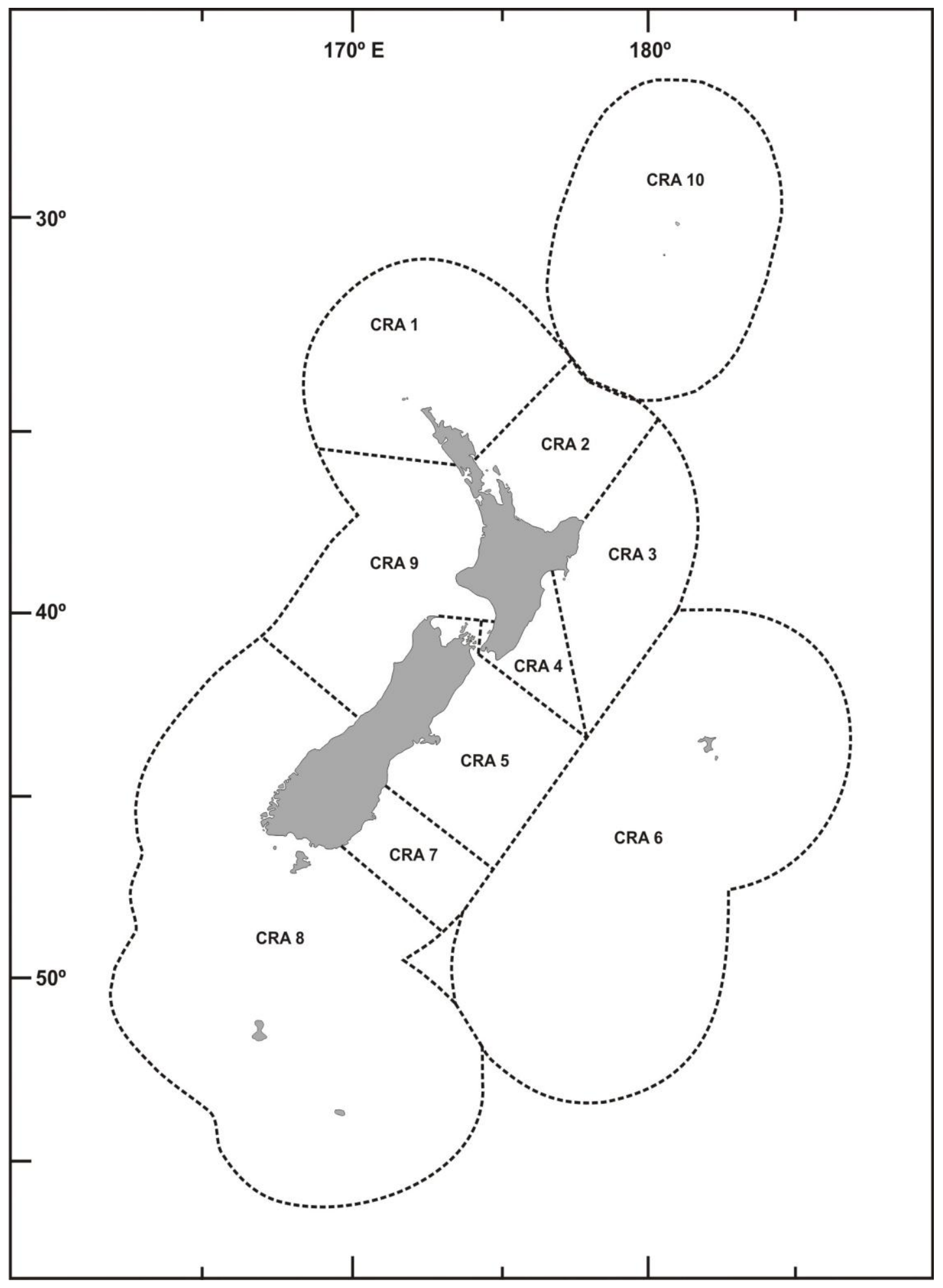

Figure 2 New Zealand Quota Management Areas for J. edwardsii. 


\subsection{Jasus edwardsii Biology}

Jasus edwardsii (family Palinuridae) inhabits coastal and offshore-seamount rocky reef habitat around New Zealand and southern Australia (Kensler 1967; Ovenden et al. 1992). Their range encompasses a wide geographic area from Three Kings Islands in the north, to the Auckland Islands in the south and from Western Australia east to the Chatham Islands. They are keystone predators of sub-tidal reef systems and play an important role in organising community structure and ecosystem functioning (Shears and Babcock 2003). A dorsal view of an adult is provided in Figure 3. Fecundity in spiny lobsters is a function of body size, and large J. edwardsii females (160 $\mathrm{mm} \mathrm{CL}$ ) are capable of producing up to 500,000 eggs annually (Annala and Bycroft 1987). Fecundity is so high that large females often mate a number of times prior to oviposition to ensure sufficient sperm supply to fertilize all the eggs in her brood (MacDiarmid and Butler 1999). As with all palinurids, fertilization is external with the male depositing a spermatophoric mass on the underside of the female abdomen, which is used to fertilize the eggs stored on her pleopods. Following mating events (usually around June), incubating females migrate offshore to deeper waters on the outer fringes of the reefs (MacDiarmid 1991). Hatching events predominantly take place in high-energy inshore environments during spring (September/October), which is thought to be a behavioural adaptation that aids in dispersal (Booth and Tarring 1986, Chiswell and Booth 1999).

The larval stage of the J. edwardsii bipartite life cycle consists of planktonic (nauplisoma and phyllosoma) and nektonic (puerulus) phases. The nauplisoma is the pre-zoea that emerges from the egg following a hatching event and is short-lived (hours) and very small in size (1 mm length) (Booth and Phillips 1994). The nauplisoma is rapidly transformed into the stage-1 phyllosoma, a leaf-like transparent zoea that is much larger and longer lived than the nauplisoma. The phyllosomas remain in offshore oceanic waters for up to 20 months as they undergo a series of developmental changes (11 stages, 17 Instars) before metamorphosing into the puerulus, the post-zoea transitional form (Booth and Phillips 1994). The final stage of the phyllosoma larva is shown in Figure 4. 


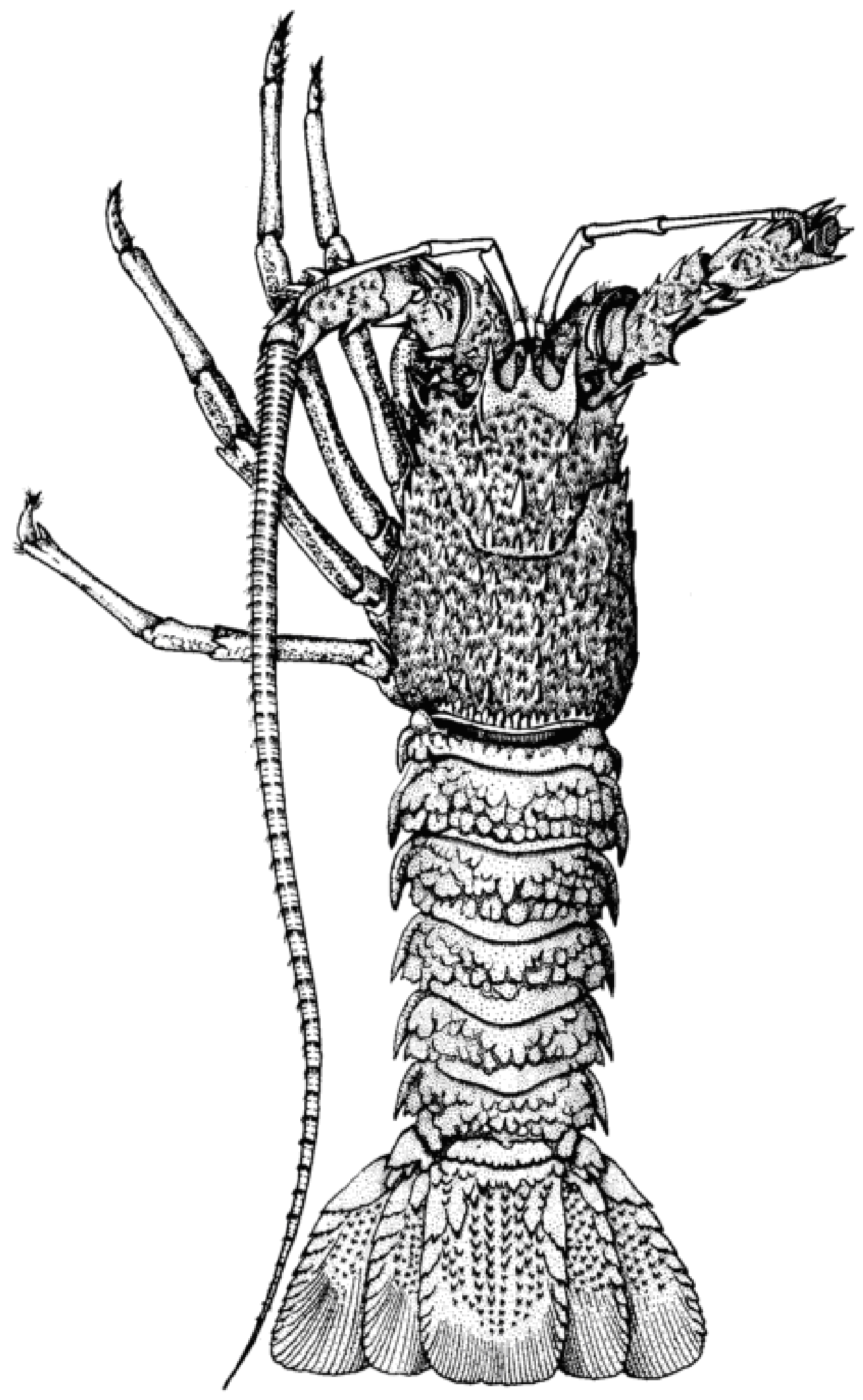

Figure 3 Adult J. edwardsii: Total length $25.4 \mathrm{~cm}$. Taken from Kensler (1967). 
Although capable of diurnal vertical movements, the phyllosoma are considered poor swimmers (Kittaka 1994), and dispersal is largely dependent on current and wind. Metamorphosis from the phyllosoma larvae into the nektonic puerulus stage is thought to take place mainly near the continental shelf break (Booth 1994) and ends J. edwardsii's planktonic larval stage. The transparent puerulus (13 $\mathrm{mm} \mathrm{CL}$ ) has a body plan that resembles the adult form, with newly developed pleopods (Figure 5) that facilitate horizontal swimming (Kittaka et al. 2005).

The metamorphosis into the puerulus is thought to be immediately followed by rapid movement towards the coast to recruit to the benthos. Jeffs et al. (2001) calculated that the non-feeding puerulus have enough nutrient reserves for a mean net swim distance of $200 \mathrm{~km}$, which infers the maximum distance from the coast that metamorphosis can take place in order for the puerulus to successfully recruit to the shore. In light of this, it is presumed that late-stage phyllosoma delay metamorphosis until triggered by some biological or physical cue (such as lowsalinity shelf water) to ensure that they are close enough to the coast to survive the trip (Philips and McWilliams 1986; Jeffs et al. 2001; Chiswell and Booth 2005). Another possibility is that final-stage phyllosoma begin to exhibit horizontal swimming behaviour prior to metamorphosis to bring them closer to the shelf (Chiswell and Booth 1999). Puerulus recruit to a variety of habitats from the shallow sub-tidal zone to depths of up to $50 \mathrm{~m}$ and immediately display the shelter-seeking behaviour that is also characteristic of adults (Kittaka et al. 2005). The first molt into the juvenile stage happens within weeks after settlement (Booth and Phillips 1994).

Jasus edwardsii is thought to have the longest-lived larval durations of any marine organism (Booth and Phillips 1994). This complex life history coupled with the dynamic environmental conditions of the south-west Pacific Ocean and Tasman Sea, provides the potential for large-scale dispersal and subsequently high levels of gene flow between populations. 


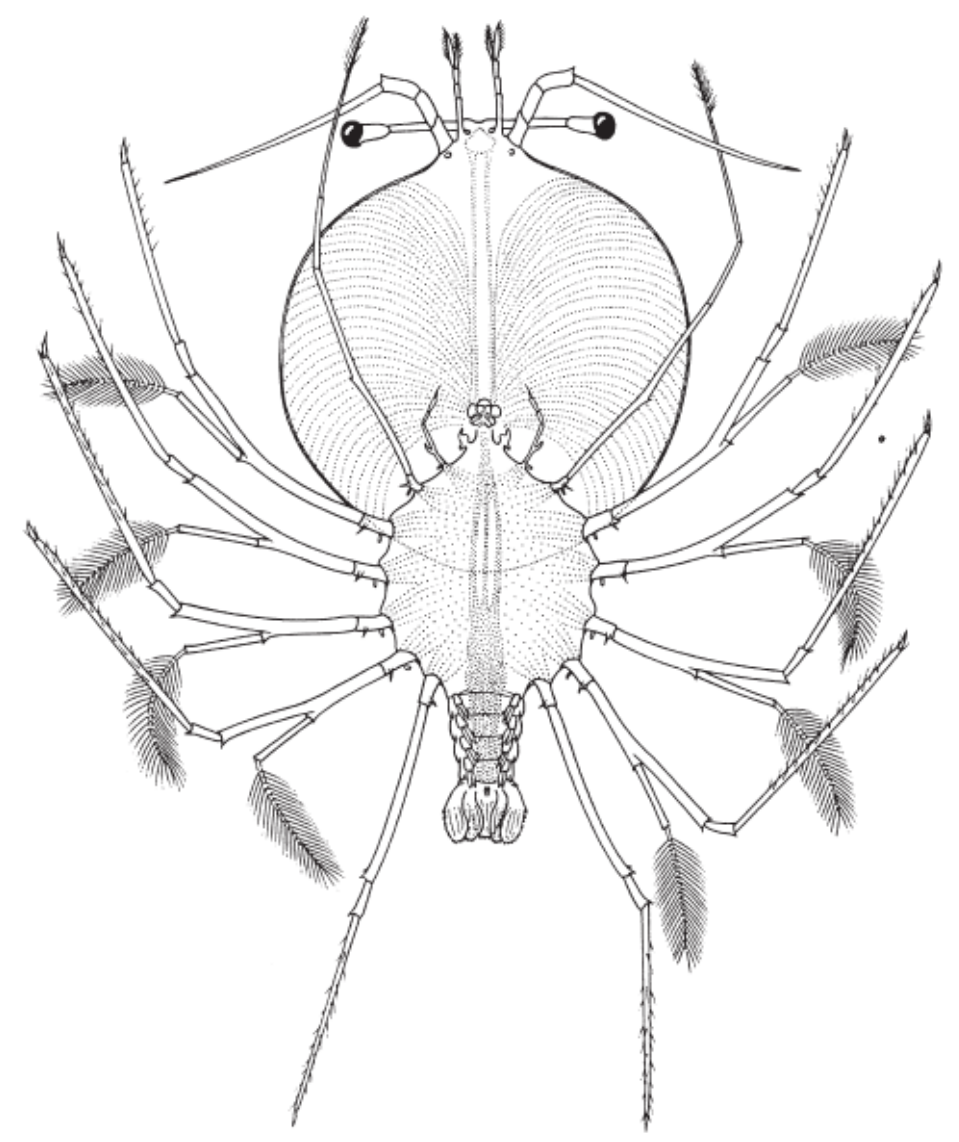

Figure 4 The final developmental stage of J. edwardsii phyllosoma larvae. Total length is $43.5 \mathrm{~mm}$. Taken from Kittaka et al. (2005).

13

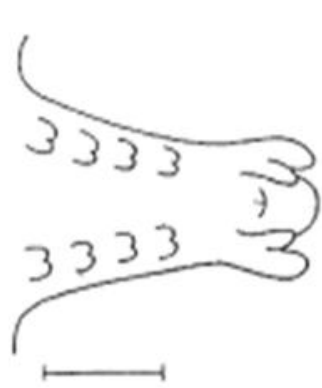

15

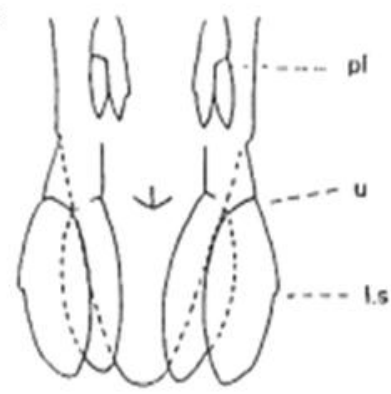

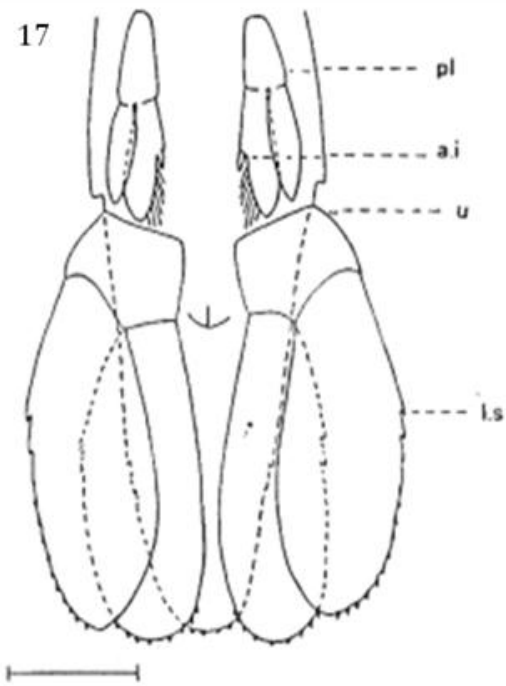

Figure 5 Distinguishing features of J. edwardsii phyllosoma instars 13, 15 and 17; pl, pleopod; u, uropod; Is, lateral spine. Bar indicates $1 \mathrm{~mm}$. Notice instar 17 uropods and pleopods fully segmented and differentiated from the abdomen and are fringed with setae presumably for advanced swimming ability. Modified from Kittaka et al. (2005). 


\subsection{Previous Genetic Analysis}

The earliest genetic analysis of J. edwardsii (Smith et al. 1980) aimed to identify inter-specific differences between $J$. edwardsii of New Zealand and $J$. novaehollandiae of Australia (now considered conspecific populations) using 21 proteins encoded by 33 loci. The study found no significant genetic differentiation between samples collected around New Zealand and Australia. Polymorphism was detected in only one of the 33 loci, and genetic identity over all loci between the two species was 0.997 , a value typical of conspecific populations supporting the notion that they are a single species (Smith et al. 1980). The study suggested that the genetic homogeneity indicated an 'open loop system' of larval recruitment. A decade later, Booth et al. (1990) used one polymorphic locus (Ldh allele) to further investigate the genetic relatedness of J. edwardsii and J. novaehollandiae populations. The analysis found no detectable heterogeneity across New Zealand samples, supporting findings from Smith et al. (1980), and concluded that keeping the two species separated was unjustified. Either trans-Tasman gene flow was homogenizing the gene pool, or the populations diverged quite recently on an evolutionary time scale. Ovenden et al. (1992) conducted a mitochondrial DNA analysis, the most sensitive technique available for stock assessment at the time (Wirgin and Waldman 2005). Samples were collected from Western Australia to the east coast of New Zealand spanning $4,600 \mathrm{~km}$ of the species range. The analysis found no genetic sub-divisions across all samples and suggested that the transTasman populations were exchanging high levels of genes and proposed that New Zealand lobster populations may be heavily reliant on Australian populations for recruits.

\subsection{Physical Processes Affecting Gene Flow}

New Zealand sits in the south-west corner of the South Pacific gyre with a predominantly eastern flowing current system (Chiswell 2009). The main current systems that influence the region are a product of the Tasman Front in the north and the Sub-Tropical Front in the south (Figure 6). 


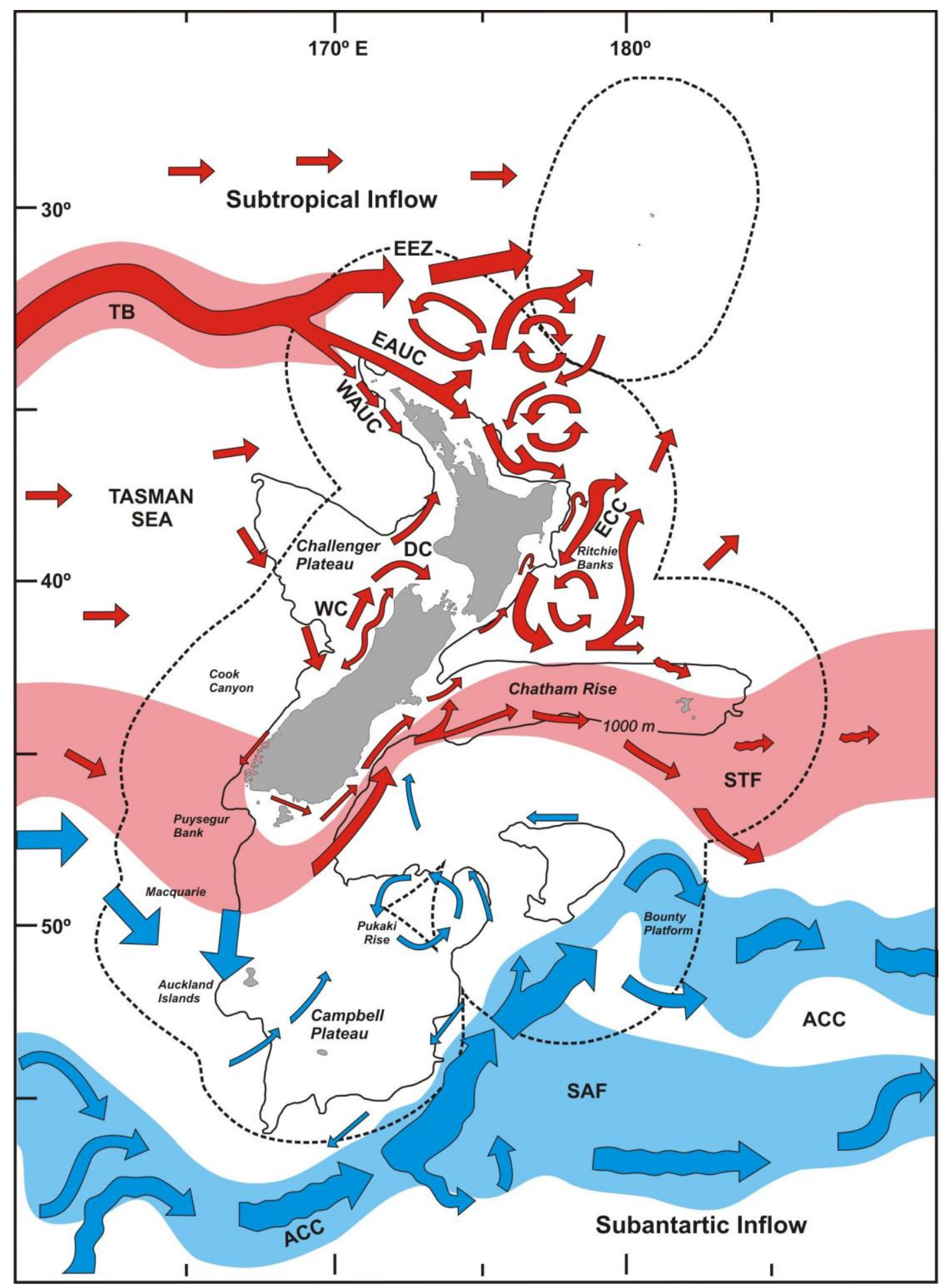

Figure 6 Prevailing currents of the waters surrounding New Zealand. Courtesy of Sebastian Hernandez. 
Warm water from the East Australian Current (EAC) moves southward along the edge of the Australian shelf where it collides with the Tasman Sea at around $34^{\circ} \mathrm{S}$ and flows eastward, commonly known as the Tasman Front (TF) (Chiswell 2009).

The TF gives rise to the East Auckland Current (EAUC) that runs south-east along the north end of the North Island. Near the East Cape, a main portion of EAUC flow turns north, and the remainder forms the East Cape Current (ECC) that moves southward along the east coast (Heath 1982). The ECC re-circulates around the Wairarapa Eddy at roughly $41^{\circ} \mathrm{S}$ and then flows eastward along the Chatham Rise (Chiswell and Booth 1999). The Sub-Tropical Convergence (STC) carries cold, nutrient-rich water from southern Australia over to Fjordland and Stewart Island at roughly $45^{\circ} \mathrm{S}$ (Heath 1982). The STC meanders along the continental shelf up the east coast of the South Island and is commonly referred to as the Southland Front (Heath 1982). Like the ECC, the Southland Front eventually hits the Chatham Rise and is deflected eastward.

The easterly prevailing current system drives a defined flow down the east coast of the North Island and up the east coast of the South Island, both eventually hitting the Chatham Rise and deflecting eastward. The Wairarapa Eddy, caused by the retroflection of the ECC, is one of the largest interruptions to this flow, and is thought to act as an important larval retentive mechanism for the North Island east coast populations (Chiswell and Booth 1999).

\subsection{Oceanographic Models}

In addition to the genetic studies conducted on J. edwardsii, several studies have used oceanographic models to investigate patterns of larval dispersal and recruitment around New Zealand and Australia. Chiswell and Booth (2008) developed a model using a Langrangian approach where J. edwardsii larval dispersal paths from each of the CRA zones were simulated using time-varying ocean currents from 1995-2003 derived from a satellite altimeter. The aim was to determine the contribution of each CRA zone to recruitment around the country to identify sourcesink relationships between management areas. The fate of larvae released in 
different zones varied substantially, and the results indicated a complex source-sink relationship between individual CRA zones. The results of this model provided insight into the demographic connectivity and transport of phyllosoma larvae around New Zealand.

The prevailing easterly flow of the region and undetectable trans-Tasman genetic differentiation (Ovenden 1992) suggests that New Zealand lobster stock may be heavily reliant on Australian populations for recruitment (Smith et al. 1980; Booth et al. 1990; Ovenden 1992). High densities of adult populations of J. edwardsii occur along the southern Australian coastline (Victoria, South Australia and Tasmania) (Phillips et al. 2000) and high numbers of mid-late stage phyllosoma larvae have been reported throughout the Tasman Sea (Booth et al. 1990; Booth and Ovenden 2000). Chiswell et al. (2003) modelled flow rates across the Tasman Sea and reported that passive drift across the body of water occurred at rates within the larval duration of J. edwardsii lifecycle and concluded that trans-Tasman dispersal was "likely to be a viable mechanism to maintain New Zealand Lobster."

\subsection{Thesis Aims}

Given the economic importance of J. edwardsii to New Zealand, understanding population structure and patterns of gene flow across the Tasman Sea is a top priority for the New Zealand Rock Lobster Industry Council (NZRLIC). The aims of this thesis are to: (1) re-examine the genetic stock structure of the red rock lobster Jasus edwardsii to test the null-hypothesis of panmixia by applying highly polymorphic microsatellite markers around New Zealand and across the Tasman Sea; (2) to characterise and quantify trans-Tasman gene flow and demographic connectivity between Australia and New Zealand; and (3) to determine if patterns of genetic diversity and connectivity can be explained using oceanographic models.

Chapter 2 presents the development and characterisation of novel microsatellite markers (the first to be developed for J. edwardsii) and is followed by the application 
of those markers in a population study around New Zealand and Australia in Chapter 3. Chapter 4 will seek to explain those patterns using oceanographic models and conclude with suggestions for future management based on the results of the genetic analysis.

\section{$1.9 \quad$ Literature Cited}

Annala, J.H. \& Bycroft, B.L. (1987) Fecundity of the New Zealand red rock lobster, Jasus edwardsii. New Zealand Journal of Marine and Freshwater Research, 21, 591-597.

Balloux, F. \& Lugon-Moulin, N. (2002) The estimation of population differentiation with microsatellite markers. Molecular ecology, 11, 155-65.

Baum, J.K. et al. (2003) Collapse and conservation of shark populations in the Northwest Atlantic. Science, 299, 389-92.

Baums, I.B., Miller, M.W. \& Hellberg, M.E. (2005) Regionally isolated populations of an imperiled Caribbean coral, Acropora palmata. Molecular ecology, 14, 1377-1390.

Becker, B.J., Levin, L. a, Fodrie, F.J. \& McMillan, P.A. (2007) Complex larval connectivity patterns among marine invertebrate populations. Proceedings of the National Academy of Sciences of the United States of America, 104, 32673272.

Begg G.A. \& Waldman J.R. (1999), A holistic approach to stock identification. Fisheries Research, 43, 35-44.

Begg, G.A., Friedland, K.D. \& Pearce, J.B. (1999) Stock identification and its role in stock assessment and fisheries management: an overview. Fisheries Research, $43,1-8$.

Bentzen, P., Taggart, C.T., Ruzzante, D.E. \& Cook, D. (1996) Microsatellite polymorphism and the population structure of Atlantic cod (Gadus morhua) in the northwest Atlantic. Canadian Journal of Fisheries and Aquatic Sciences, $53,2706-2721$.

Bohonak AJ (1999) Dispersal, gene flow, and population structure, The Quarterly Review of Biology, 74, 21-45.

Booth, J.D. \& Phillips, B.F. (1994) Early life history of spiny lobster. Crustaceana, 66, 271-294. 
Booth, J.D. \& Tarring S.C. (1986) Settlement of the red rock lobster, Jasus edwardsii , near Gisborne, New Zealand. New Zealand Journal of Marine and Freshwater Research, 20, 291-297.

Booth, J.D. (1994) Jasus edwardsii larval recruitment off the east coast of New Zealand, Proceedings of the Fourth International Workshop on Lobster Biology and Management. Crustaceana, 66, 295-317.

Booth, J.D., Street, R.J. \& Smith, P.J. (1990) Systematic status of the rock lobsters Jasus edwardsii from New Zealand and J . novaehollandiae from Australia. New Zealand Journal of Marine and Freshwater Research, 24, 239-249.

Botsford, L. (2001) Physical influences on recruitment to California Current invertebrate populations on multiple scales. ICES Journal of Marine Science, 58, 1081-1091.

Bradbury, I.R., Laurel, B., Snelgrove, P.V.R., Bentzen, P. \& Campana, S.E. (2008) Global patterns in marine dispersal estimates: the influence of geography, taxonomic category and life history. Proceedings. Biological sciences / The Royal Society, 275, 1803-1809.

Caley, M.J. et al. (1996) Recruitment and the local dynamics of open marine populations. Annual Review of Ecology and Systematics, 27, 477-500.

Carson, H.S., Cook, G.S., Lopez Duarte, P.C. \& Levin, L.A. (2011) Evaluating the importance of demographic connectivity in a marine metapopulation. Ecology, 92, 1972-1984.

Carvalho G.R, \& Hauser L. (1994) Molecular genetics and the stock concept in fisheries. Reviews in Fish Biology and Fisheries, 4, 326-350.

Chambers G.K. \& MacAvoy E.S. (2000) Microsatellites: consensus and controversy. Comp. Biochem. Physiol. Biology, 126, 455-476

Chiswell, S.M. \& Booth, J.D. (1999) Rock lobster Jasus edwardsii larval retention by the Wairarapa Eddy off New Zealand. Marine Ecology Progress Series, 183, 227-240

Chiswell, S.M. \& Booth, J.D. (2005) Distribution of mid- and late-stage Jasus edwardsii phyllosomas : Implications for larval recruitment processes. New Zealand Journal of Marine and Freshwater Research, 39, 1157-1170

Chiswell, S.M. \& Booth, J.D. (2008) Sources and sinks of larval settlement in Jasus edwardsii around New Zealand: Where do larvae come from and where do they go? Marine Ecology Progress Series, 354, 201-217 
Cowen, R.K. (2002) Oceanographic influences on larval dispersal and retention and their consequences for population connectivity. Coral Reef Fishes, Chapter 7, 149-170, Copyright $@$ Academic Press.

Coyle, T. (1988) Stock identification and fisheries management: the importance of using several methods in a stock identification study. Taking Stock: defining and managing shared resources, Proceedings from the Australian Society for fish biology 173-182.

Crivello, J.F., Jr, D.F.L. \& Keser, M. (2005) The genetic stock structure of the american lobster (homarus americanus) in Long Island Sound and Hudson Canyon. Journal of Shellfish Research, 24, 841-848.

DeYoung R.W. and Honeycutt R.L. (2005) The Molecular tool box: Genetic techniques in wildlife ecology and management, Journal of Wildlife Management, 69, 4 1362-1384

Doherty PJ. (1981) Coral reef fishes: recruitment-limited assemblages? Proc. 4th Int. Coral Reef Symp, 2, 465-70

Fisher, R. (2005) Swimming speeds of larval coral reef fishes: impacts on selfrecruitment and dispersal. Marine Ecology Progress Series, 285, 223-232.

Garoia, F., Guarniero, I., Ramsak, A., Ungaro, N., Landi, M., Piccinetti, C., Mannini, P. \& Tinti, F. (2004) Microsatellite DNA variation reveals high gene flow and panmictic populations in the Adriatic shared stocks of the European squid and cuttlefish. Hereditry, 93, 166-174.

Gerlach, G., Atema, J., Kingsford, M.J., Black, K.P. \& Miller-Sims, V. (2007) Smelling home can prevent dispersal of reef fish larvae. Proceedings of the National Academy of Sciences of the United States of America, 104, 858-863.

Gilg, M.R. \& Hilbish, T.J. (2003) The geography of marine larval dispersal: Coupling genetics with fine-scale physical oceanography. Ecology, 84, 2989-2998.

Hauser, L., Adcock, G.J., Smith, P.J., Ramiréz, J.H.B. \& Carvalho, G.R. (2002) Loss of microsatellite diversity and low effective population size in an overexploited population of New Zealand snapper (Pagrus auratus). Proceedings of the National Academy of Sciences of the United States of America, 99, 1174211747.

Hauser, L. \& Carvalho, G.R. (2008) Paradigm shifts in marine fisheries genetics: ugly hypotheses slain by beautiful facts. Fish and Fisheries, 9, 333-362.

Heath, R.A. (1982) A review of the physical oceanography of the seas around New Zealand. New Zealand Journal of Marine and Freshwater Research, 19, 79124. 
Hedgecock, D., Barber, P.H. \& Edmands, S. (2007) Genetic approaches to measuring connectivity. Oceanography 20, 70-79.

Hilborn, R., Quinn, T.P., Schindler, D.E. \& Rogers, D.E. (2003) Biocomplexity and fisheries sustainability. Proceedings of the National Academy of Sciences of the United States of America 100, 6564-8.

Hutchings, J.A \& Baum, J.K. (2005) Measuring marine fishes biodiversity: temporal changes in abundance, life history and demography. Philosophical transactions of the Royal Society of London. Series B, Biological Sciences, 360, 315-338.

Hutchinson, W.F., Carvalho, G.R. \& Rogers, S. (2001) Marked genetic structuring in localized spawning populations of cod Gadus morhua in the North Sea and adjoining waters as revealed by microsatellites. Marine Ecology Progress Series, 223, 251-260.

Ihssen P.E., Booke H.E., Casselman J.M., McGlade J.M., Payne N.R. \& Utter F.M. (1981) Stock identification: materials and methods. Canadian Journal of Fisheries and Aquatic Sciences 38, 1838-1855.

Jeffs, A.G., Chiswell, S.M. \& Booth, J.D. (2001) Distribution and condition of pueruli of the spiny lobster Jasus edwardsii offshore from north-east New Zealand. Marine and Freshwater Research, 52, 1211-1216.

Jones, G.P., Milicich, M.J., Emslie, M.J. \& Lunow, C. (1999) Self-recruitment in a coral reef fish population. Nature, $402,802-804$.

Kimura, M. \& Crow, J.F. (1964) The number of alleles that can be maintained in a finite population. Genetics 49, 725-738.

Kimura, M. \& Ohta, T. (1978) Stepwise mutation model and distribution of allelic frequencies in a finite population. Proceedings of the National Academy of Sciences of the United States of America, 75, 2868-2872.

Kittaka, J. (1994) Culture of phyllosomas of spiny lobster and its application to studies of larval recruitment and aquaculture. Crustaceana, 66, 258-270.

Kittaka, J., Ono, K., Booth, J. \& Webber, W.R. (2005) Development of the red rock lobster, Jasus edwardsii, from egg to juvenile. New Zealand Journal of Marine and Freshwater Research, 39, 263-277.

Krug, P.J. \& Zimmer, R.K. (2004) Developmental dimorphism: consequences for larval behavior and dispersal potential in a marine gastropod. The Biological Bulletin, 207, 233-246. 
Levin, L.A. (2006) Recent progress in understanding larval dispersal: new directions and digressions. Integrative and comparative biology, 46, 282-297.

Lowe, W.H. \& Allendorf, F.W. (2010) What can genetics tell us about population connectivity? Molecular Ecology, 19, 3038-3051

MacDiarmid, A. (1991) Seasonal changes in depth distribution, sex ratio and size frequency of spiny lobster Jasus edwardsii on a coastal reef in northern New Zealand. Marine Ecology Progress Series, 70, 129-141.

Macdiarmid, A.B. \& Butler, M.J. (1999) Sperm economy and limitation in spiny lobsters. Behavioral Ecology and Sociobiology, 46, 14-24.

Machado-Schiaffino, G., Juanes, F. \& Garcia-Vazquez, E. (2011) Identifying unique populations in long-dispersal marine species: Gulfs as priority conservation areas. Biological Conservation, 144, 330-338.

Olsson, J., Mo, K., Florin, a-B., Aho, T. \& Ryman, N. (2011) Genetic population structure of perch Perca fluviatilis along the Swedish coast of the Baltic Sea. Journal of fish biology, 79, 122-137.

Ovenden, J.R., Brasher, D.J. \& White, R.W.G. (1992) mDNA analysis of the red rock lobster Jasus edwardsii shows an apparent absence of population subdivisions throughout Australasia. Marine Biology, 326, 319-326.

Palumbi, S.R. \& Warner, R.R. (2003) Why gobies are like hobbits. Science, 299, 51-52.

Palumbi, S.R. (2003) Population genetics, demographic connectivity, and the design of marine reserves. Ecological Applications, 13, 146-158.

Phillips, B.F. \& McWilliam, P.S. (1986) The pelagic phase of spiny lobster development. Canadian Journal of Fisheries and Aquatic Sciences, 43, 21532163.

Pinsky, M.L., Jensen, O.P., Ricard, D. \& Palumbi, S.R. (2011) Unexpected patterns of fisheries collapse in the world's oceans. Proceedings of the National Academy of Sciences of the United States of America, 108, 8317-8322.

Ricker, W.E., (1981) Changes in the average size and average age of Pacific Salmon. Canadian Journal of Fisheries and Aquatic Sciences, 1981, 38, 1636-1656

Roberts, C.M. (1997) Connectivity and management of Caribbean coral reefs. Science, $278,1454-1457$

Ruttenberg, B. et al. (2005) Elevated levels of trace elements in cores of otoliths and their potential for use as natural tags. Marine Ecology Progress Series, 297, 273-281. 
Ruzzante, D.E. et al. (2006) Biocomplexity in a highly migratory pelagic marine fish, Atlantic herring. Proceedings. Biological sciences / The Royal Society 273: 1459-64.

Ruzzante, D.E., Taggart, C.T. \& Cook, D (1998) A nuclear DNA basis for shelf- and bank-scale population structure in northwest Atlantic cod (Gadus morhua): Labrador to Georges Bank. Molecular ecology, 7, 1663-1680.

Sale, P.F. et al. (2005) Critical science gaps impede use of no-take fishery reserves. Trends in ecology \& evolution, 20, 74-80.

Shaklee J. \& Bentzen P. (1998) Genetic identification of stocks of marine fish. Bulletin of Marine Science, 62, 589-621.

Shanks, A.L., Grantham, B. a \& Carr, M.H. (2003) Propagule dispersal distance and the size and spacing of Marine Reserves. Ecological Applications, 13, 159-169.

Shears, N. \& Babcock, R (2003) Continuing trophic cascade effects after 25 years of no-take marine reserve protection. Marine Ecology Progress Series, 246, 1-16.

Smith M.T. \& Addison J.T. (2003) Methods for stock assessment of crustacean fisheries. Fisheries Research, 65, 231-256.

Smith, P.J., Mckoy, J.L. \& Machin, P.J. (1980) Genetic variation in the rock lobsters Jasus edwardsii and Jasus novaehollandiae. New Zealand Journal of Marine and Freshwater Research, 14, 55-63.

Swearer, S.E. et al. (2002) Evidence of self recruitment in demersal marine populations, Bulletin of Marine Science, 70, 251-271.

Taylor, M.S. \& Hellberg, M.E. (2003) Genetic evidence for local retention of pelagic larvae in a Caribbean reef fish. Science, 299, 107-9.

Waples, R.S. (1998) Separating the wheat from the chaff : Patterns of genetic differentiation in high Gene Flow Species. Journal of Heredity 438-450.

Waples, R.S. \& Gaggiotti, O. (2006) What is a population? An empirical evaluation of some genetic methods for identifying the number of gene pools and their degree of connectivity. Molecular ecology, 15, 1419-39.

Ward R.D (2000) Genetics in fisheries management, Hydrobiologia, 420, 191-201.

Ward, R.D. \& Grewe, P.M. (1994) Appraisal of molecular genetic techniques in fisheries. Reviews in Fish Biology and Fisheries, 4, 300-325 
Weber, J. L. (1990) Informativeness of human (dC-dA)n (dG-dT)n polymorphisms. Genomics, 7, 524-530

Weersing, K. \& Toonen, R. (2009) Population genetics, larval dispersal, and connectivity in marine systems. Marine Ecology Progress Series, 393, 1-12.

White, C. et al. (2010) Ocean currents help explain population genetic structure. Proceedings. Biological sciences / The Royal Society, 277, 1685-1694.

Worm, B. et al. (2006) Impacts of biodiversity loss on ocean ecosystem services. Science, 314, 787-90 


\section{Chapter II: Characterisation of polymorphic microsatellite markers for the red rock lobster Jasus edwardsii (Hutton 1875)}

\subsection{Abstract}

Jasus edwardsii is New Zealand's largest seafood export species and supports valuable customary and recreational fisheries. Nine novel microsatellite markers were developed from 454 sequence data and scored across 45 individuals collected from Wellington, New Zealand $\left(41^{\circ} 20^{\prime} \mathrm{S}, 174^{\circ} 48^{\prime} \mathrm{E}\right)$ to obtain genetic diversity indices. All loci were polymorphic with the number of alleles per locus ranging from 6-39. Observed and expected heterozygosity ranged from 0.563-0.937 and 0.583-0.961, respectively. There were no significant deviations from Hardy-Weinberg equilibrium for any of the loci examined following standard Bonferroni corrections. Null allele frequencies were low $(<10 \%)$ across all loci. These are the first microsatellite markers to be developed for Jasus edwardsii and are employed to study the genetic structure across New Zealand and Australia in Chapter 3 of this thesis. 


\subsection{Introduction}

Microsatellite loci are among the most variable types of DNA sequences and are widely distributed throughout the eukaryotic genome (Ellegren 2004). Microsatellites occur as simple sequence repeats (2-5 bp) that are normally less than $300 \mathrm{bp}$ long (Deyoung and Honeycutt 2005) and generally appear in the non-coding portions of the DNA, making them selectively neutral. Polymorphisms of microsatellite loci are expressed as variation in sequence length and arise during DNA replication through a process known as "slipped-strand mispairing" (Levinson and Gutman 1987). The high levels of variability and selective neutrality characteristic of microsatellite loci makes them ideal markers for fine-scale studies of gene flow, stock identification, DNA profiling, and parentage and pedigree analysis (Chambers and MacAvoy 2000).

This chapter presents the development of 9 novel microsatellite markers for the red rock lobster Jasus edwardsii (Hutton 1875). J. edwardsii supports lucrative seafood export markets in New Zealand and Australia and is also a highly targeted species of the recreational fisheries. In New Zealand, the commercial fishery is divided into 10 management areas (CRA 1-10) and the stock is presumed to form a single panmictic population throughout the country. The assumption of panmixia is based on allozyme (Smith et al. 1980; Booth et al. 1990) and mDNA analysis (Ovenden 1992). Given that J. edwardsii has one of the longest-lived pelagic larval durations in the marine environment, any significant genetic differentiation between populations would presumably be at very low levels and possibly below the resolving power of those previously applied techniques. Highly polymorphic microsatellites, however, offer a higher resolving power than more traditional genetic techniques and may detect fine-scale genetic differentiation that has previously gone undetected. Any differentiation detected could potentially have large implications for the management of J. edwardsii in New Zealand and Australia. The markers developed in this chapter are applied in a population study throughout New Zealand and Australia in Chapter 3. 


\subsection{Materials and Methods:}

\subsubsection{4 template preparation}

Genomic DNA for 454 sequencing was extracted from the abdominal tissue from individuals collected near Cape Campbell, New Zealand ( $\left.41^{\circ} 43^{\prime} \mathrm{S}, 174^{\circ} 16^{\prime} \mathrm{E}\right)$ using a phenol-chloroform protocol (Table 1; Sambrook et al. 1989). DNA concentration (ng/ul) and quality (260/280 values) were determined using a nano-drop (IMPLEM NanoPhotometer ${ }^{\mathrm{TM}}$ Peal v1.0). High quality extracts were pooled from 4 individuals and sent for 454 sequencing to the High-Throughput DNA Sequencing Unit at the Department of Anatomy and Structural Biology, University of Otago.

\subsubsection{GS-FLX sequencing procedure (454 life sciences)}

Library preparation was conducted by breaking the double helix DNA ladder into short (400-600) double stranded fragments. The fragments were split into individual bands and attached to micron-sized beads where they were subjected to an emulsion PCR process that replicates the DNA strand into millions of copies and that become immobilized on the capture beads. The single strands were copied by an enzyme by depositing complimentary bases. The DNA-capture beads were placed on a PicoTitorPlate (454 life sciences) with various reagents and ran on a 454 sequencing system (454GS-FLX instrument) following the King and Scott-Horton (2008) pyrosequencing procedure. The run generated 102,000 sequences with a mean length of 571 base pairs. Figure 1 shows distribution of lengths of sequences generated by the 454 run. 
Sequence Lengths for 83,579 Nucleotide Sequences

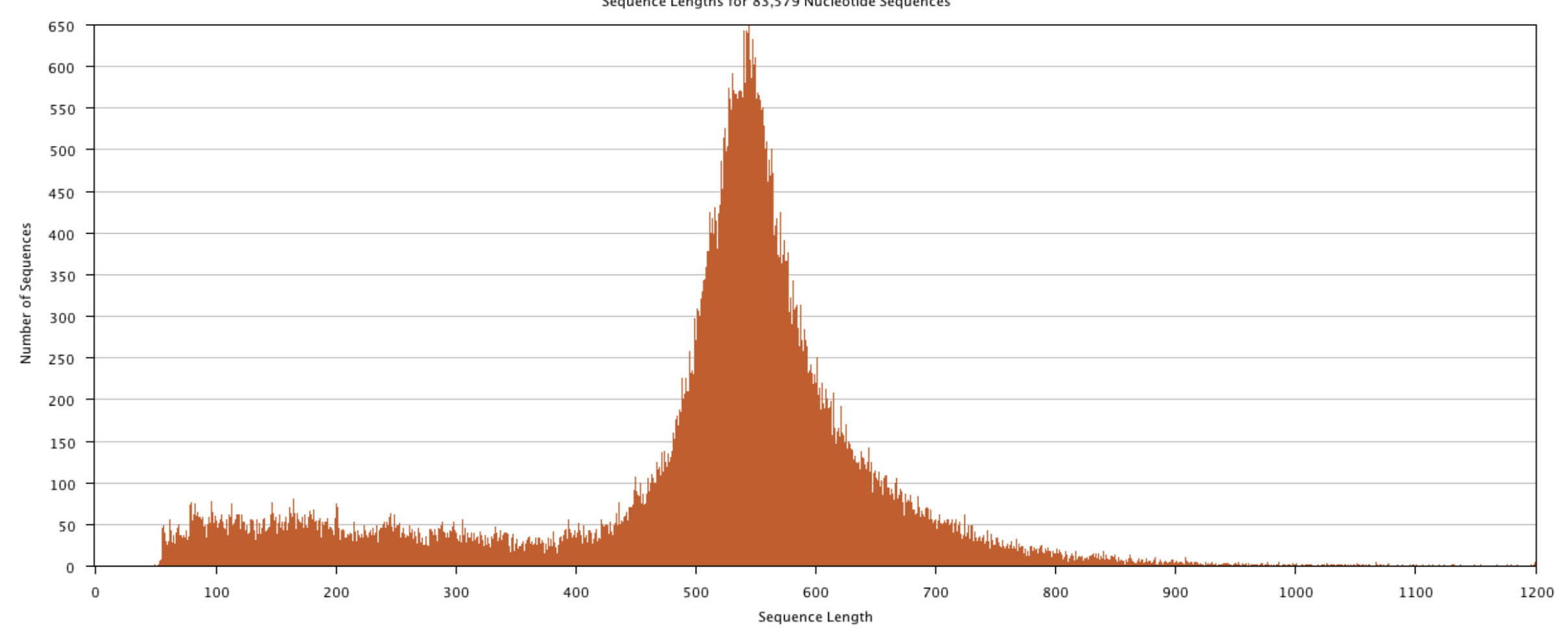

Figure 1 Sequence lengths of 454 results from GS-FLX sequencing instrument produced by Genious Pro 5.1.4. Average length (571 bp). 


\subsubsection{Screening for Tandem Repeats}

Sequences were imported into Geneious Pro 5.1.4C and screened for perfect and imperfect tandem repeats using Phobos 3.3.1.1. All di, tri, tetra and penta repeats (min length $90 \mathrm{bp}$, min perfection $80 \%$ ) were identified totalling 7,509 regions. Repeat motifs that appeared in the middle of a sequence, not surrounded by other repeating regions, and of sufficient quality $(\leq 2$ unidentified base pairs in entire sequence) were extracted to a different file for primer development. Primers were designed by Primer3 (Rozen and Skaletsky 2000) based on conditions in Table 2.

Table 1 DNA extreaction protocol (adopted from Sambrook 1989).

\begin{tabular}{|c|c|c|c|}
\hline $\begin{array}{c}\text { CELL LYSIS AND } \\
\text { PROTEINT DIGESTIONS }\end{array}$ & SAMPLE PURIFICATION & DNA PRECIPITATION & DNA RE-HYDRATION \\
\hline $\begin{array}{l}\text { Add } 400 \mu \text { l of } \\
\text { extraction buffer (10 } \\
\text { mM Tris- } \mathrm{HCl} \text { ph } 8.0 \text {, } \\
50 \mathrm{mM} \mathrm{NaCl} 10 \mathrm{mM} \\
\text { EDTA) , } 10 \text { ul of } 10 \% \\
\text { sodium dodecyl } \\
\text { sulphate (SDS) and } 20 \\
\mu \text { of } 10 \mathrm{mg} / \mathrm{ml} \\
\text { Proteinase } \mathrm{K} \text { to each } \\
\text { tissue sample. } \\
\text { Incubate @ } 55^{\circ} \mathrm{C} \text { for } 2 \\
\text { hours or overnight. }\end{array}$ & $\begin{array}{l}\text { Add } 400 \mu \mathrm{l} \text { phenol to } \\
\text { each sample and invert } \\
\text { several times. Spin } \\
\text { tubes at } 13,000 \mathrm{rpm} \text { for } \\
5 \text { min and pipette } \\
\text { supernatant into a } \\
\text { fresh } 1.7 \mathrm{ml} \text { tube. } \\
\text { Add } 400 \mu \mathrm{l} \text { of } \\
\text { Chloroform-Isoamyl } \\
(24: 1) \text { to each sample. } \\
\text { Invert several times } \\
\text { and spin at } 13,000 \text { rpm } \\
\text { for } 5 \text { min. Remove } \\
\text { supernatant and place } \\
\text { into a fresh } 1.7 \text { ml } \\
\text { tube. }\end{array}$ & $\begin{array}{l}\text { Add } 0.9 \mathrm{ml} \text { of chilled } \\
100 \% \text { ethanol and } 40 \mathrm{ul} \\
\text { of } 3 \mathrm{M} \text { sodium acetate } \\
\mathrm{pH} 5.2 \text {. to each sample. } \\
\text { Mix gently and place at - } \\
20^{\circ} \mathrm{C} \text { for } 60 \text { min. } \\
\text { Spin the samples at } \\
13,000 \text { rpm at } 4 \mathrm{C} \text { for } 30 \\
\text { min and then remove } \\
100 \% \text { ethanol and wash } \\
\text { with } 70 \% \text { ethanol } \\
\text { Spin at } 13,000 \text { rpm at } \\
4^{\circ} \mathrm{C} \text { for } 10 \text { min. Remove } \\
\text { ethanol from tube and } \\
\text { let pellet dry }\end{array}$ & $\begin{array}{l}\text { Re-suspend in } 50 \mu \mathrm{lTE} \\
\text { buffer ( } 10 \mathrm{mM} \text { Tris-HCl } \\
\mathrm{pH} 8.0,1 \mathrm{mM} \text { EDTA). } \\
\text { Allow to sit for } 1 \text { hour } \\
\text { at room temperature } \\
\text { before freezing. }\end{array}$ \\
\hline
\end{tabular}

\subsubsection{DNA extraction for primer development}

DNA for primer development was extracted from pereiopod tissue taken from the Cape Campbell individuals using the phenol-chloroform protocol (Table 1) and stored at $-20^{\circ} \mathrm{C}$. Tissue samples were taken from each individual pereiopod and suspended in $80 \% \mathrm{EtOH}$ for up to 3 months before extractions were performed. The pereiopods were labelled accordingly and stored at $-80^{\circ} \mathrm{C}$. A small segment $\left(1 \mathrm{~mm}^{2}\right)$ was cut from tissue samples when preparing extractions and minced prior to cell lysis and protein digestion. 


\subsubsection{Primer Development}

Selection criteria of primer pairs for development were based on the following factors: (1) pair hairpin score; (2) pair primer-dimer score; and (3) the difference in calculated melting temperature $\left(T_{M}\right)$. Primer pairs that satisfied the requirements in Table 2 were kept for PCR testing. In total 60 primer pairs were synthesised.

Table 2 Primer design conditions as used for Primer3 in Geneious Pro 5.1.4 @

\begin{tabular}{cc}
\hline Primer conditions & Primer Pair conditions \\
\hline Primer length: $16-27$ & Max Hairpin: 4 \\
Tm: $50-70^{\circ} \mathrm{C}$ & Tm difference: $1.5^{\circ} \mathrm{C}$ \\
$\% G C: 55-75$ & Max Primer-Dimer: 3 \\
Hairpin: $0-4$ & Product Size: $150-500$ \\
Primer-Dimer: $0-3$ & \\
GC clamp: 1 & \\
\end{tabular}

Primers were screened using a Touchdown PCR (TD-PCR) protocol. TD-PCR eliminates many of the uncertainties when calculating a melting temperature (Tm) and determining an optimal annealing temperature (Ta) of a primer pair (Korbie and Mattick, 2008). TD-PCR starts with Ta above the calculated Tm of the primer pair and then decreases with every cycle $\left(0.5^{\circ} /\right.$ cycle for 20cycles). This results in an increased specificity with the higher temperatures and an increased yield with the subsequent lower more permissive temperatures (Hecker and Roux, 1996). Amplifications were performed on GeneAmp 2700 (Applied Biosystems) thermocyclers in a final reaction volume of $12.5 \mu \mathrm{l}$, containing $6.75 \mu \mathrm{l}$ MyTaq Red Mix 2X Bioline ${ }^{\circledR}, 0.75 \mu \mathrm{l}$ of Forward and Reverse primers, $50-100$ ng of DNA template and ddH20 to volume (Table 3). Product was then viewed on a $2 \%$ Agorose gel.

PCR conditions were modified from Korbie and Mattick (2008) and were as follows (Table 4): Initial denaturing for $3 \mathrm{~min}$ at $95^{\circ} \mathrm{C}$, followed by $10 \mathrm{TD}$ cycles of $30 \mathrm{~s}$ at $95^{\circ} \mathrm{C}$, $45 \mathrm{~s}$ at $\mathrm{T}_{\mathrm{a}}\left(-1.0^{\circ} \mathrm{C} / \mathrm{cycle}\right)$, and $45 \mathrm{~s}$ at $72^{\circ} \mathrm{C}$, followed by 25 standard cycles of $30 \mathrm{~s}$ at $95^{\circ} \mathrm{C}, 45 \mathrm{~s}$ at $\mathrm{T}_{\mathrm{a}}$ (lowest temperature of TD) and $45 \mathrm{~s}$ at $72^{\circ} \mathrm{C}$ and finishing with a final extension step of $15 \mathrm{~min}$ at $72^{\circ} \mathrm{C}$. Fifteen primer pairs (20\%) amplified consistently in the expected size region and were retained for further screening. 
Table 3 PCR Reaction set-up: For each primer pair reactions were set up as follows.

\begin{tabular}{|c|c|c|}
\hline Ingredient & Volume ( $\mu \mathrm{l})$ & Concentration \\
\hline MyTaq Red Mix 2X Bioline ${ }^{\circledR}$ & 6.25 & \\
\hline Taq DNA polymerase & & 0.11 units $/ \mu l$ \\
\hline Tris-HCl pH 8.5 & & $82.5 \mathrm{mM}$ \\
\hline$(\mathrm{NH} 4) 2 \mathrm{SO} 4$ & & $22 \mathrm{mM}$ \\
\hline $\mathrm{MgCl} 2$ & & $1.65 \mathrm{mM}$ \\
\hline dNTPs & & $0.22 \mathrm{mM}$ \\
\hline Forward Primer & 0.75 & $10 \mu \mathrm{M}$ \\
\hline Reverse Primer & 0.75 & $10 \mu \mathrm{M}$ \\
\hline Template & 0.5 & $50-100 \mathrm{ng} / \mathrm{ul}$ \\
\hline $\mathrm{ddH} 20$ & to 12.5 & \\
\hline Total PCR volume & 12.5 & \\
\hline
\end{tabular}

\subsubsection{Primer Screening}

The retained primer pairs were then tagged with fluorochrome labels $6-\mathrm{FAM}^{\mathrm{TM}}$ and $\mathrm{HEX}^{\mathrm{TM}}$ and tested initially on eight individuals from two populations (Hauraki Gulf and Stewart Island) for possible scoring errors and size polymorphism. Microsatellite loci can be sized and scored using fluorescently tagged DNA fragments (PCR product using fluorochrome tags on $5^{\prime}$ end of forward primer) in combination with an appropriate size standard. Genotyping results appear as fluorescent peaks that will vary in size according to number of repeat units. Genotyping was conducted on an ABI 3730XLs (Applied Biosystems) sequencer and loci were scored using a 500LIZ size standard in GeneMarker V1.97 (www.softgenetics.com). Three loci had significant scoring issues and another three were monomorphic; these six loci were discarded. The remaining nine loci (Figure 2) were then screened against 45 individuals collected from Wellington's south coast $\left(41^{\circ} 20^{\prime} \mathrm{S}, 174^{\circ} 48^{\prime} \mathrm{E}\right)$ to obtain basic intrapopulation diversity indices. 
Table 4 Touchdown (TD) PCR protocol (Korbie and Mattick 2008).

\begin{tabular}{llll}
\hline Step & Phase & Temperature $\left({ }^{\circ} \mathrm{C}\right)$ & Time \\
\hline 1 & Initial denaturing & 95 & $3: 00$ \\
2 & Denature & 95 & $0: 30$ \\
3 & Anneal* & $70-60$ & $0: 45$ \\
4 & & $60-50$ & $0: 45$ \\
\hline & Extension & 72 & \\
\hline 5 & Repeat steps 2-4 (10 cycles) & $0: 30$ \\
& Denature & 95 & $0: 45$ \\
7 & Anneal & 60 & $0: 45$ \\
\hline 7 & & 50 & \\
\hline 9 & Extension & 72 & $15: 00$ \\
\hline
\end{tabular}

${ }^{*} \mathrm{~T}_{\mathrm{a}}$ is reduced by $1.0^{\circ} \mathrm{C}$ each cycle

\subsection{Results and Discussion}

Summary statistics are located in Table 5. MICROCHECKER 2.2.3 (Van Oosterhout et al. 2004) found no evidence of large allele dropout or scoring error due to stuttering. FSTAT 2.9.3 (Goudet 1995) was used to determine number of alleles per locus and inbreeding coefficients, which ranged from 6-39 and -0.026-0.221, respectively. Observed and expected heterozygosity were calculated by Arlequin 3.5.1.2 (Excoffier et al. 2005) and values ranged from 0.563-0.937 and from 0.583-0.961, respectively. GENEPOP 4.1.0 (Raymond and Rouset 1993) detected no evidence of significant linkage disequilibrium among any pairs of loci or deviations from Hardy-Weinberg equilibrium following standard Bonferroni corrections; Markov-chain parameters were 10,000 dememorization steps, 1,000 batches and 10,000 iterations per batch. FreeNA found low levels $(<10 \%)$ of null allele frequencies across all loci. Null alleles are widespread across taxa and are particularly common in marine invertebrates ( $\mathrm{Li}$ et al. 2003; Hedgecock et al. 2004). However, frequencies at levels reported here are too low to introduce bias into estimates of population differentiation (Chapius and Estoup 2007). These microsatellite markers are the first to be developed for $J$. edwardsii and are used in a population genetic analysis of J. edwardsii throughout New Zealand and Australia in the following chapter. 


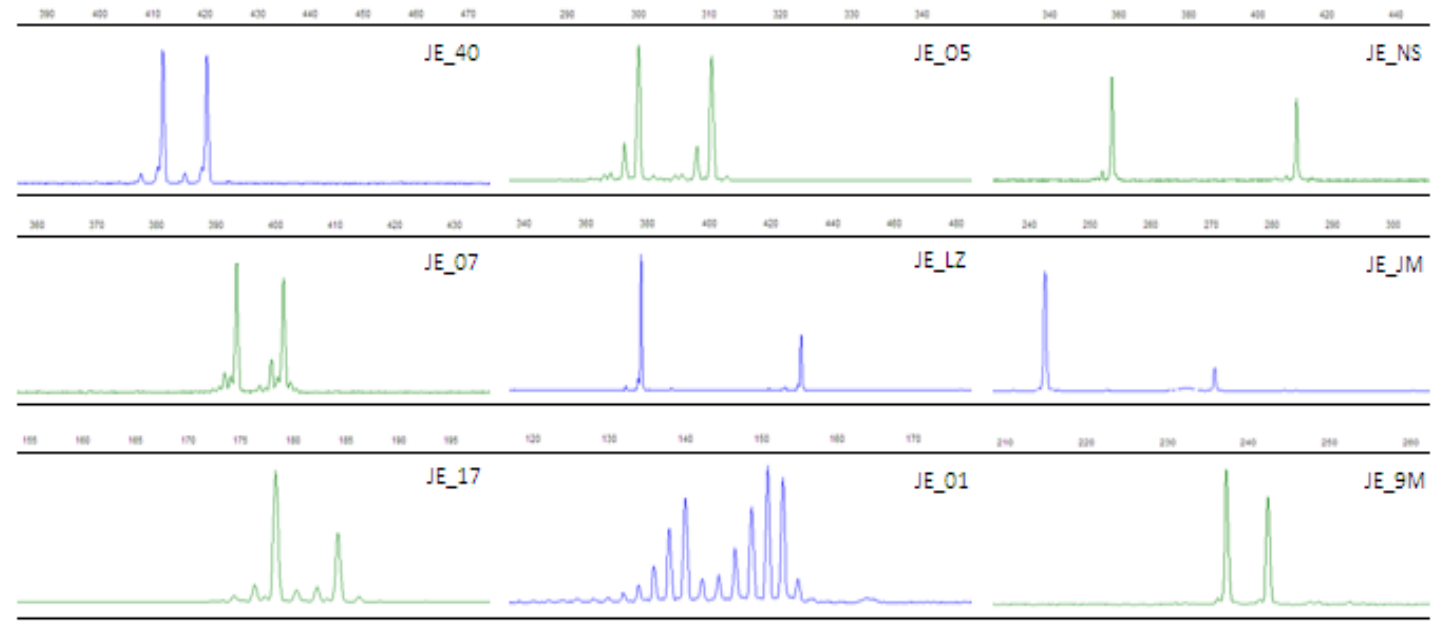

Figure 2 Chromatograph images of primers as seen in GeneMarker v1.97. Microsatellites in blue are labelled with fluorochrome tag 6-FAM ${ }^{\mathrm{TM}}$ and in green with $\mathrm{HEX}^{\mathrm{TM}}$.

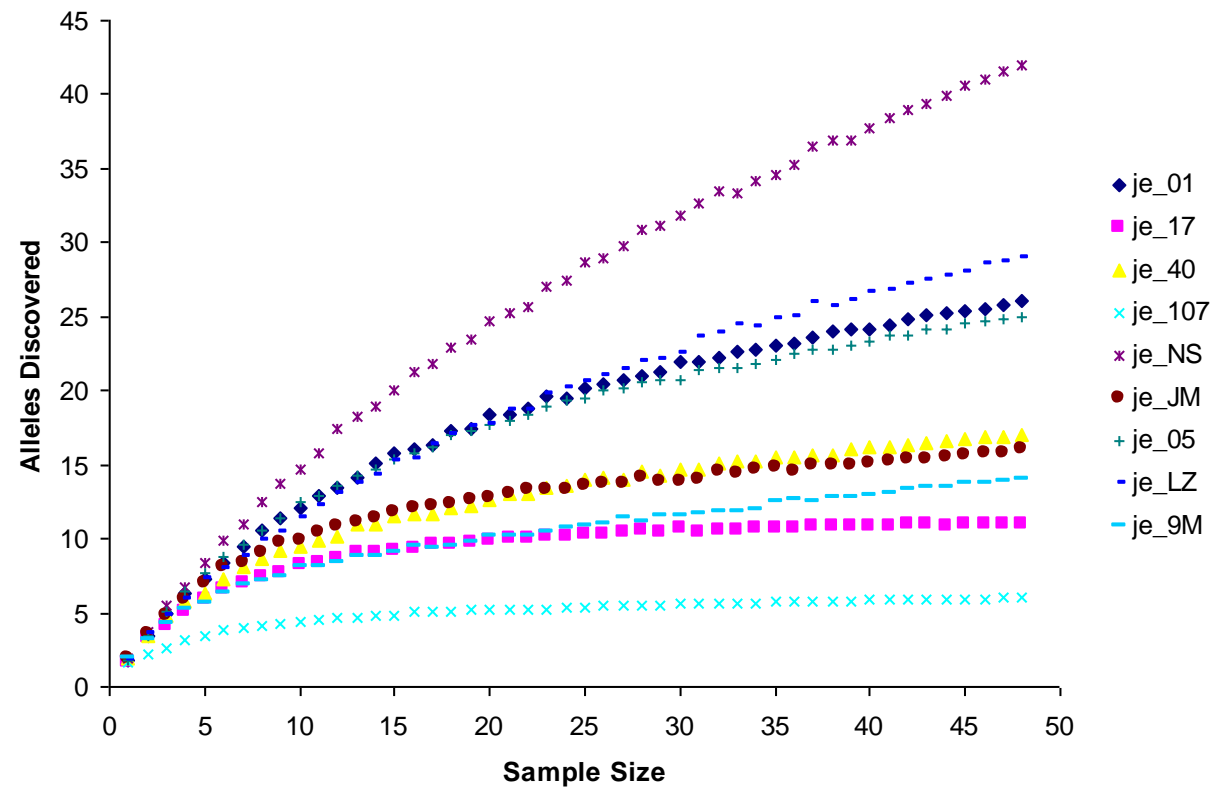

Figure 3 Allele discovery curves for each locus for the Wellington population. The curve for each locus reaches an asymptote when genetic diversity is completely sampled. Curves were generated using PopGenKit Package (Paquette 2011) in R 2.13.1. 
Table 5 Primer characteristics and sequences of microsatellite loci for the red rock lobster Jasus edwardsii.

\begin{tabular}{|c|c|c|c|c|c|c|c|c|c|c|c|c|}
\hline $\begin{array}{l}\text { Locus } \\
\text { name }\end{array}$ & $\begin{array}{l}\text { GenBank } \\
\text { acc no. }\end{array}$ & $\begin{array}{l}\text { Repeat } \\
\text { Motif }\end{array}$ & Sequence $\left(5^{\prime} \rightarrow 3^{\prime}\right)$ & TD $_{T_{A}}$ & $\mathbf{N}$ & $\mathbf{N}_{\mathrm{A}}$ & $\begin{array}{c}\text { Size } \\
\text { Range }\end{array}$ & $\mathbf{H}_{\mathbf{O}}$ & $\mathbf{H}_{\mathrm{E}}$ & $\mathbf{P}_{\text {HWE }}$ & $\mathbf{N}_{\mathrm{F}}$ & $F_{\text {IS }}$ \\
\hline \multirow[t]{2}{*}{ JE_01 } & JN806248 & $(\mathrm{CA})_{62}$ & F: GTC TTT AAT CCA GCT TGG CCT TCC & $70-60$ & 45 & 25 & $116-206$ & 0.813 & 0.939 & 0.015 & 0.073 & 0.137 \\
\hline & & & R: CGA GAG AGA GAG TGT GTG TGT ACG & & & & & & & & & \\
\hline \multirow[t]{2}{*}{ JE_17 } & JN806249 & $(\mathrm{ATAC})_{13}$ & F: CGC GAA CGG AGT CAA GGA ACG & $70-60$ & 45 & 11 & $160-208$ & 0.689 & 0.882 & 0.065 & 0.101 & 0.221 \\
\hline & & & R: TCA GAA CAT TAA CCC AGC CAG GTG & & & & & & & & & \\
\hline \multirow[t]{2}{*}{ JE_NS } & JN806252 & $(C A G)_{50}$ & F: AGGATAGGTTCTCCCGTTCGC & $70-60$ & 48 & 39 & $282-507$ & 0.937 & 0.961 & 0.411 & 0.005 & 0.025 \\
\hline & & & R: CCGTGCTCCGCTTCACC & & & & & & & & & \\
\hline \multirow[t]{2}{*}{ JE_JM } & JN806253 & $(\mathrm{TTAGG})_{3}(\mathrm{TA})_{2}$ & F: GCC TCC TAC AGC CCT CTG G & $70-60$ & 48 & 16 & $254-354$ & 0.875 & 0.961 & 0.037 & 0.027 & 0.046 \\
\hline & & $(\text { GGTTA })_{25}$ & R: TGT CCT GCT TCG CCA TCA GC & & & & & & & & & \\
\hline \multirow[t]{2}{*}{ JE_O5 } & JN806254 & $(\mathrm{TACCT})_{20}$ & F: ACC GCT GCT GAT TGG ACT ACC TG & $70-60$ & 48 & 24 & $224-414$ & 0.875 & 0.937 & 0.287 & 0.014 & 0.067 \\
\hline & & & R: CCT CAA GAC CGT GGG TGG GTG & & & & & & & & & \\
\hline \multirow[t]{2}{*}{ JE_LZ } & JN806255 & $(\mathrm{GGTTA})_{33}$ & F: GTG CTC CTC CAT ACA CAC CAA GAC G & $70-60$ & 48 & 28 & $258-523$ & 0.896 & 0.891 & 0.179 & 0.000 & -0.006 \\
\hline & & & R: ACC TGA CCT AAC CTA CCC TAC CCT G & & & & & & & & & \\
\hline \multirow[t]{2}{*}{ JE_40 } & JN806250 & $(G T A G)_{62}$ & F: GTG TGG TGG GTA ATG TGA T & $60-50$ & 45 & 17 & $352-436$ & 0.917 & 0.894 & 0.411 & 0.000 & -0.026 \\
\hline & & & R: CGC TGA GAA CCA CCT AT & & & & & & & & & \\
\hline \multirow[t]{2}{*}{ JE_07 } & JN806251 & $(\mathrm{CGT})_{52}$ & F: TCC TTA CTC CCG CCG ATG CC & $60-50$ & 45 & 6 & $393-408$ & 0.563 & 0.583 & 0.249 & 0.002 & 0.036 \\
\hline & & & R: ACG GAC GGA CGA CGA CGA AC & & & & & & & & & \\
\hline \multirow[t]{2}{*}{ JE_9M } & JN806256 & $(\mathrm{ACCTA})_{9}(\mathrm{ACCAA})_{3}$ & F: TCT GTC TGT TGA GTG CCG TC & $60-50$ & 45 & 12 & $187-277$ & 0.833 & 0.866 & 0.069 & 0.024 & 0.038 \\
\hline & & $(\mathrm{ACCTA})_{7}$ & R: GCC AGG GAG GAG GGT GTA G & & & & & & & & & \\
\hline
\end{tabular}

Annealing temperature of touchdown protocol $\left(\mathrm{T}_{\mathrm{A}}\right)$; number of individuals genotyped $(\mathrm{N})$; number of alleles per locus $\left(\mathrm{N}_{\mathrm{A}}\right)$; observed heterozygosity $\left(\mathrm{H}_{\mathrm{O}}\right)$; expected heterozygosity $\left(\mathrm{H}_{\mathrm{E}}\right)$; $\mathrm{p}$-value for HWE deviation $\left(\mathrm{P}_{\mathrm{HWE}}\right)$; null allele frequency $\left(\mathrm{N}_{\mathrm{F}}\right)$; inbreeding coefficient $\left(\mathrm{F}_{\mathrm{IS}}\right)$. 


\subsection{Literature Cited}

Bentzen, P., Taggart, C.T., Ruzzante, D.E. \& Cook, D. (1996) Microsatellite polymorphism and the population structure of Atlantic cod Gadus morhua in the northwest Atlantic. Canadian Journal of Fisheries and Aquatic Sciences, $53,2706-2721$.

Booth, J.D., Phillips, B.F. (1994) Early life history of spiny lobster. Proceedings from the fourth international workshop on lobster biology and management, Crustaceana, 66, 271-294.

Booth, J.D., Street, R.J., Smith, P.J. (1990) Systematic status of the rock lobsters Jasus edwardsii from New Zealand and J. novaehollandiae from Australia. New Zealand Journal of Marine and Freshwater Research, 24, 239-249.

Chapuis, M.-P., Estoup, A. (2007) Microsatellite null alleles and estimation of population differentiation. Molecular biology and Evolution, 24, 621-31.

Chambers, G. K., \& MacAvoy, E. S. (2000). Microsatellites: consensus and controversy. Comparative biochemistry and physiology. Part B, Biochemistry \& molecular biology, 126(4), 455-76.

American lobster Homarus americanus in Long Island Sound and the Hudson Canyon. Journal of Shellfish Research, 24, 841-848.

Deyoung, R.W., Honeycutt, R.L. (2005) The molecular toolbox: Genetic Techniques in wildlife ecology and management. Journal of Wildlife Management, 69, 13621384

Drummond, A.J., Ashton, B., Buxton, S., Cheung, M., Cooper, A., Duran, C., Field, M., Heled, J., Kearse, M., Markowitz, S., Moir, R., Stones-Havas, S., Sturrock, S. Thierer, T. \& Wilson, A. (2010) Geneious v5.3, http://www.geneious.com.

Ellegren, H. (2004). Microsatellites: simple sequences with complex evolution. Nature reviews. Genetics, 5(6), 435-45.

Excoffier, L., Laval, G., Schneider, S. (2005) Arlequin ver. 3.0: An integrated software package for population genetics data analysis. Evolutionary Bioinformatics Online, 1, 47-50.

Goudet J. (1995) FSTAT (Version 1.2): A Computer Program to Calculate F-Statistics, Heredity, 86, 485-486.

Hedgecock D, Li G, Hubert S, Bucklin K, Ribes V (2004) Widespread null alleles and poor cross-species amplification of microsatellite DNA loci cloned from the pacific oyster, Crassostrea gigas. Journal of Shellfish Research, 23, 379-385. 
Kensler, C. (1967) The distribution of spiny lobsters in New Zealand waters

(Crustacea: Decapoda: Palinuridae). New Zealand Journal of Marine and Freshwater Research, 1, 412-420.

King C., Scott-Horton T. (2008). Pyrosequencing: A Simple Method for Accurate Genotyping. Journal of Visualized Experiments, 11.

Kittaka, J. (1994) Culture of phyllosomas of spiny lobster and its application to studies of larval recruitment and aquaculture. Crustaceana, 66, 258-270.

Korbie, D.J., Mattick, J.S. (2008) Touchdown PCR for increased specificity and sensitivity in PCR amplification. Nature protocols, 3, 1452-1456.

Levinson, G., Gutman, G.A., (1987) Slipped-strand mispairing: a major mechanism for DNA sequence evolution. Mol. Biol. Evolution, 4, 203-221.

Li, G., Hubert, S., Bucklin, K., Ribes, V. \& Hedgecock, D. (2003) Characterization of 79 microsatellite DNA markers in the Pacific oyster Crassostrea gigas. Molecular Ecology Notes, 3, 228-232.

Mayer, C. (2006-2010) Phobos 3.3.11, www.rub.de/spezzoo/cm/cm phobos.htm.

Ministry of Fisheries, Science (2010) Report from the Mid-Year Fishery Assessment Plenary: stock assessments and yield estimates (Unpublished report held in NIWA Greta Point library, Wellington).

Ovenden, J.R., Brasher, D.J., White, R.W.G. (1992) mDNA analysis of the red rock lobster Jasus edwardsii shows an apparent absence of population subdivisions throughout Australasia. Marine Biology, 326, 319-326.

Raymond, M., Rousset, F. (1993) GENEPOP (Version 1.2): Population Genetics Software for Exact Tests and Ecumenicism. Heredity, 86, 248-249.

Rozen, S., Skaletsky, HJ. (2000) Primer3 on the WWW for general users and for biologist programmers, Bioinformatics Methods and Protocols: Methods in Molecular Biology. Humana Press, Totowa, NJ, pp 365-386.

Sambrook, J., Fritsch, E.F., Maniatus, T. (1989) Molecular Cloning: A Laboratory Manual, $2^{\text {nd }}$ ed. Cold Spring Harbour Laboratory Press, New York

Shears, N., Babcock, R. (2003) Continuing trophic cascade effects after 25 years of no-take marine reserve protection. Marine Ecology Progress Series, 246, 1-16.

Smith, P.J., Mckoy, J.L., Machin, P.J. (1980) Genetic variation in the rock lobsters Jasus edwardsii and Jasus novaehollandiae. New Zealand Journal of Marine and Freshwater Research, 14, 55-63. 
Van Oosterhout, C., Hutchinson, W.F., Wills, D.P.M., Shipley, P. (2004) Micro-Checker: Software for Identifying and Correcting Genotyping Errors in Microsatellite Data. Molecular Ecology Notes 4, 535-538. 


\section{Chapter III: Microsatellite analysis reveals isolation of Stewart Island and strong source-sink relationship between Australia and New Zealand}

\subsection{Abstract}

Understanding patterns of larval dispersal and gene flow across a species' range is an important component of an effective fishery management strategy. This study investigated the genetic connectivity of the red rock lobster Jasus edwardsii in New Zealand at large spatial scales (hundreds to thousands of kilometres) using highly polymorphic microsatellite markers (developed in Chapter 2). Jasus edwardsii is thought to have the longest pelagic larval duration of any marine species, which provides the potential for large scale dispersal and consequently high levels of gene flow. Despite this expectation, the analysis revealed significant population structure using both the Infinite Allele Model (IAM; $\left.F_{S T}=0.011 P<0.05\right)$ and the Stepwise Mutation Model (SMM; $\left.R_{S T}=0.028 \quad P<0.05\right)$ within New Zealand and across the Tasman Sea, and rejected the null-hypothesis of panmixia based on earlier mDNA analysis. Stewart Island was determined to be the most different from all other populations sampled, suggesting high levels of self-recruitment and restricted gene flow with populations north of the Foveaux Straight. The analysis also identified strong asymmetrical gene flow across the Tasman Sea from Australia to New Zealand and significantly larger effective population sizes in Australia. This suggests a sourcesink relationship between the two countries meaning the New Zealand fishery may be reliant on Australian stocks for recruitment. The results from this study identified patterns of significant spatial structure at a wide range of scales for a species thought to have the longest larval duration in the marine environment. These results highlight the need to re-evaluate the population structure of a number of commercially targeted species that presumably form panmictic populations based on mDNA analysis. I suggest that the results of this study be incorporated into the future management strategies of Jasus edwardsii in New Zealand. 


\subsection{Introduction}

The traditional view for most of the $20^{\text {th }}$ century was that, given the wide range of marine organisms that exhibit a pelagic larval stage, the abundance of larvae in offshore oceanic waters, and the spatial and temporal scale of ocean currents, marine populations are open systems characterised by high levels of demographic connectivity and gene flow (see Levin 2006 for a review). However, the application of recent advances in genetics (Hedgecock et al. 2007), otolith microchemistry (Thorrold et al. 2007) and oceanographic modelling (Cowen 2006) have countered this argument, identifying a wide spectrum of connectivity across a range of scales, from significant genetic differentiation at several kilometres (Mokhtar-Jamai et al. 2011) to panmixia across hundreds of kilometres (Herwerden et al. 2003).

Although the marine environment appears to have fewer obvious barriers to dispersal than terrestrial or freshwater systems (Palumbi 1994), physical oceanographic processes (Largier 2003) and larval behaviour (Krug and Zimmer 2004; Fisher 2005; Gerlach et al 2007) can work to limit dispersal potential by increasing larval retention to natal habitats. This can eventually develop into strong genetic clines at small spatial scales if sustained over long periods of time. However, because the spatial scale of these patterns varies widely depending on location and species, there appears to be no general rule-of-thumb applicable to connectivity in the marine environment (Toonen et al. 2009).

Most marine species, particularly invertebrates, have a bi-partite life cycle that consists of a sessile adult stage and a dispersing larval stage. The dispersing larval stage poses many challenges to measuring connectivity between populations due to the logistics behind physically tagging and monitoring hundreds of thousands of microscopic larvae as they disperse over large oceanographic distances. Because larvae carry with them heritable genes, genetic markers can act as a sort of natural 'tag' that can be used to infer population connectivity over evolutionary time scales (Palumbi and Warner 2003) and also over much shorter scales through the use of assignment testing (Manel et al. 2005). 
Understanding connectivity and patterns of gene flow between populations is of particular importance when dealing with highly-targeted commercial fish species. The spatial scale of a single managed fishery may in fact include a number of genetically distinct populations, and a disregard for this biological structure could lead to an erosion of genetic diversity (Ruzzante et al. 2006). A reduction in genetic diversity would not only have immediate effects on the yield of the fishery but also on the long-term stability of the ecosystem and the potential recovery of the fishery in a stochastic environment (Worm et al. 2006). Identifying heterogeneous genetic populations and managing them independently so as to maintain the highest possible levels of diversity, should be a top priority for management (Hutchings and Baum 2005). Beyond just identifying discrete populations, genetic analysis can also provide valuable information on stock recruitment and source-sink relationships within a fishery. In a fishery where multiple stocks are exploited at different levels (Ricker 1981) particular protection needs to be provided to areas that act as sources of recruitment to ensure that they continue to maintain high levels of larval emigration (Crowder et al. 2000).

Pelagic larval duration is often used as an indicator for dispersal potential and to infer the degree of connectivity between populations (Shanks et al. 2009). When considering the PLD of J. edwardsii (see Chapter 1), it is perhaps not surprising that previous genetic studies applying allozyme (Smith et al. 1980; Booth et al. 1990) and mDNA (Ovenden et al. 1992) analysis have failed to detect any population structure around New Zealand. It is likely that if any genetic differentiation does occur, it will be at relatively low levels, even at large spatial scales, and below the resolving power of previously applied techniques. Trans-Tasman gene flow is also of particular interest to the New Zealand Rock Lobster Industry as previous genetic analysis (Ovenden et al. 1992) and passive drift oceanographic models (Chiswell et al. 2003) suggests a historical source-sink relationship between Australia and New Zealand. It is evident that gene flow is occurring between the two populations, however, at what levels remains unknown. Furthermore, it has been proposed that New Zealand rock lobster stock is reliant on recruitment from Australian populations (Chiswell et 
al. 2003); if true, this would have important implications for the management and sustainability of New Zealand rock lobster fishery.

The objectives of this chapter were to apply the highly polymorphic microsatellite markers from Chapter 2 to: (1) test the null hypothesis of panmixia and identify genetic differentiation between J. edwardsii populations throughout New Zealand; (2) to provide genetic evidence of directional gene flow across the Tasman Sea; and (3) to quantify the relative contribution of Australian stock to the New Zealand fishery using assignment testing. The highly polymorphic nature of microsatellites provides for more discriminatory power than traditional molecular techniques and can often detect differentiation that has been overlooked by previous studies (Crivello et al. 2005). It is hypothesized that microsatellites will reveal significant population structure given the scale of our study and identify asymmetric gene flow across Tasman Sea from Australia.

\subsection{Materials and Methods}

\subsubsection{Study Species}

The red rock lobster Jasus edwardsii supports valuable commercial fisheries in both New Zealand and Australia. It is a keystone predator of sub-tidal rocky reef systems (Shears and Babcock 2003) with a range that encompasses ten degrees of latitude and stretches over 5,500 km from the Chatham Island in New Zealand to Western Australia. Jasus edwardsii is thought to have the longest PLD of any marine species and can remain in offshore oceanic waters for up to 20 months where it undergoes 11 developmental stages with 17 instars before developing into the nektonic puerulus and recruiting to the coast (Booth and Phillips 1994).

\subsubsection{Sampling}

A total of 336 adult individuals from 7 populations were collected by commercial fishers between January and November 2011 and genotyped across 8 microsatellite loci (see Chapter II). Sample sizes ranged from 45-48 individuals per population. Samples were collected from five CRA zones in New Zealand (CRA 2, 4, 5, 6, and 8; 
see Chapter I) and from the Southern Zone (SZRLF) of the South Australia Rock Lobster Fishery. Geographical coordinates and the corresponding management zone from where samples were collected are given in Table 1. Samples covered roughly 10 degrees of latitude and over 3,500 km across the Tasman Sea to South Australia.

Table 1 Sampling locations for J. edwardsii collection.

\begin{tabular}{lllll}
\hline Sample Sites & Abbreviation & N & $\begin{array}{l}\text { Corresponding } \\
\text { Management Zone }\end{array}$ & Coordinates $^{\text {a }}$ \\
\hline Hauraki Gulf & HG & 48 & CRA 2 & $36^{\circ} 34^{\prime} \mathrm{S} 174^{\circ} 46^{\prime} \mathrm{E}$ \\
Wellington & WEL & 48 & CRA 4 & $41^{\circ} 20^{\prime} \mathrm{S} 174^{\circ} 48^{\prime} \mathrm{E}$ \\
Chatham Islands & CHI & 45 & CRA 6 & $43^{\circ} 55^{\prime} \mathrm{S} 176^{\circ} 43^{\prime} \mathrm{W}$ \\
Kaikoura & KAI & 48 & CRA 5 & $42^{\circ} 24^{\prime} \mathrm{S} 173^{\circ} 40^{\prime} \mathrm{E}$ \\
South West Coast & SWC & 44 & CRA 8 & $43^{\circ} 53^{\prime} \mathrm{S} 166^{\circ} 09^{\prime} \mathrm{E}$ \\
Stewart Island & SI & 47 & CRA 8 & $46^{\circ} 38^{\prime} \mathrm{S} 167^{\circ} 37^{\prime} \mathrm{E}$ \\
South Australia & SA & 48 & SZRLF & $36^{\circ} 49^{\prime} \mathrm{S} 139^{\circ} 49^{\prime} \mathrm{E}$ \\
\hline
\end{tabular}

$\mathrm{N}$; number of individuals genotyped

${ }^{a}$ Coordinates are rounded to the minute

\subsubsection{Laboratory Protocol and PCR Amplification}

Tissue samples for DNA extraction were taken from the pereiopods and antennae preserved in $99 \%$ ethanol and the remains were stored in $50 \mathrm{~mL}$ PP-test tubes at $80^{\circ} \mathrm{C}$. DNA for PCR amplification was extracted using a modified phenol-chloroform protocol (see Chapter II). Samples were screened using a TD-PCR protocol (Chapter 2). TD-PCR eliminates many of the uncertainties when calculating a melting temperature $(\mathrm{Tm})$ and determining an optimal annealing temperature ( $\mathrm{Ta}$ ) of a primer pair (Korbie and Mattick 2008). TD-PCR starts with Ta above the calculated Tm of the primer pair and then decreases with every cycle, resulting in an increased specificity with the higher temperatures and an increased yield with the subsequent lower more permissive temperatures (Hecker and Roux 1996).

PCR conditions were modified from Korbie and Mattick (2008) and were as follows: an initial denaturing step for $3 \mathrm{~min}$ at $95^{\circ} \mathrm{C}$, followed by $10 \mathrm{TD}$ cycles of $30 \mathrm{~s}$ at $95^{\circ} \mathrm{C}$, $45 \mathrm{~s}$ at $\mathrm{T}_{\mathrm{a}}\left(-1.0^{\circ} \mathrm{C} /\right.$ cycle $)$, and $45 \mathrm{~s}$ at $72^{\circ} \mathrm{C}$, followed by 25 standard cycles of $30 \mathrm{~s}$ at $95^{\circ} \mathrm{C}, 45 \mathrm{~s}$ at $\mathrm{T}_{\mathrm{a}}$ (lowest temperature of TD) and $45 \mathrm{~s}$ at $72^{\circ} \mathrm{C}$, with a final extension step of $15 \mathrm{~min}$ at $72^{\circ} \mathrm{C}$. 
Amplifications were performed on a GeneAmp 2700 (Applied Biosystems) thermocycler in a final reaction volume of $12.5 \mu$, containing $6.75 \mu$ l MyTaq Red Mix $2 \mathrm{X}$ Bioline ${ }^{\circledR}, 0.75 \mu \mathrm{l}$ of the forward and reverse primers, $50-100$ ng of DNA template and $\mathrm{ddH} 20$ to volume (Table 3). PCR product was viewed on a $2 \%$ Agorose gel. Genotyping was conducted on an ABI 3730XLs sequencer (Applied Biosystems) and loci were scored by eye using $5^{\prime}$ fluorophore labels with a 500 LIZ size standard in GeneMarker V1.97 (www.softgenetics.com).

\subsection{Analysis}

\subsubsection{Genetic Diversity}

Microchecker 2.2.3 (Van Oosterhout et al. 2004) was used to identify deviations from HWE resulting from large allele drop-out, scoring errors due to stuttering or the presence of null alleles. FSTAT 2.9.3 (Goudet 1995) was used to calculate the number of alleles per locus $\left(N_{A}\right)$, private alleles, and inbreeding coefficients $\left(F_{I S}\right)$. Exact tests for deviations from Hardy-Weinberg Equilibrium were performed by GENEPOP 4.1 (Raymond and Rouset 1993) (http://genepop.curtin.edu.au/) and linkage equilibrium by Arlequin 3.5.1.2 (Excoffier et al. 2005). P-values were adjusted for multiple comparisons using sequential Bonferroni corrections (Rice 1989). Markov-chain parameters were 10,000 dememorization steps, 1,000 batches and 10,000 iterations per batch. Allele discovery curves were generated using PopGenKit (Rioux Paquette 2011) in R to determine if sample size was sufficient based on loci polymorphism. 


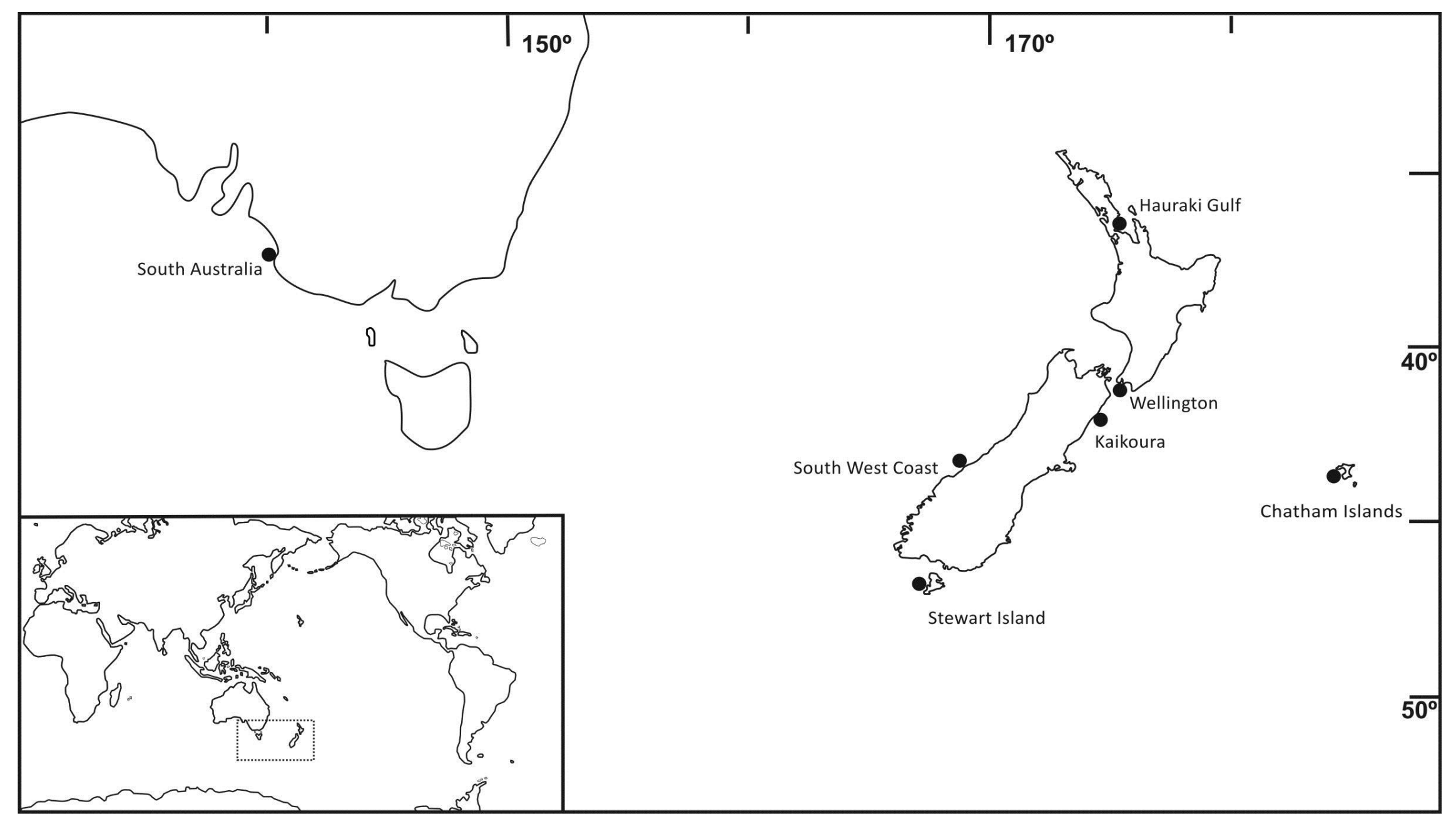

Figure 1 Sampling locations for J. edwardsii throughout New Zealand and on the Australian coast: HG, Hauraki Gulf; WEL, Wellington; KAI, Kaikoura; CHI, Chatham Islands; SWC, South West Coast; SI, Stewart Island; SA, South Australia. 


\subsubsection{Population Structure}

Population differentiation was measured using $F_{S T}$ (Weir and Cockerham 1984), which measures the variation in allele frequencies across populations assuming the Infinite Allele Model (IAM); Arlequin 3.5.1.2 (Excoffier et al. 2005) was used with 10,000 steps in the Markov Chain. $R_{S T}$ values, which incorporate the Stepwise Mutation Model (SMM) of microsatellites, were also estimated. There is much debate over whether the IAM or the SMM is more appropriate when using microsatellite loci that have imperfect repeats (Estoup and Cornuet 1999). As mentioned in Chapter 1, the SMM is thought to more accurately reflect the mutation pattern of microsatellite loci, however, is often considered inappropriate in its application when the repeating region is either compound or interrupted (Van Herwerden et al. 2003). Although some of the loci in this study showed signs of imperfections (Chapter 2; Table 5), both models were incorporated into the analyses.

Isolation by distance plots were produced of Slatkin's linear $F_{S T}\left(F_{S T} /\left(1-F_{S T}\right)\right)$ and $R_{S T}$ $\left(R_{S T} / 1-R_{S T}\right)$ ) values as a function of oceanographic distance in IBDWS 3.21 (Jensen et al. 2005) with 10,000 randomizations to determine if genetic differentiation was a product of distance between sample sites. To visualize the genetic relationships between populations, a dendrogram was constructed with the unweighted pair group method and arithmetic mean (UPGMA; Swofford and Olsen 1990) based on Nei's (1972) minimum distance by TFPGA (Miller 1997); bootstrap analysis was based on 10,000 psuedoreplicates.

Arlequin v.3.5.1.2 was also used to perform a hierarchal analysis of molecular variance (AMOVA) based on 10,000 permutations. Populations were grouped into a number of clusters to determine the maximum proportion of the total genetic variation that could be attributed to differences between groups. Clusters were based on pairwise comparisons of variation in allele frequencies as well as geographic regions of sample sites. 


\subsubsection{Bayesian Analysis}

Assignment tests were carried out using a Bayesian approach (Rannala and Mountain 1997) as implemented in GENECLASS 2 (Piry et al 2004). This program develops a reference genotype for each population and then, based on the "leave one-out" methodology by Paetkau et al. (2004), assigns each individual to a population based on the highest probability of a genotypic match to one of the reference populations. This method has shown to outperform STRUCTURE in situations when gene flow between populations is high (Waples and Gaggiotti 2006). Probability computations were based on 10,000 simulated individuals with an exclusion threshold of $P<0.05$. Populations were also grouped into clusters based on results from the dendrogram by TFPGA for assignment tests. STRUCTURE 2.3.2 (Pritchard et al. 2000) was used to infer population structure without prior sampling information. The admixture model with correlated allele frequencies among clusters and uninformed priors was launched using a burn-in period of 50,000 and 500,000 MCMC iterations with $\mathrm{K}$ ranging from 1-7 (5 replicates/K). The appropriate $\mathrm{K}$ value for the data set was selected based an estimate of the posterior probability of the data for a given $\mathrm{K}, \operatorname{Pr}(\mathrm{X} \mid \mathrm{K})$ (Pritchard et al. 2000).

\subsubsection{Trans-Tasman Gene Flow}

It has been suggested that J. edwardsii populations in Australia act as a source of larval recruits for New Zealand populations, particularly on the southwest coast of the South Island (Chiswell et al. 2003), and therefore, portions of the New Zealand fishery may be dependent on Australian populations for recruitment. To help better understand this relationship MIGRATE 3.2.1.6 (Beerli and Felsenstein 1999) was used to determine rates of gene flow between the two countries. The program uses a Markov chain Monte Carlo approach and sample genealogies that are then used to find the maximum likelihood estimate of a full migration matrix with population sizes. Dispersal rates $\left(\mathrm{N}_{\mathrm{e}} \mathrm{m}\right)$ and effective population sizes $\left(\mathrm{N}_{\mathrm{e}}\right)$ of New Zealand and Australian populations were determined using a stepwise mutation model (Brownian motion) and default settings for the remaining parameters. Results are expressed as $M$ (migration parameter: mutation scaled immigration rate that represents the 
importance of variability brought into the population by immigration compared to the variability by mutation) and $\Theta$ (mutation scaled effective population size). Based on the one migrant per generation (OMPG) rule, populations can be considered isolated when $M<1$ as gene flow is not at levels sufficient to prevent loss of alleles and minimize loss of heterozygosity within sub-populations (Mills and Allendorf 1996). If $\Theta$ and $M$ are multiplied together the number of immigrants per generation can be determined. MIGRATE was also used to determine rates of gene flow between Stewart Island and the other New Zealand populations.

\subsection{Results}

\subsubsection{Hardy-Weinberg and Linkage Equilibrium}

Microchecker found no evidence of large allele drop out and detected evidence of scoring error due to stutter at only one locus (je_01). Deviations from HWE varied widely across each loci and each population and were almost always (81 \%) a result of heterozygote deficiency. No locus deviated significantly from HWE across all samples following standard Bonferroni corrections (Table 2). Locus je_01 deviated significantly at 6 out of the 7 populations and was excluded from any further analysis. Expected $\left(\mathrm{H}_{\mathrm{E}}\right)$ and observed $\left(\mathrm{H}_{\mathrm{O}}\right)$ heterozygosity at each locus ranged from 0.476 (je_107) to 0.975 (je_NS) and from 0.417 (je_107) to 0.958 (je_NS). All populations showed evidence of heterozygote deficiency (Table 3). Global expected $\left(H_{E}\right)$ and observed $\left(\mathrm{H}_{\mathrm{O}}\right)$ heterozygosity ranged from $0.829(\mathrm{SI})$ to $0.877(\mathrm{SA})$ and from 0.773 (SWC) to 0.823 (WEL) across all loci, respectively. Inbreeding coefficients ranged from $0.048(\mathrm{CHI})$ to $0.103(\mathrm{SA})$ and were significant at all populations. Linkage disequilibrium was not observed for any loci pairs that consistently appeared across all populations.

\subsubsection{Genetic Diversity}

The 8 microsatellite loci showed a wide range of polymorphism (Table 4); the total number of alleles per locus ranged from 10 (je_107) to 74 (je_NS). The number of alleles per locus per population ranged from 5 (je_107: HG, SI) to 42 (je_NS: SA). Private alleles were present in all populations (55 in total). SI had the lowest number 
of private alleles ( 3 private alleles) and WEL the highest (15 private alleles). The total number of alleles per population was lowest at SI (109) and highest at SA (157). The mean number of alleles per locus was also lowest at SI (13.63) and highest at SA (19.63). Allele discovery curves showed the number of alleles for each microsatellite locus begin to plateau around 50 individuals implying that the sample size used in the study was sufficient to capture the majority of alleles in each population.

Table 2 Ho, observed heterozygosity; He, expected heterozygosity; Fis, Inbreeding coefficient; at nine microsatellite loci across 7 populations (bold values: significant deviation from HWE).

\begin{tabular}{llll} 
& \multicolumn{3}{l}{ JE_01 } \\
\cline { 2 - 4 } Population & $\mathrm{H}_{\mathrm{O}}$ & $\mathrm{H}_{\mathrm{E}}$ & $\mathrm{F}_{\mathrm{IS}}$ \\
\hline HG & $\mathbf{0 . 7 9 2}$ & 0.922 & 0.143 \\
WEL & 0.813 & 0.939 & 0.137 \\
CHI & $\mathbf{0 . 7 7 8}$ & 0.940 & 0.174 \\
KAI & $\mathbf{0 . 7 7 1}$ & 0.943 & 0.184 \\
SI & $\mathbf{0 . 6 3 8}$ & 0.934 & 0.319 \\
SWC & $\mathbf{0 . 7 5 0}$ & 0.927 & 0.193 \\
SA & $\mathbf{0 . 6 4 6}$ & 0.965 & 0.333
\end{tabular}

\begin{tabular}{lll} 
JE_17 & & \\
\hline$H_{O}$ & $H_{E}$ & $F_{I S}$ \\
\hline $\mathbf{0 . 6 6 7}$ & 0.848 & 0.215 \\
0.688 & 0.886 & 0.226 \\
0.756 & 0.869 & 0.132 \\
0.750 & 0.850 & 0.118 \\
$\mathbf{0 . 9 3 6}$ & 0.864 & -0.085 \\
$\mathbf{0 . 6 5 9}$ & 0.862 & 0.237 \\
0.625 & 0.866 & 0.281
\end{tabular}

\begin{tabular}{lll} 
JE_40 & & \\
\hline$H_{O}$ & $H_{E}$ & $F_{I S}$ \\
\hline $\mathbf{0 . 7 0 8}$ & 0.916 & 0.288 \\
0.917 & 0.894 & -0.026 \\
0.867 & 0.883 & 0.018 \\
0.875 & 0.888 & 0.014 \\
$\mathbf{0 . 9 3 6}$ & 0.830 & -0.129 \\
0.864 & 0.893 & 0.033 \\
$\mathbf{0 . 6 8 7}$ & 0.893 & 0.231
\end{tabular}

\begin{tabular}{llll} 
& \multicolumn{2}{l}{ JE_107 } & \\
\cline { 2 - 4 } & $\mathrm{H}_{\mathrm{O}}$ & $\mathrm{H}_{\mathrm{E}}$ & $\mathrm{F}_{\mathrm{IS}}$ \\
\hline HG & 0.583 & 0.549 & -0.063 \\
WEL & 0.563 & 0.583 & 0.036 \\
CHI & 0.533 & 0.496 & -0.076 \\
KAI & 0.417 & 0.489 & 0.150 \\
SI & 0.468 & 0.476 & 0.017 \\
SWC & 0.455 & 0.504 & 0.099 \\
SA & 0.583 & 0.640 & 0.090
\end{tabular}

\begin{tabular}{lll} 
JE_NS & & \\
\hline$H_{O}$ & $H_{E}$ & $F_{I S}$ \\
\hline $\mathbf{0 . 7 9 2}$ & 0.944 & 0.162 \\
0.938 & 0.960 & 0.023 \\
0.956 & 0.966 & 0.011 \\
0.958 & 0.964 & 0.006 \\
$\mathbf{0 . 8 0 9}$ & 0.966 & 0.164 \\
0.910 & 0.967 & 0.061 \\
0.958 & 0.975 & 0.017
\end{tabular}

\begin{tabular}{lll} 
JE_JM & & \\
\hline$H_{O}$ & $H_{E}$ & $F_{I S}$ \\
\hline 0.896 & 0.930 & 0.037 \\
0.875 & 0.917 & 0.046 \\
0.911 & 0.922 & 0.012 \\
0.854 & 0.892 & 0.043 \\
$\mathbf{0 . 7 8 7}$ & 0.923 & 0.148 \\
0.841 & 0.902 & 0.069 \\
0.854 & 0.920 & 0.073
\end{tabular}

\begin{tabular}{|c|c|c|c|c|c|c|c|c|c|}
\hline & \multicolumn{3}{|l|}{ JE_O5 } & \multicolumn{3}{|l|}{ JE_LZ } & \multicolumn{3}{|l|}{ JE_9M } \\
\hline & $\mathrm{H}_{\mathrm{O}}$ & $\mathrm{H}_{\mathrm{E}}$ & $F_{1 S}$ & $\mathrm{H}_{\mathrm{O}}$ & $\mathrm{H}_{\mathrm{E}}$ & $F_{1 S}$ & $\mathrm{H}_{\mathrm{O}}$ & $\mathrm{H}_{\mathrm{E}}$ & $F_{1 S}$ \\
\hline HG & 0.896 & 0.930 & 0.037 & 0.833 & 0.892 & 0.066 & 0.875 & 0.869 & -0.007 \\
\hline WEL & 0.875 & 0.937 & 0.067 & 0.896 & 0.890 & -0.010 & 0.833 & 0.866 & 0.038 \\
\hline $\mathrm{CHI}$ & 0.644 & 0.926 & 0.307 & 0.844 & 0.878 & 0.039 & 0.911 & 0.860 & -0.061 \\
\hline KAI & 0.750 & 0.922 & 0.188 & 0.938 & 0.839 & -0.119 & 0.833 & 0.844 & 0.013 \\
\hline SI & 0.745 & 0.902 & 0.176 & 0.830 & 0.886 & 0.064 & 0.766 & 0.787 & 0.027 \\
\hline SWC & 0.705 & 0.938 & 0.251 & 0.818 & 0.887 & 0.079 & 0.932 & 0.872 & -0.069 \\
\hline SA & 0.833 & 0.932 & 0.107 & 0.938 & 0.923 & -0.015 & 0.833 & 0.866 & 0.039 \\
\hline
\end{tabular}


Table 3 Ho, observed heterozygosity; He, expected heterozygosity; Na, number of alleles; Fis, inbreeding coefficient averaged across 8 microsatellite loci.

\begin{tabular}{lllll}
\hline Population & $\mathrm{H}_{\mathrm{O}}$ & $\mathrm{H}_{\mathrm{E}}$ & $\mathrm{Na}$ & $\mathrm{F}_{\mathrm{IS}}$ \\
\hline $\mathrm{HG}$ & & & & \\
$\mathrm{WEL}$ & 0.781 & 0.860 & 17 & 0.092 \\
$\mathrm{CHI}$ & 0.823 & 0.867 & 20 & 0.050 \\
KAI & 0.803 & 0.850 & 19 & 0.048 \\
SI & 0.797 & 0.836 & 18 & 0.052 \\
SWC & 0.785 & 0.829 & 19 & 0.048 \\
SA & 0.773 & 0.853 & 15 & 0.095 \\
\hline
\end{tabular}

Table 4 Allele size variations at 8 microsatellite loci, mean number of alleles, number of private alleles and total number of alleles at 7 populations across 8 microsatellite loci.

\begin{tabular}{lllllllll}
\hline Locus & HG & WEL & CHI & KAI & SI & SWC & SA & Total \\
\hline JE_17 & 11 & 11 & 11 & 11 & 9 & 10 & 10 & 14 \\
JE_40 & 19 & 17 & 17 & 20 & 10 & 17 & 22 & 28 \\
JE_107 & 5 & 6 & 6 & 6 & 5 & 8 & 7 & 10 \\
JE_NS & 28 & 39 & 34 & 37 & 35 & 33 & 42 & 74 \\
JE_JM & 15 & 16 & 22 & 14 & 17 & 20 & 20 & 28 \\
JE_O5 & 18 & 25 & 18 & 20 & 13 & 20 & 22 & 29 \\
JE_LZ & 26 & 27 & 23 & 20 & 12 & 26 & 22 & 46 \\
JE_9M & 12 & 14 & 10 & 12 & 8 & 13 & 12 & 16 \\
\hline Mean & 16.75 & 19.38 & 17.63 & 17.50 & 13.63 & 18.38 & 19.63 & 30.63 \\
Private Alleles & 6 & 15 & 7 & 6 & 3 & 9 & 9 & 55 \\
Total Alleles & 134 & 155 & 141 & 140 & 109 & 147 & 157 & 245 \\
\hline
\end{tabular}



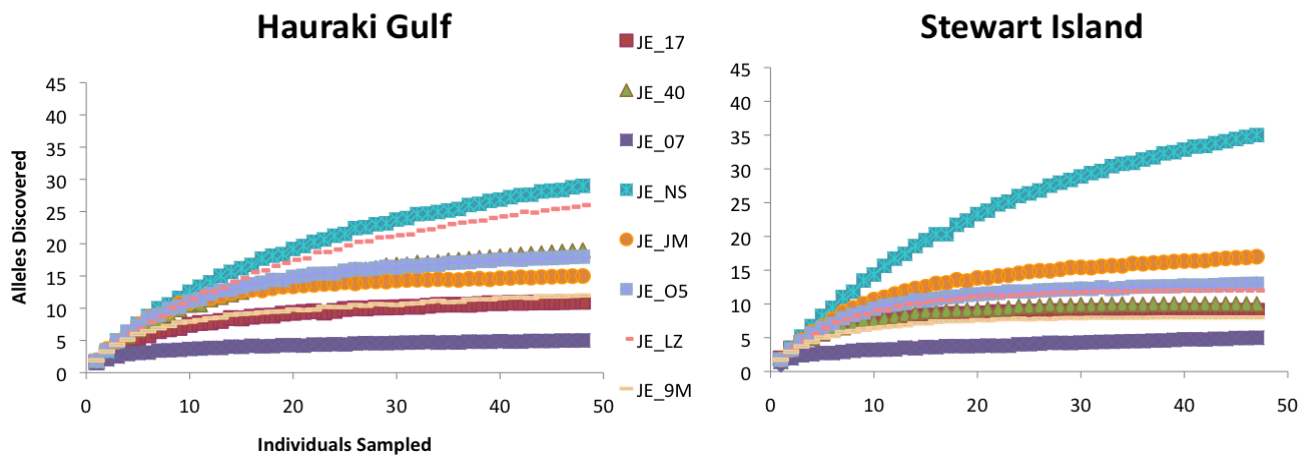

Chatham Islands

Wellington
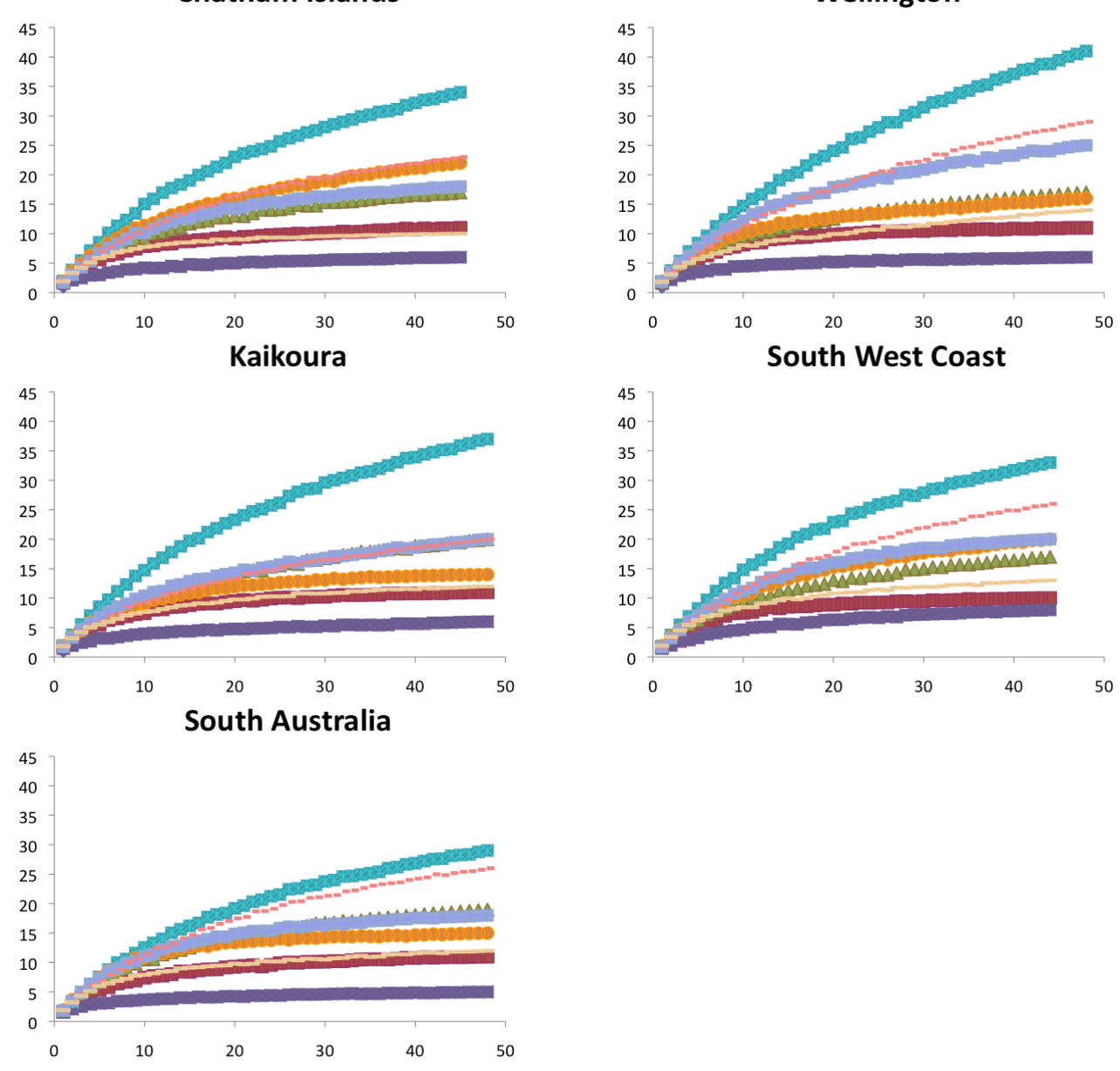

Figure 2 Allele discovery curves at 7 populations across 8 microsatellite loci.

\subsubsection{Population Structure}

Significant global $F_{S T}(0.011)$ and $R_{S T}(0.029)$ values support the rejection of the nullhypothesis that J. edwardsii forms a single panmictic population throughout its range. Pairwise $F_{S T}$ values (Table 5) showed significant values at 19 out of 21 pairwise comparisons. SI had the highest mean pairwise $F_{S T}$ value of all population comparisons $(0.016 \pm 0.002 \mathrm{SD})$, which ranged from 0.014 with $\mathrm{CHI}$ to 0.018 with 
SWC. SWC had the lowest mean pairwise value of $0.008( \pm 0.005)$. Despite SA being the most geographically isolated population, SA had a mean pairwise $F_{S T}$ value with other populations below SI $(0.015 \pm 0.001)$. The two non-significant comparisons were between SWC and CHI and between SWC and KAI.

Pairwise $R_{S T}$ values (Table 5) detected significant differentiation at 12 out of 22 population comparisons. Significant values were detected in all of the SI and SA pairwise comparisons and between HG and SWC. $R_{S T}$ values were generally higher than their $F_{S T}$ equivalent. SI had the highest mean value of 0.058 ( $\pm 0.03 \mathrm{SD}$ ). A maximum pairwise comparison of 0.113 occurred between SI with SA. All pairwise comparisons that did not include SI or SA, except between HG and SWC, were nonsignificant.

The dendrogram of genetic relatedness based on Nei's (1972) minimum distance showed SI to be the most genetically distinct population of all populations sampled (Figure 3). KAI and SWC formed a node as the most closely related populations at the other end of the dendrogram. KAI, SWC, WEL and $\mathrm{CHI}$ all formed a tightly clustered grouping at one end of the dendrogram, which is supported by $R_{S T}$ values that showed none of the pairwise comparisons to be significant and $F_{S T}$ values that reported very low levels of significant differentiation $(<0.008)$. A Mantel test found no significant correlation between the logarithmic relationship of oceanic distance and genetic distance $\left(F_{S T} /\left(1-F_{S T}\right) P=0.147\right.$ and $\left.R_{S T} /\left(1-R_{S T}\right) P=0.203\right)$. Although not significant, a positive correlation was detected which may suggest a weak pattern of isolation by distance across the range of J. edwardsii (Figure 4).

Table 5 Matrix of pairwise comparisons of population differentiation using $F_{S T}$ (below diagonal) and $R_{S T}$ (above diagonal) values at 7 populations using 8 microsatellite loci (bold values: sig. $p<0.05$ ).

\begin{tabular}{llllllll}
\hline Population & HG & SI & CHI & WEL & KAI & SWC & SA \\
\hline HG & & $\mathbf{0 . 0 2 0}$ & 0.003 & 0.009 & 0.004 & $\mathbf{0 . 0 1 7}$ & $\mathbf{0 . 0 7 3}$ \\
SI & $\mathbf{0 . 0 1 7}$ & & $\mathbf{0 . 0 5 1}$ & $\mathbf{0 . 0 4 3}$ & $\mathbf{0 . 0 5 2}$ & $\mathbf{0 . 0 6 7}$ & $\mathbf{0 . 1 1 3}$ \\
CHI & $\mathbf{0 . 0 0 7}$ & $\mathbf{0 . 0 1 4}$ & & 0.002 & -0.005 & -0.004 & $\mathbf{0 . 0 3 3}$ \\
WEL & $\mathbf{0 . 0 0 7}$ & $\mathbf{0 . 0 1 8}$ & $\mathbf{0 . 0 0 7}$ & & -0.007 & 0.001 & $\mathbf{0 . 0 5 6}$ \\
KAI & $\mathbf{0 . 0 1 0}$ & $\mathbf{0 . 0 1 5}$ & $\mathbf{0 . 0 0 8}$ & $\mathbf{0 . 0 0 7}$ & & -0.002 & $\mathbf{0 . 0 5 3}$ \\
SWC & $\mathbf{0 . 0 0 8}$ & $\mathbf{0 . 0 1 7}$ & 0.004 & $\mathbf{0 . 0 0 4}$ & 0.004 & & $\mathbf{0 . 0 1 9}$ \\
SA & $\mathbf{0 . 0 1 5}$ & $\mathbf{0 . 0 1 7}$ & $\mathbf{0 . 0 1 6}$ & $\mathbf{0 . 0 1 5}$ & $\mathbf{0 . 0 1 7}$ & $\mathbf{0 . 0 1 3}$ &
\end{tabular}



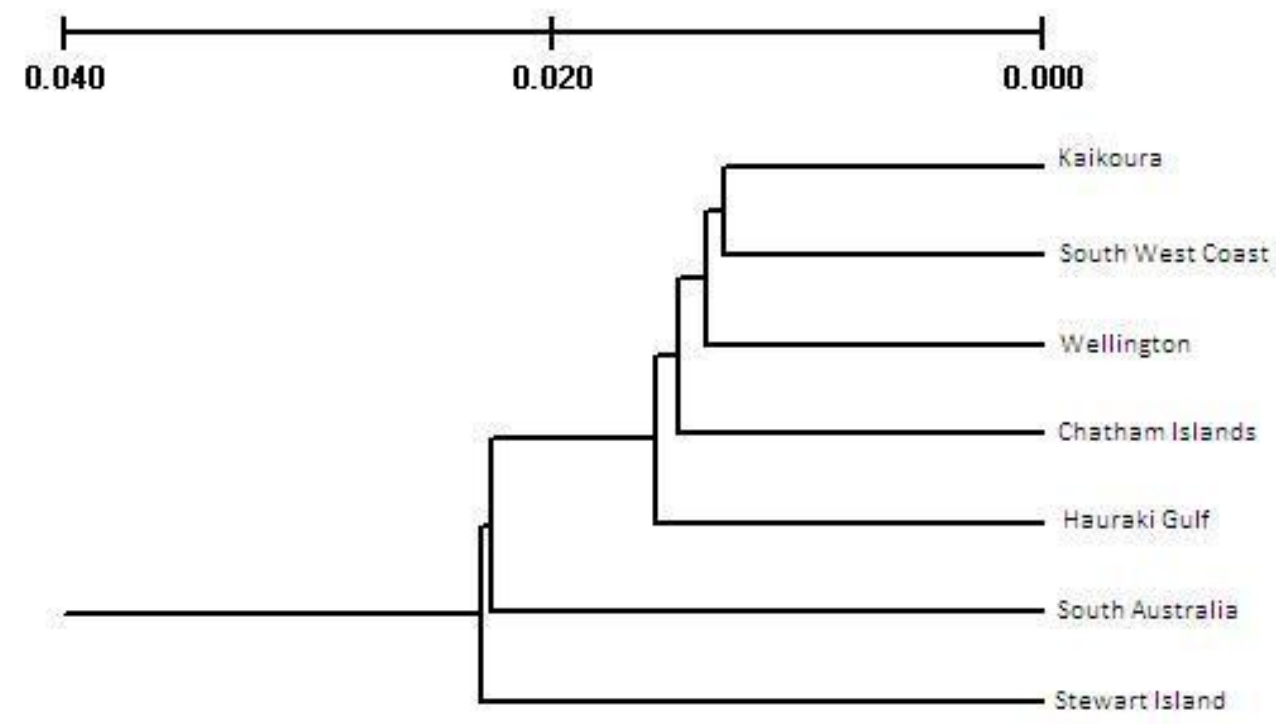

Figure 3 UPGMA Cluster using Nei's (1972) minimum distance as implemented in TFPGA by bootstrap analysis with 10,000 pseudoreplicates.

Based on Bayesian assignment tests (Rannala \& Mountain 1997) by GENECLASS 2, $153(47 \%)$ individuals were correctly assigned to corresponding sampled populations with a mean value of $46 \%$ ( $\pm 9.5 \mathrm{SD}$ ) per population (Table $6 \mathrm{~A})$. SI had the highest number of individuals correctly assigned (30; $64 \%)$ and SWC the lowest (16; $36 \%)$. The probability simulation algorithm by Paetkau et al. (2004) determined that $82 \%$ $( \pm 1.6 \mathrm{SD})$ of individuals had probability values above the exclusion threshold $(P>0.05)$ for their correct populations. However, mean probability values were low $(p=0.38 \pm$ 0.04 SD) across all populations which suggests that many of those individuals were also assigned probability values that were above the exclusion threshold for other populations.

When populations were grouped into 3 clusters based on the dendrogram of Nei's minimum distance (Australia, Stewart Island and New Zealand) the mean value of correctly assigned individuals jumped up to $70 \%$ (Table 6B). The New Zealand group had a successful assignment rate of $81.5 \%$ and assigned $11 \%$ of individuals to Australia. Stewart Island had a successful assignment rate of $76.6 \%$. The South Australian cluster assigned roughly $48 \%$ of individuals to New Zealand and $46 \%$ to South Australia. This suggests that there is a strong SA genetic signature in the New Zealand populations. 

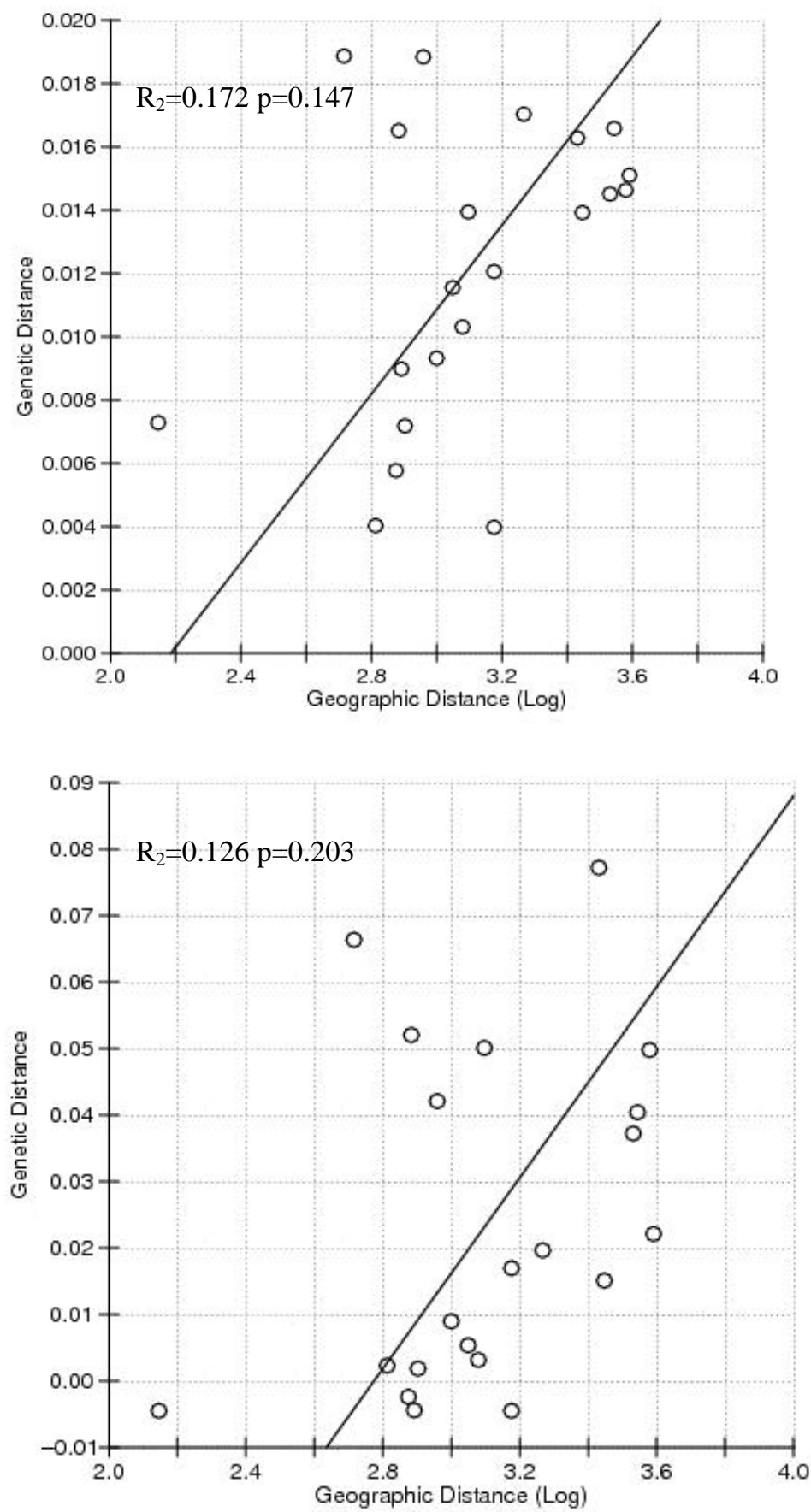

Figure 4 Isolation by distance generated by IBWS 3.2.1. Pairwise genetic distances (Slatkin's linearized $F_{S T}$ (above) and $R_{S T}$ (below)) plotted against the logarithm of minimum oceanographic distance between populations. 
Table 6 Assignment tests (Rannala and Mountain 1997) for (A) individuals from each sampling location (rows) assigned to each population (columns) and (B) clustering of populations based on AMOVA results. Numbers represent percentages of individuals assigned to each population and values in bold are correct assignments.

\begin{tabular}{|c|c|c|c|c|c|c|c|}
\hline A & HG & SI & $\mathrm{CHI}$ & WEL & KAI & SWC & SA \\
\hline HG & 54 & 10 & 10 & 6 & 6 & 6 & 6 \\
\hline SI & 6 & 64 & 11 & 2 & 2 & 9 & 6 \\
\hline $\mathrm{CHI}$ & 7 & 2 & 40 & 18 & 9 & 16 & 9 \\
\hline WEL & 6 & 2 & 17 & 42 & 15 & 19 & 0 \\
\hline KAI & 15 & 0 & 6 & 8 & 44 & 13 & 15 \\
\hline SWC & 0 & 2 & 14 & 18 & 14 & 36 & 16 \\
\hline SA & 6 & 10 & 8 & 13 & 8 & 8 & 46 \\
\hline B & \multicolumn{2}{|c|}{ New Zealand } & \multicolumn{2}{|r|}{ Stewart Island } & \multicolumn{2}{|r|}{ Australia } & \\
\hline New Zealand & \multicolumn{2}{|l|}{82} & \multicolumn{2}{|r|}{8} & \multicolumn{2}{|r|}{11} & \\
\hline Stewart Island & \multicolumn{2}{|l|}{17} & \multicolumn{2}{|r|}{77} & \multicolumn{2}{|r|}{6} & \\
\hline Australia & \multicolumn{2}{|l|}{48} & \multicolumn{2}{|r|}{6} & \multicolumn{2}{|r|}{46} & \\
\hline
\end{tabular}

An analysis of molecular variance (AMOVA) determined the highest proportion of total variance attributed to variation between groups occurred when SI was separated from the other New Zealand populations forming its own clusters (Table 7). This clustering scheme attributed $4.90 \%(P<0.05)$ to variation between groups and $95 \%$ to variation within populations using $R_{S T}$. A slightly lower percentage of total variation $(4.07 \%, P<0.05)$ was attributed to differences between groups when HG was also removed to form its own group. When populations were grouped into regional clusters (New Zealand and Australia) the percentage of total variation attributed to variation between groups was $3.62 \%$ and $0.45 \%$ using $R_{S T}$ and $F_{S T}$, respectively.

Bayesian cluster analysis performed in STRUCTURE 2.3.2 was unable to identify any clear population structure from the data set. No clear trend was seen in $\operatorname{Ln} P(D)$ as a function of $K$ across 5 replicates with $K$ varying from 1-7 (Figure 5). As a result, the appropriate number of clusters formed by the data set could not be determined. However, the most convincing clustering pattern appeared when $\mathrm{K}=2$ in which SI had the highest membership coefficient of 0.753 while the other populations had the majority of individuals assigned to the opposite cluster (Figure 5). 

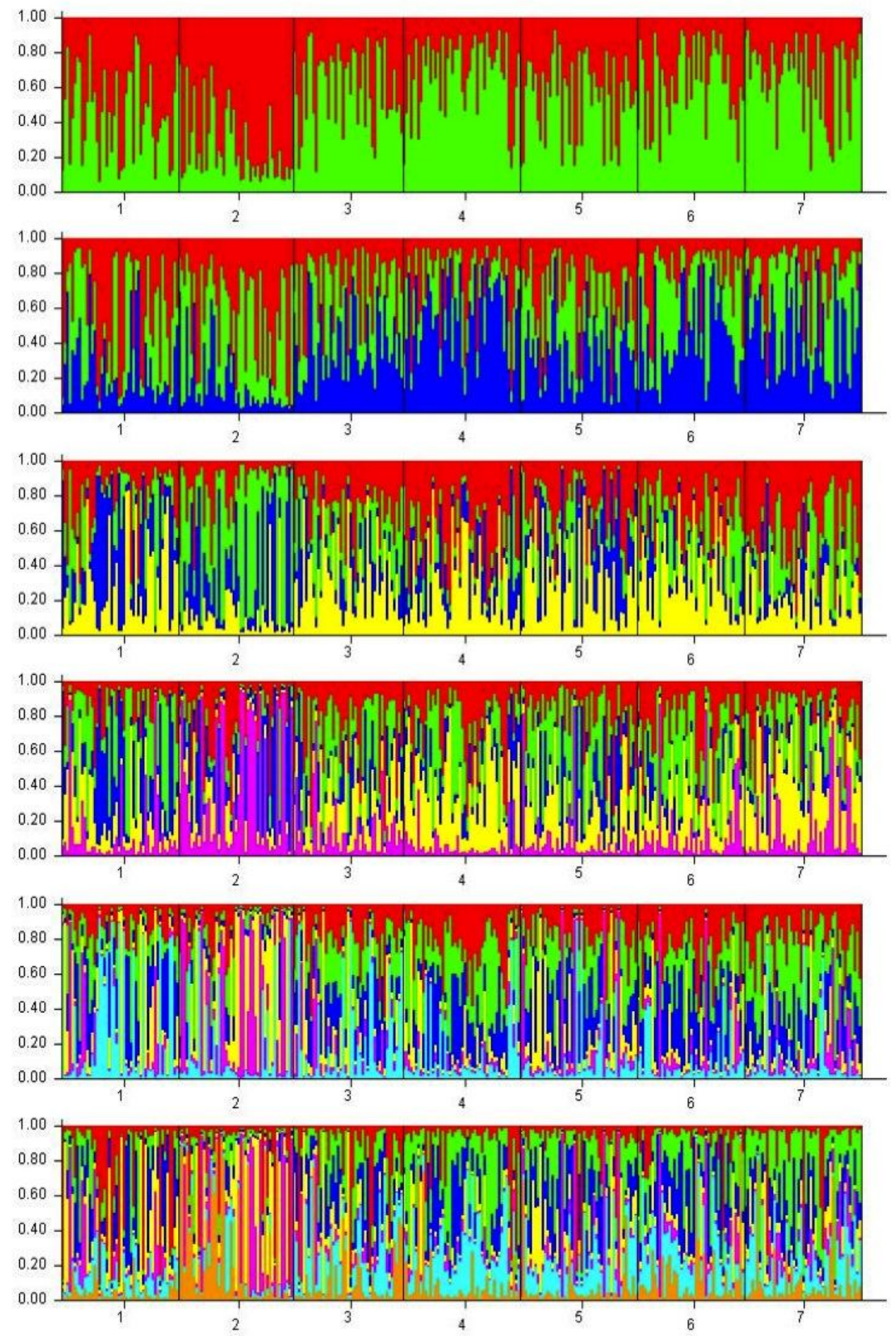

Figure 5 Structure 2.3.2 results with pre-defined clusters $\mathrm{K}$ ranging from 2-7. Each individual in the data set is represented by a single vertical line, which is partitioned into $\mathrm{K}$ segments that represent that individual's estimated membership fraction in each of the $\mathrm{K}$ inferred clusters (Pritchard et al. 2000). 


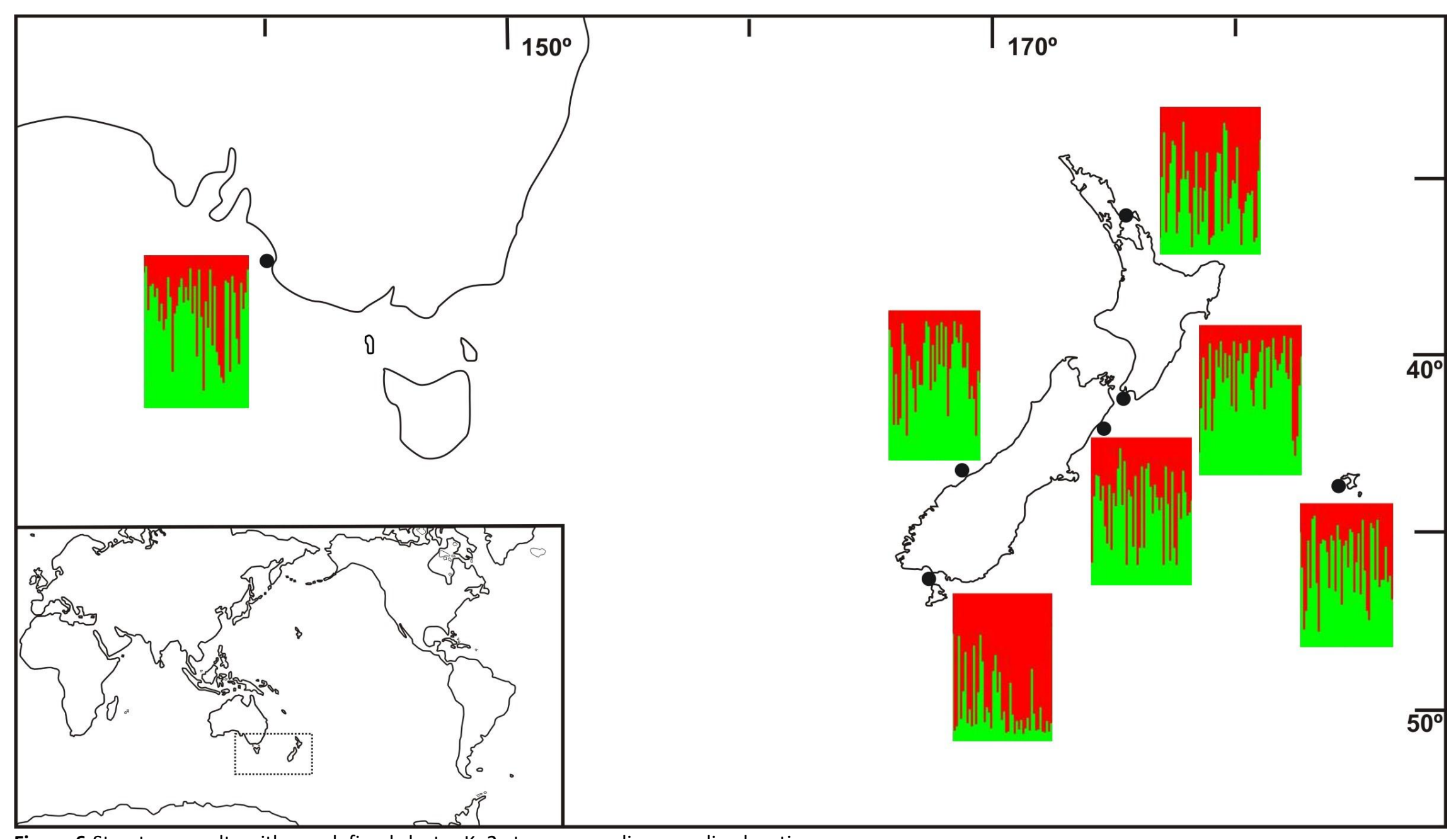

Figure 6 Structure results with pre-defined cluster $\mathrm{K}=2$ at corresponding sampling locations. 
Table 7 Hierarchical analysis of molecular variance (AMOVA) among 3 different clustering situations: (A) 4 groups: $\mathrm{SA}, \mathrm{SI}, \mathrm{HG}$ and WEL/KAI/SWC/CHI, (B) 3 groups: $\mathrm{SA}, \mathrm{SI}$, and $\mathrm{HG} / \mathrm{WEL} / \mathrm{KAI} / \mathrm{SWC} / \mathrm{CHI}$ and (C) 2 groups; SA and New Zealand Populations.

\begin{tabular}{|c|c|c|c|c|c|}
\hline $\begin{array}{l}\text { Source of } \\
\text { Variation }\left(\boldsymbol{R}_{S T}\right)\end{array}$ & Df & $\begin{array}{l}\text { Sum of } \\
\text { Squares }\end{array}$ & $\begin{array}{l}\text { Variance } \\
\text { Components }\end{array}$ & Variation (\%) & $\begin{array}{l}\text { Significance } \\
\text { Tests ( } P \text { value) }\end{array}$ \\
\hline \multicolumn{6}{|l|}{ A } \\
\hline Among Groups & 3 & 156890.51 & 335.65 & 4.07 & 0.027 \\
\hline $\begin{array}{l}\text { Among Populations } \\
\text { Within Groups }\end{array}$ & 3 & 20783.03 & -10.85 & -0.13 & 0.581 \\
\hline Within Populations & 649 & 5146881.44 & 7930.48 & 96.07 & $<0.001$ \\
\hline $\begin{array}{l}\text { Source of } \\
\text { Variation }\left(\boldsymbol{F}_{S T}\right)\end{array}$ & Df & $\begin{array}{l}\text { Sum of } \\
\text { Squares }\end{array}$ & $\begin{array}{l}\text { Variance } \\
\text { Components }\end{array}$ & Variation (\%) & $\begin{array}{l}\text { Significance } \\
\text { Tests ( } P \text { value) }\end{array}$ \\
\hline \multicolumn{6}{|l|}{ A } \\
\hline Among Groups & 3 & 31.80 & 0.03 & 0.83 & 0.031 \\
\hline $\begin{array}{l}\text { Among Populations } \\
\text { Within Groups }\end{array}$ & 3 & 18.34 & 0.02 & 0.61 & $<0.001$ \\
\hline Within Populations & 649 & 2519.63 & 3.88 & 98.56 & $<0.001$ \\
\hline $\begin{array}{l}\text { Source of } \\
\text { Variation }\left(\boldsymbol{R}_{S T}\right)\end{array}$ & Df & $\begin{array}{l}\text { Sum of } \\
\text { Squares }\end{array}$ & $\begin{array}{l}\text { Variance } \\
\text { Components }\end{array}$ & Variation (\%) & $\begin{array}{l}\text { Significance } \\
\text { Tests ( } P \text { value) }\end{array}$ \\
\hline \multicolumn{6}{|l|}{ B } \\
\hline Among Groups & 2 & 137330.99 & 398.51 & 4.90 & 0.049 \\
\hline $\begin{array}{l}\text { Among Populations } \\
\text { Within Groups }\end{array}$ & 4 & 37475.77 & 17.74 & 0.22 & 0.241 \\
\hline Within Populations & 649 & 5007810.62 & 7716.20 & 94.88 & $<0.001$ \\
\hline $\begin{array}{l}\text { Source of } \\
\text { Variation }\left(\boldsymbol{F}_{S T}\right)\end{array}$ & Df & $\begin{array}{l}\text { Sum of } \\
\text { Squares }\end{array}$ & $\begin{array}{l}\text { Variance } \\
\text { Components }\end{array}$ & Variation (\%) & $\begin{array}{l}\text { Significance } \\
\text { Tests ( } P \text { value) }\end{array}$ \\
\hline \multicolumn{6}{|l|}{ B } \\
\hline Among Groups & 2 & 20.69 & 0.03 & 0.93 & 0.005 \\
\hline $\begin{array}{l}\text { Among Populations } \\
\text { Within Groups }\end{array}$ & 4 & 22.16 & 0.02 & 0.66 & $<0.001$ \\
\hline Within Populations & 649 & 2214.63 & 3.41 & 98.42 & $<0.001$ \\
\hline $\begin{array}{l}\text { Source of } \\
\text { Variation }\left(\boldsymbol{R}_{S T}\right)\end{array}$ & Df & $\begin{array}{l}\text { Sum of } \\
\text { Squares }\end{array}$ & $\begin{array}{l}\text { Variance } \\
\text { Components }\end{array}$ & Variation (\%) & $\begin{array}{l}\text { Significance } \\
\text { Tests ( } P \text { value) }\end{array}$ \\
\hline \multicolumn{6}{|l|}{ C } \\
\hline Among Groups & 1 & 71325.37 & 303.38 & 3.62 & 0.060 \\
\hline $\begin{array}{l}\text { Among Populations } \\
\text { Within Groups }\end{array}$ & 5 & 106348.17 & 142.95 & 1.71 & $<0.001$ \\
\hline Within Populations & 649 & 5146881.44 & 7930.48 & 94.67 & $<0.001$ \\
\hline $\begin{array}{l}\text { Source of } \\
\text { Variation }\left(\boldsymbol{F}_{S T}\right)\end{array}$ & Df & $\begin{array}{l}\text { Sum of } \\
\text { Squares }\end{array}$ & $\begin{array}{l}\text { Variance } \\
\text { Components }\end{array}$ & Variation (\%) & $\begin{array}{l}\text { Significance } \\
\text { Tests ( } P \text { value) }\end{array}$ \\
\hline \multicolumn{6}{|l|}{ C } \\
\hline Among Groups & 1 & 10.84 & 0.018 & 0.45 & 0.011 \\
\hline $\begin{array}{l}\text { Among Populations } \\
\text { Within Groups }\end{array}$ & 5 & 39.30 & 0.043 & 1.08 & $<0.001$ \\
\hline Within Populations & 649 & 2519.63 & 3.88 & 98.47 & $<0.001$ \\
\hline
\end{tabular}




\subsubsection{Trans-Tasman Gene Flow}

Maximum likelihood dispersal estimates calculated by MIGRATE 3.2.1.6 identified significant asymmetric gene flow across the Tasman Sea from Australia to New Zealand but not in the opposite direction (Table 8A). Considerably larger immigration rates were detected from Australia to New Zealand (1.812-2.022) than from New Zealand to Australia (0.899-0.965). Migration rates of less than 1 migrant per generation are not at sufficient levels to prevent loss of alleles and can be considered separate from other populations (OMPG rule; see Mills and Allendorf 1996). Furthermore, effective population sizes $(\Theta)$ were determined to be much larger in Australia (more than 5 times) than in New Zealand despite broader sampling throughout New Zealand. MIGRATE also identified asymmetric gene flow between Stewart Island and the other New Zealand populations (Table 8B); significant levels were detected from Stewart Island to the north (1.633-1.764) but not in the opposite direction (0.88-0.954).

Table 8 Maximum likelihood estimates of migration rate (M) between (A) Australia and New Zealand (with effective population sizes $(\Theta)$ ) and $(B)$ Stewart Island and mainland New Zealand. Confidence intervals (90\%) are shown.

\begin{tabular}{lll}
\hline A & & \\
Dispersal direction & $\mathrm{M}$ & $90 \% \mathrm{Cl}$ \\
\hline Australia to New Zealand & 1.953 & $1.812-2.022$ \\
New Zealand to Australia & 0.932 & $0.899-0.965$ \\
\hline Populations & 0 & $90 \% \mathrm{Cl}$ \\
\hline New Zealand & 5.948 & $5.809-6.092$ \\
Australia & 29.911 & $26.536-31.567$ \\
\hline & & \\
\hline B & & $90 \% \mathrm{Cl}$ \\
Dispersal direction & $\mathrm{M}$ & $1.633-1.764$ \\
\hline Stewart Island to New Zealand & 1.703 & $0.888-0.954$ \\
New Zealand to Stewart Island & 0.921 &
\end{tabular}




\subsection{Discussion}

This study has determined that J. edwardsii cannot be considered as a single homogenous population throughout its range and has identified significant genetic structure in populations around New Zealand and across the Tasman Sea. These findings support the rejection of the null hypothesis of panmixia. Although the levels of genetic differentiation were relatively low $\left(F_{S T}=0.011\right.$ and $\left.R_{S T}=0.029\right)$, previous studies have determined weaker levels of differentiation $\left(F_{S T}=0.003\right.$ Knutsen et al. 2011) to be highly biologically significant and likely to represent discrete populations. This study also detected asymmetric gene flow across the Tasman Sea from Australia to New Zealand, which suggests a certain degree of dependence of the New Zealand stock on Australian recruits. The polymorphic microsatellite markers applied in this study offered a higher resolving power than previously applied techniques (allozyme and mDNA analysis) and have identified significant genetic structure in a species with one of the longest PLDs in the marine environment. These findings align with a number of other studies that have shown significant population structure at relatively small spatial scales despite long larval durations (Taylor and Hellberg 2003; Baums et al 2005; Bowen et al 2006) and provides further evidence that connectivity in the marine environment is not always directly correlated to PLD (Toonen et al. 2009).

The analysis did not reveal a significant isolation by distance regression model which suggests that the genetic structure is more likely a product of complex oceanographic features rather than dispersal limitations based solely on distance between populations. Isolation by distance has been reported in a number of organisms with short larval durations (Mokhtar-Jamai 2011; Alberto et al. 2011; Horne et al. 2011) but was not detected in this analysis. Genetic homogeneity was detected at large spatial scales $(1500 \mathrm{~km})$ and heterogeneity at small spatial scales (520 km) using both IAM and SMM. This highlights the need to use microsatellite markers to re-evaluate the population structure of other commercially targeted species that are presumed to form panmictic populations based on allozyme or mDNA analysis. 
Many of the findings in this analysis are supported by oceanographic dispersal and recruitment models for J. edwardsii developed by Chiswell et al. (2003) and Chiswell and Booth (2008) that were introduced in Chapter 1. A more detailed analysis of these models and the cohesiveness with the genetic patterns reported in this chapter will be presented in Chapter 4.

\subsubsection{Within-Population Diversity}

Heterozygote deficiencies were observed across all populations sampled. Heterozygote deficiencies have been reported as a common occurrence in marine species and are generally associated with null alleles, particularly when dealing with invertebrates with large effective population sizes like J. edwardsii (Li et al. 2003; Hedgecock et al. 2004). Null alleles in this study may have contributed in some part to the heterozygote deficiencies observed, but because null alleles are locus specific it would be expected that deviations from HWE caused by null alleles at a particular locus would appear in every population sampled. In this analysis, however, no locus deviated significantly at every population and therefore null alleles cannot be used to explain all of the heterozygote deficiencies observed.

Heterozygote deficiencies may also be a product of inbreeding or the Wahlund effect (Van Oosterhout et al. 2004), where two or more genetically differentiated populations are sampled as one (Maggio et al. 2009). Given that the samples were collected within a small area relative to the PLD of J. edwardsii, it is unlikely that the data was influenced by the Wahlund Effect (Maggio et al. 2009). This suggests that heterozygote deficiencies observed in this study may be largely explained by inbreeding.

Stewart Island had the lowest levels of genetic diversity with the lowest number of private alleles, mean number of alleles per locus and total number of alleles. The low levels of genetic diversity at SI suggests a certain level of over-exploitation in that area relative to the other populations and the intensive fishing in the area may be one explanation for the low levels of genetic diversity. A reduction in genetic 
diversity and effective population size resulting from intensive fishing pressure has been well documented for a number of commercially harvested species in New Zealand (Hauser et al. 2002) and worldwide (Hutchings and Baum 2005). Since the introduction of rock lobster into the New Zealand QMS (1991) CRA 8 (Stewart Island corresponding management area) has been allocated the largest portion of the TACC and consequently has reported the highest levels of commercial catch (Table 9). Although the fishing pressure in this area has been the most intensive, catch-perunit-effort (CPUE) has remained well above any other management area (Star 2011) indicating that populations are stable and unlikely to be over-exploited.

Stewart Island was also determined to be the most genetically distinct population. It may be the case that discrete oceanographic processes in the region have isolated SI and enhanced self-recruitment, leading to a reduction in the effective population size. This could also explain the low levels of genetic diversity (Frankham 1996). Furthermore, the effects of genetic drift and inbreeding on genetic diversity (number of alleles) are intensified when effective population sizes are reduced.

The South Australia population contained the highest levels of genetic diversity. Mean number of alleles per locus and the total number of alleles were the highest of any population sampled. This suggests that the South Australia population may have the largest effective population size (Frankham 1996), which is further supported by results from the MIGRATE analysis that determined SA to be much larger than New Zealand, despite more intensive and widespread sampling in New Zealand. The Southern Zone of the South Australian lobster fishery has reported consistent landings well above any New Zealand CRA zones since 1990 (Table 9). Despite a relatively small stretch of coastline $(350 \mathrm{~km})$ the total area of suitable habitat may be much larger in the SZRLF than in any of the CRA areas in New Zealand and thus able to support far larger populations. 
Table 9 Reported mean annual commercial catch and CPUE values (with standard deviations) for New Zealand CRA zones (Star 2011) and South Australia Southern Zone (Linnane et al 2011) for the J. edwardsii fishery from 1990-2010. Measurements of coastline were taken from Chiswell and Booth (2003) for CRA zones.

\begin{tabular}{lllll}
\hline $\begin{array}{l}\text { Quota Management } \\
\text { Area }\end{array}$ & $\begin{array}{l}\text { Sample } \\
\text { Location }\end{array}$ & $\begin{array}{l}\text { Mean Commercial } \\
\text { Catch } \\
\text { (Metric tones) }\end{array}$ & $\begin{array}{l}\text { CPUE } \\
\text { (kg/potlift) }\end{array}$ & $\begin{array}{l}\text { Length of } \\
\text { Coastline } \\
(\mathrm{Km})\end{array}$ \\
\hline SZRLF & SA & $1723 \pm 177.53 \mathrm{SD}$ & $1.25 \pm 0.42$ SD & 350 \\
CRA 8 & SI, SWC & $776 \pm 140.32$ SD & $1.48 \pm 0.94$ SD & 1112 \\
CRA 5 & KAI & $325 \pm 29.27$ SD & $0.98 \pm 0.64$ SD & 1016 \\
CRA 6 & CHI & $341 \pm 23.16 S D$ & $1.17 \pm 0.33$ SD & 277 \\
CRA 4 & WEL & $486 \pm 99.42 S D$ & $0.89 \pm 0.38 S D$ & 580 \\
CRA 2 & HG & $221 \pm 14.74 S D$ & $0.63 \pm 0.30 S D$ & 739 \\
\hline
\end{tabular}

\subsubsection{Stock Structure}

Microsatellite analysis revealed significant population structure throughout New Zealand and contrasts previous analysis by Ovenden et al. (1992). Global $F_{S T}$ and $R_{S T}$ were low but significant $(p<0.05)$ at 0.011 and 0.029 , respectively. Although low, significant values indicate a certain degree of restriction to gene flow between sampled populations. Although the Bayesian clustering analysis STRUCTURE revealed extensive admixture and minimal spatial structuring, in cases where gene flow is high, testing for variation in frequency of alleles can be more powerful than applying STRUCTURE analysis (Hubisz et al. 2009).

Allele frequency variation based on the IAM found 19 out of 21 pairwise comparisons to be significant but only 12 pairwise comparisons based on the SMM. Stewart Island and South Australia were the only populations to show significant pairwise differences across all populations under both the IAM and SMM. These results were supported by the AMOVA, which attributed among-group variation to be the highest ( $5 \%$ ) when $\mathrm{SI}$ was excluded from the New Zealand grouping. AMOVA also detected significant spatial structure between groups when HG was excluded from the New Zealand cluster ( $\sim \%$ ); however, this was only partially supported by variation in allele frequency analysis. Under the IAM, all of the HG pairwise values were significant but only one of the values (with SWC) was significant under the SMM (excluding SI and SA). 
Hauraki Gulf was the most northern of the sample sites and significant $\mathrm{F}_{\mathrm{ST}}$ values across the board indicated some degree of restriction of gene flow to populations to the south. The main portion of the East Auckland Current deflects northward before joining up with the East Cape Current and gives rise to a number of topographical eddies (Heath 1982). These eddies could work to enhance self-recruitment in the region and also limit the amount of larvae that enter the East Cape Current and are dispersed to the south. This would explain the subtle but significant genetic differences for populations such as WEL, CHI and KAI. Furthermore, low $\mathrm{F}_{\mathrm{ST}}$ values with SWC, despite being separated by a large distance, may be evidence of some gene flow up the west coast of the North Island and around the North Cape. These findings are not supported by $R_{S T}$ values that showed none of the comparisons to be significant, except for with SWC, and instead suggest unrestricted gene flow with the centrally located populations.

WEL, $\mathrm{KAI}, \mathrm{CHI}$ and SWC pairwise $\mathrm{F}_{\mathrm{ST}}$ comparisons were all very low $(<0.008)$, with a mean value of 0.006 ( \pm 0.002 SD), two of which were non-significant (SWC and CHI, SWC and KAI); this suggests relatively unrestricted gene flow between these populations. This trend was supported under the SMM, which found none of the pairwise comparisons to be significant, and the dendrogram of Nei's genetic distance that clustered those four populations as the most closely related.

The genetic similarity of the SWC population to the central east coast populations (KAI, WEL, CHI) can be largely explained by the oceanographic currents and features of the region. The Westland Current flows north along the east coast of the South Island and eventually meets the D'Urville current that sweeps through the Cook Straight as shown in Figure 7. The Westland current therefore has the potential to carry larvae from the West Coast of the South Island north through the Cook Straight to the central New Zealand populations. The Cook Straight was formed between 16,000 and 6,000 years ago as a result of sea level rise (Lewis et al. 1994), and because there is no evidence of an east-west genetic break, it appears to have 
facilitated gene flow between the west and east coast populations since its formation.

Stanton (1976) and Harris (1990) suggest, however, that the Westland Current is inherently variable and dominated by upwelling caused by its northerly flow that would direct larvae offshore to the west and restrict transport through the straight (Apte and Gardner 2002). Prevailing NW winds also generate strong upwelling along the north east coast of the South Island and drive the majority of the water coming through the Cook Straight offshore in an easterly direction (Apte and Gardner 2002). Any larvae within these currents would be either caught in the Wairarapa eddy or lost from the coastal system. These localised upwelling events at the northwest and northeast tip of the South Island, and the subsequent offshore movement of planktonic larvae from the coastal system, is thought to be an explanation for the north-south genetic break reported in a number of studies (Apte and Gardner 2002; Waters and Roy 2004).

A meta-analysis of genetic connectivity patterns in New Zealand by Gardner et al. (2010) showed that $33 \%$ of genetic connectivity studies in New Zealand reported some degree of north-south population differentiation. The majority of those studies reported the break to be around $42^{\circ}$ latitude, near Cape Campbell on the east coast and Little Wanganui River on the west coast. This break is also supported by the Department of Conservation to separate the Northern and Southern biogeographical zones of New Zealand (Gardner et al. 2010). Given the strong evidence for restriction to gene flow between SI and the other New Zealand populations, this genetic analysis confirms a north-south genetic break, but does not support the genetic break at $42^{\circ}$ south. Instead this study shows that populations to the south of $42^{\circ}$ (SWC) are genetically homogenous to populations above (WEL) the proposed break. Strong evidence suggests that the north south-genetic break in this analysis appears at Foveaux Straight. There was no evidence for east-west genetic break. The unparalleled larval duration of J. edwardsii may explain, in part why findings in this study are inconsistent with some of the previous genetic studies around New Zealand. 
The Waiarapa Eddy is the largest retentive mechanism along the east coast of New Zealand and is thought to be the most significant oceanographic feature influencing recruitment in the region (Lesser 1978; Chiswell and Roemmich 1998; Chiswell and Booth 2008). It has been well documented that larvae become entrapped in this eddy and are kept within successful recruitment distance from the coastline for the duration of the pelagic larval stage, instead of being swept away from the coast and lost from the system entirely (Chiswell and Booth 1999).

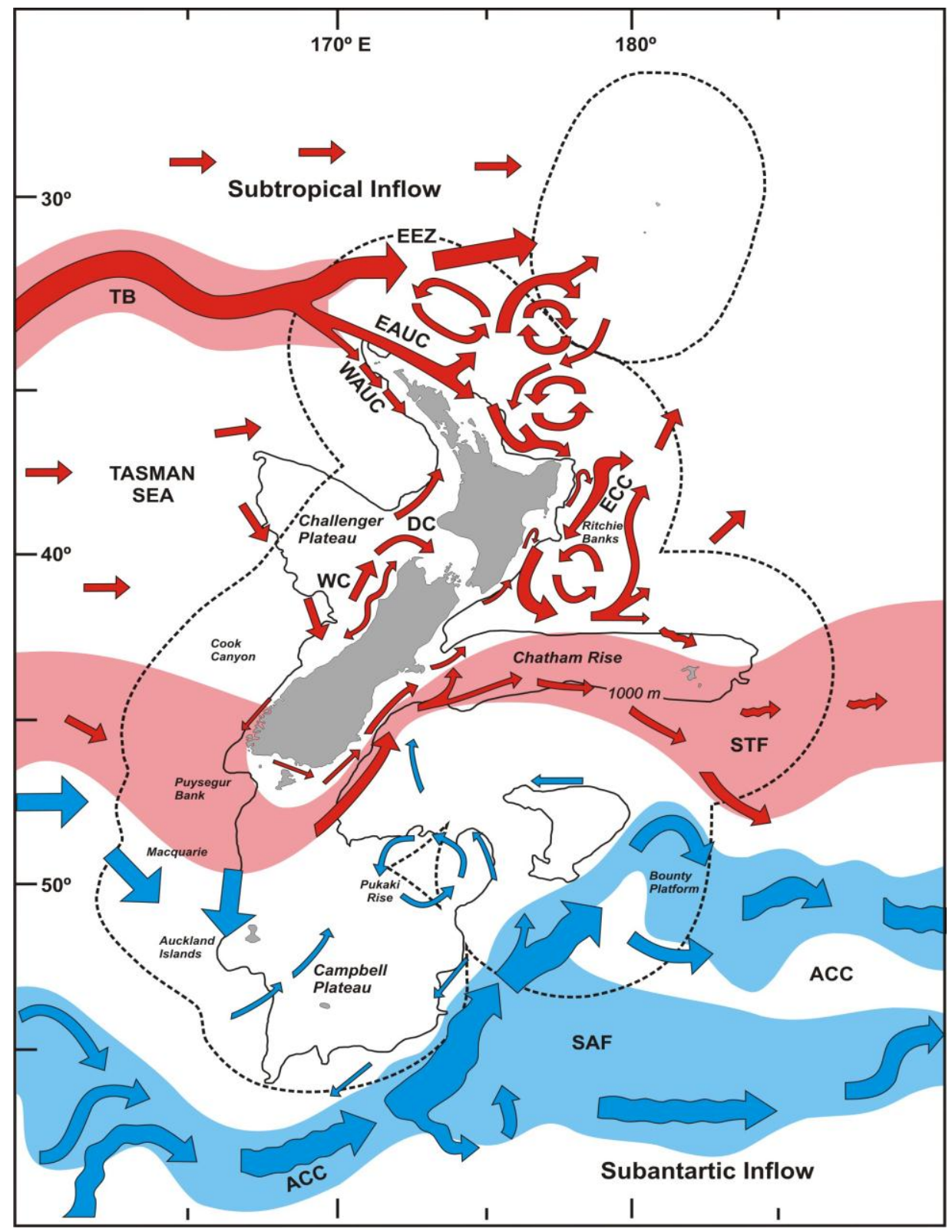

Figure 7 Prevailing current systems of New Zealand.Courtesy of Sebastian Hernandez. 
This oceanographic feature may play an important role in maintaining genetic homogeneity for J. edwardsii along the east coast by trapping phyllosoma larvae from a number of sources and providing a homogenized supply of recruits to east coast populations.

Genetic analysis also suggests that Chatham Islands is connected by high levels of gene flow to the mainland and, despite its oceanographic isolation, showed little differentiation from the other central zone populations. The Chatham Islands sit in an overwhelming easterly flowing current system (Figure 7). The ECC from the north and the Southland Current from the south deflect eastward at the Chatham Rise and along with the D'Urville Current may be maintaining homogeneity by transporting larvae from the mainland out to the islands. The Wairarapa Eddy could also be a source of recruits out to the islands. However, the size of the islands offers a very small recruitment window for the larvae. It is worth noting that a number of the CRA 6 commercial fishermen believe that adult lobsters are walking across the Chatham Rise out to the islands (pers comm, Daryl Sykes). This would explain high densities of large adults from year to year despite intensive fishing pressure. Further investigation is needed to determine if this is the case.

The strongest pattern of genetic differentiation occurred when comparing Stewart Island with the other populations. Pairwise values of allele frequency variation indicated that SI was the most genetically distinct and the only New Zealand population with significant levels under both mutation models. Allele frequency variation also determined that samples taken from South Australia, which is thousands of kilometres away from New Zealand, are more closely related to the New Zealand populations than the Stewart Island population is. Demographic connectivity based on assignment tests (Table 6B) also determined that the New Zealand populations are more connected to Australia than they are to Stewart Island. Further evidence of this was also presented by STRUCTURE, which detected a clustering trend that showed SI to be more distinct than SA from the other New Zealand populations (Figure 6). Differentiation between groups based on AMOVA 
was the highest $(4.6 \% \mathrm{p}<0.05)$ when $\mathrm{SI}$ was separated from the New Zealand populations.

The results from the assignment tests (Table 6B) showed that Stewart Island had a successful assignment rate of nearly $80 \%$. This suggests that an overwhelming majority of adult individuals in that population originate from that region and is evidence for self-recruitment. This is further supported by the MIGRATE analysis that determined Stewart Island to receive non-significant levels of gene flow from the other populations to the north (Table 8B). This asymmetric flow indicates that very few larvae are travelling southward against the currents, and consequently Stewart Island populations are almost entirely maintained by local recruits. The highly variable nature of the Southland Current as it flows through the Foveaux Straight suggests no clear pattern of flow, but rather the currents are largely wind driven (about $30 \%$ of the time the general flow direction is reversed and runs in a westerly direction (Chiswell 1996)) and could be one of the oceanographic processes retaining larvae in the region. The eddy that forms around the Pukaki Rise (Figure 7) to the south east of Stewart Island could also be retaining larvae near the bottom of the South Island and enhancing local recruitment.

As mentioned earlier, due to its geographic isolation in the south, Stewart Island could be characterised by unique oceanographic processes that are not only retaining larvae in the region but also restricting dispersal to the other New Zealand populations sampled. The Subtropical Convergence flows easterly across the bottom of the Tasman Sea and moves past Stewart Island and up the east coast of the South Island, deflecting eastward at the Chatham Rise at roughly $44^{\circ} \mathrm{S}$ (Vincent et al. 1991). The deflection occurs south of the KAl sample site and could prevent larvae from recruiting to this region. This would explain the significant genetic differentiation between SI, KAl and the other centrally located east coast populations. On the west coast, larvae released north of Milford Sounds would be predominantly directed north by the Westland current, explaining the relatively high levels of differentiation between the SI and the SWC population. 


\subsubsection{Trans-Tasman Gene Flow}

It has been previously suggested that larval dispersal is occurring across the Tasman Sea at levels high enough to maintain New Zealand J. edwardsii populations, particularly along the west coast of the South Island. This assumption has been based on: (1) the lack of mDNA genetic differentiation between New Zealand and Australian populations (Ovenden et al. 1992); (2) the detection of mid-late stage phyllosoma larvae in Tasman Sea (Booth et al. 1990, Booth and Ovenden 2000); and (3) the results from oceanographic models (Chiswell et al. 2003). The southwest coast of New Zealand supports a productive J. edwardsii fishery with high levels of annual recruitment (Booth and Breen 1992), however, there are no apparent oceanographic retention mechanisms in the region that could trap larvae and facilitate self-recruitment (Heath 1980; Chiswell et al. 2003). This implies that the larvae recruiting to this coast are coming from another source.

The results from the trans-Tasman gene flow analysis using microsatellite markers clearly showed asymmetric gene flow from Australia to New Zealand (Table 8A) and support a historical source-sink relationship between the two countries. Significant migration rates were determined from Australia to New Zealand but not in the other direction, based on the OMPG rule proposed by Mills and Allendorf (1996). These findings are perhaps not surprising given the predominant easterly flowing current systems of the region. Relatively large population sizes in Australia also supports a substantial contribution of Australian recruits to New Zealand lobster populations.

Bayesian assignment tests determined that roughly $11 \%$ (Table 6B) of New Zealand individuals came from South Australia. This number provides some indication of the level of successful recruitment across the Tasman Sea and the proportion of New Zealand adult lobsters that are of Australian origin. This will be discussed in further detail in the following chapter. Interestingly, the assignment tests also showed that almost half of the South Australia population belonged to the New Zealand group, implying that there is a strong Australian signature in the New Zealand populations and provides further evidence for asymmetric gene flow. Generally, these results 
highlight the limit of assignment tests in situations where gene flow is highly asymmetrical and where population structure is relatively low (Manel et al. 2005).

Genetic analysis showed the SA population to be most closely related to SWC of all the locations sampled and suggests that larvae released from South Australia predominantly recruit to the southwest coast of the South Island. SA and SI are the most genetically distinct of the pairwise comparisons in this study, which supports the isolation of Stewart Island from gene flow and larval recruits coming from Australia. It is important to note that only one population from Australia was sampled, and it may be the case that other locations in Australia, such as Tasmania, would have a different source-sink relationship with Stewart Island than the South Australia population sampled in this analysis.

\subsubsection{Conclusions}

This analysis identified significant genetic structure of J. edwardsii populations in New Zealand and across the Tasman Sea and has rejected the null-hypothesis of panmixia. This analysis provides strong genetic evidence for asymmetric transTasman gene flow and the reliance of New Zealand lobster populations on recruitment from Australia. This has important implications for the future management of the species as it is likely that the effects of a stock decline in Australia will be felt in New Zealand, particularly on the south west coast. An exception to this may be the Stewart Island population, as it appears to be genetically distinct from all other populations and characterized by high levels of self-recruitment. 


\subsection{Literature Cited}

Alberto, F. et al. (2011) Isolation by oceanographic distance explains genetic structure for Macrocystis pyrifera in the Santa Barbara Channel. Molecular Ecology, 20, 2543-2554.

Apte S, Gardner JPA (2002) Population genetic subdivision in the New Zealand greenshell mussel (Perna canaliculus) inferred from single-strand conformation polymorphism analysis of mitochondrial DNA. Molecular Ecology, 11, 1617-1628.

Baums, I.B., Miller, M.W. \& Hellberg, M.E. (2005) Regionally isolated populations of an imperiled Caribbean coral, Acropora palmata. Molecular ecology, 14, 1377-1390.

Beerli, P. (1998) Estimation of migration rates and population sizes in geographically structured populations. Advances in Molecular Biology, 39-53 in G. Carvalho, ed. Advances in molecular ecology. NATO-ASI Workshop Series. IOS Press, Amsterdam.

Beerli, P. \& Felsenstein, J. (1999) “Maximum-likelihood estimation of migration rates and effective population numbers in two populations using a coalescent approach." Genetics, 152, 763-773.

Booth, J.D., Street, R.J. \& Smith, P.J. (1990) Systematic status of the rock lobsters Jasus edwardsii from New Zealand and J . novaehollandiae from Australia. New Zealand Journal of Marine and Freshwater Research, 24, 239-249.

Booth JD \& Phillips BF (1994) Early life history of spiny lobster. Crustaceana, 66, 271294.

Booth JD, Breen PA (1992) Stock structure in the New Zealand red rock lobster, Jasus edwardsii. Report No. 92/20, Ministry of Agriculture and Fisheries, Wellington

Booth, J.D. \& Ovenden, J.R. (2000) Distribution of Jasus spp (Decapoda: Palinuridae ) phyllosomas in southern waters: implications for larval recruitment. Marine Ecology Progress Series, 200, 241-255.

Bowman MJ, Kibblewhite AC, Murtagh RA, Chiswell SM, Sanderson BG (1983) Circulation and mixing in greater Cook Strait, New Zealand. Oceanolog Act, 6, 383-391.

Chiswell, S. \& Roemmich, D. (1998) The East Cape Current and two eddies: a mechanism for larval retention? New Zealand Journal of Marine and Freshwater Research, 32, 385-397. 
Chiswell, S.M. \& Booth, J.D. (1999) Rock lobster Jasus edwardsii larval retention by the Wairarapa Eddy off New Zealand. Marine Ecology Progress Series, 183, 227-240.

Chiswell, S.M. \& Booth, J.D. (2008) Sources and sinks of larval settlement in Jasus edwardsii around New Zealand: Where do larvae come from and where do they go? Marine Ecology Progress Series, 354, 201-217.

Chiswell, S.M. (1996) Variability in the Southland Current, New Zealand. New Zealand Journal of Marine and Freshwater Research, 30, 1-17.

Chiswell, S.M., Wilkin, J., Booth, JD., Stanton, B. (2003) Trans-Tasman Sea larval transport: Is Australia a source for New Zealand rock lobsters? Marine Ecology Progress Series, 247, 173-182.

Crivello, J.F., Jr, D.F.L. \& Keser, M. (2005) The genetic stock structure of the American lobster (Homarus americanus) in Long Island Sound and Hudson Canyon. Journal of Shellfish Ecology, 24, 841-848.

Cowen, R. K., Paris, C. B., \& Srinivasan, A. (2006). Scaling of connectivity in marine populations. Science, 311, 522-7. doi:10.1126/science.1122039

Crowder LB, Lyman SJ, Figuera WF, Priddy J. (2000) Source-sink dynamics and the problem of marine reserves. Bulletin of Marine Science, 66, 799-820.

Estoup, A. \& Cornuet, J.-M. (1999). Microsatellite evolution: inferences from populationdata. In Microsatellites: Evolution and Applications (Goldstein, D. B. \& Schlotterer, C. eds), pp. 49-65. New York: Oxford University Press, Inc.

Excoffier, L. G. Laval, and S. Schneider (2005) Arlequin ver. 3.0: An integrated software package for population genetics data analysis. Evolutionary Bioinformatics Online 1, 47-50.

Fisher, R. (2005) Swimming speeds of larval coral reef fishes: impacts on selfrecruitment and dispersal. Marine Ecology Progress Series, 285, 223-232.

Frankham, R. (1996) Relationship of genetic variation and population size in wildlife. Conservation Biology, 10, 1500-1508.

Gerlach, G., Atema, J., Kingsford, M.J., Black, K.P. \& Miller-Sims, V. (2007) Smelling home can prevent dispersal of reef fish larvae. Proceedings of the National Academy of Sciences of the United States of America, 104, 858-863.

Goudet J (2001) FSTAT, a Program to Estimate and Test Gene Diversities and Fixation Indices Version 2.9.3. Available from http://www.unil.ch/izea/softwares/fstat.html 
Harris TFW (1990) Greater Cook Strait, Form and Flow (ed. Gordon DP), pp. 1-212. DSIR Marine and Freshwater, Wellington, New Zealand.

Hauser, L., Adcock, G.J., Smith, P.J., Ramiréz, J.H.B. \& Carvalho, G.R. (2002) Loss of microsatellite diversity and low effective population size in an overexploited population of New Zealand snapper (Pagrus auratus). Proceedings of the National Academy of Sciences of the United States of America, 99, 1174211747.

Heath, R.A. (1982) A review of the physical oceanography of the seas around New Zealand. New Zealand Journal of Marine and Freshwater Research, 19, 79124.

Heath RA (1980) Eastward oceanic flow past northern New Zealand, New Zealand Journal of Marine and Freshwater Research, 14:2, 169-182.

Hecker, K.H. \& Roux, K.H. (1996) High and low annealing temperatures increase both specificity and yield in touchdown and stepdown PCR. BioTechniques, 20, 478-485.

Hedgecock, D., Barber, P. H., \& Edmands, S. (2007). Genetic approaches to Measuring Connectivity. Oceanography, 20(3), 70-79.

Hedgecock D, Li G, Hubert S, Bucklin K, Ribes V (2004) Widespread null alleles and poor cross-species amplification of microsatellite DNA loci cloned from the Pacific oyster, Crassostrea gigas. Journal of Shellfisheries Research, 23, 379385.

Hilborn, R., Quinn, T.P., Schindler, D.E. \& Rogers, D.E. (2003) Biocomplexity and fisheries sustainability. Proceedings of the National Academy of Sciences of the United States of America, 100, 6564-6568.

Horne, J.B. et al. (2011) Limited ecological population connectivity suggests low demands on self-recruitment in a tropical inshore marine fish (Eleutheronema tetradactylum: Polynemidae). Molecular Ecology, 20, 2291306.

Hubisz, M.J., Falush, D., Stephens, M. \& Pritchard, J.K. (2009) Inferring weak population structure with the assistance of sample group information. Molecular Ecology Resources, 9, 1322-1332.

Hutchings, J.A \& Baum, J.K. (2005) Measuring marine fishes biodiversity: temporal changes in abundance, life history and demography. Philosophical transactions of the Royal Society of London. Series B, Biological Sciences, 360, 315-338. 
Jensen, J.L., Bohonak, A.J., and Kelley, S.T. (2005). Isolation by distance, web service. BMC Genetics 6: 13. v.3.21 http://ibdws.sdsu.edu/

Korbie, D.J. \& Mattick, J.S. (2008) Touchdown PCR for increased specificity and sensitivity in PCR amplification. Nature Protocols, 3, 1452-1456.

Knutsen, H. et al. (2011) Are low but statistically significant levels of genetic differentiation in marine fishes "biologically meaningful"? A case of coastal Atlantic cod. Molecular Ecology, 20, 768-783.

Krug, P.J. \& Zimmer, R.K. (2004) Developmental dimorphism: consequences for larval behavior and dispersal potential in a marine gastropod. The Biological Bulletin, 207, 233-246.

Largier, J.L. (2003) Considerations in Estimating Larval Dispersal Distances From Oceanographic Data. Ecological Applications, 13, 71-89.

Lewis K.B., Carter, L., Davey, F.J. (1994) The opening of the Cook Straight: Interglacial tidal scour and aligning basins at a subduction to transform plate edge. Marine Geology, 116:3, 293-312

Lesser, J.H.R. (1978) Phyllosoma larvae of Jasus edwardsii (Hutton) (Crustacea: Decapoda: Palinuridae) and their distribution off the east coast of the North Island, New Zealand. New Zealand Journal of Marine and Freshwater Research, 12:4, 357-370.

Levin, L. A. (2006). Larval dispersal : Recent progress in understanding new directions and digressions. Integrative and Comparative Biology, 46(3), 282-297.

Li, G. et al. (2003) Characterization of 79 microsatellite DNA markers in the Pacific oyster Crassostrea gigas. Molecular Ecology Notes, 3, 228-232.

Maggio, T., Brutto, S.L., Garoia, F., Tinti, F. \& Arculeo, M. (2009) Microsatellite analysis of red mullet Mullus barbatus ( Perciformes, Mullidae ) reveals the isolation of the Adriatic Basin in the Mediterranean Sea. (2009). International Council for the Exploration of the Sea, Oxford Journals, 1882-1891.

Manel, S., Gaggiotti, O. E., \& Waples, R. S. (2005). Assignment methods: matching biological questions with appropriate techniques. Trends in ecology \& evolution, 20(3), 136-42.

Meirmans, P.G. \& Hedrick, P.W. (2011) Assessing population structure: F(ST) and related measures. Molecular Ecology Resources, 11, 5-18.

Miller, M. P. (1997) Tools for population genetic analyses (TFPGA) 1.3; A Windows program for the analysis of allozyme and molecular population genetic data. 
Mills, L.S. \& Allendorf, F.W. (1996) The One-Migrant-per-Generation Rule in Conservation and Management. Conservation Biology, 10, 1509-1518.

Mokhtar-Jamaï, K. et al. (2011) From global to local genetic structuring in the red gorgonian Paramuricea clavata: the interplay between oceanographic conditions and limited larval dispersal. Molecular Ecology, 20, 3291-3305

Oosterhout, C. Van et al. (2004) Micro-Checker: Software for Identifying and Correcting Genotyping Errors in Microsatellite Data. Molecular Ecology Notes, $4,535-538$.

Ovenden, J.R., Brasher, D.J. \& White, R.W.G. (1992) Mitochondrial DNA analyses of the red rock lobster Jasus edwardsii supports an apparent absence of population subdivisions throughout Australasia. Marine Biology, 112, 319-326.

Paetkau D, Slade R, Burden M, Estoup A (2004) Direct, real-time estimation of migration rate using assignment methods: a simulation-based exploration of accuracy and power. Molecular Ecology, 13, 55-65.

Palumbi, S. R. (1994) Genetic Divergence, Reproductive Isolation, and Marine Speciation. Annual Review of Ecology and Systematics, 25, 547-57.

Palumbi, S. R., \& Warner, R. R. (2003). Why gobies are like Hobbits. Science, 299(5603), 51-2. doi:10.1126/science.1080775

Palumbi, S. R. (2004) Marine Reserves and Ocean Neighbourhoods: The Spatial Scale of Marine Populations and Their Management. Annual Review of Environmental Resources, 29, 31-68.

Piry S, Alapetite A, Cornuet, J.-M., Paetkau D, Baudouin, L., Estoup, A. (2004) GeneClass2: A Software for Genetic Assignment and First-Generation Migrant Detection. Journal of Heredity, 95, 536-539.

Pritchard JK, Stephens M, Donnelly P (2000) Inference of population structure using multilocus genotype data. Genetics, 155, 945-959.

Rannala B, Mountain JL (1997) Detecting immigration by using multilocus genotypes. Proceedings of the National Academy of Sciences, 94, 9197-9201.

Raymond, M., Rousset, F. (1993) GENEPOP (Version 1.2): Population Genetics Software for Exact Tests and Ecumenicism. Heredity, 86, 248-249.

Rice WR (1989) Analyzing tables of statistical tests. Evolution, 43, 223-235.

Ricker, W.E. (1981) Changes in the Average Size and Average Age of Pacific Salmon, Canadian Journal of fisheries and Aquatic Sciences, 38, 1636-1656. 
Rioux Paquette, Sebastien (2011) Popgenkit package for ' $R$ '.

Ruzzante, D.E. et al. (2006) Biocomplexity in a highly migratory pelagic marine fish, Atlantic herring. Proceedings. Biological sciences / The Royal Society, 273, 1459-1464.

Shanks, A.L., Grantham, B. a \& Carr, M.H. (2003) Propagule dispersal distance and the size and spacing of Marine Reserves. Ecological Applications, 13, 159-169.

Shears, N. \& Babcock, R. (2003) Continuing trophic cascade effects after 25 years of no-take marine reserve protection. Marine Ecology Progress Series, 246, 1-16.

Smith, P.J., Mckoy, J.L. \& Machin, P.J. (1980) Genetic variation in the rock lobsters Jasus edwardsii and Jasus novaehollandiae. New Zealand Journal of Marine and Freshwater Research, 14, 55-63.

Stanton, B.R. (1976) Circulation and hydrology off the west coast of the South Island, New Zealand, New Zealand Journal of Marine and Freshwater Research, 10:3, 445-467

Swearer, S.E. et al. (2002) Evidence of self-recruitment in demersal marine populations. Bulletin of Marine Science, 70, 251-271.

Swofford D.L., Olsen C.J. (1990) Phylogeny reconstruction. In: Hillis DM, Moritz C, eds. Molecular Systematics. Sunderland, Mass: Sinauer Press, 41, 1-501.

Thomas, L. \& Bell, J.J. (2011) Characterization of polymorphic microsatellite markers for the red rock lobster, Jasus edwardsii (Hutton 1875). Conservation Genetics Resources Online.

Thorrold, S. R., Zacherl, D., \& Levin, L. a. (2007). Population Connectivity and larval dispersal. Oceanography, 20(3), 80-89.

van Herwerden, L., Benzie, J., \& Davies, C. (2003). Microsatellite variation and population genetic structure of the red throat emperor on the Great Barrier Reef. Journal of Fish Biology, 62(5), 987-999.

Waples, R.S. \& Gaggiotti, O. (2006) What is a population? An empirical evaluation of some genetic methods for identifying the number of gene pools and their degree of connectivity. Molecular Ecology, 15, 1419-39

Waples, R.S. (1998) Separating the Wheat from the Chaff: Patterns of Genetic Differentiation in High Gene Flow Species. Journal of Heredity, 89, 438-450.

Waters JM, Roy MS (2004) Phylogeography of a high-dispersal New Zealand sea-star: does upwelling block gene-flow? Molecular Ecology, 13, 2797-2806. 
Weir, B.S. \& Cockerham, S.S. (1984) Estimating F-statistics for the analysis of population structure. Evolution 38, 1358-1370.

Wirgin I, Waldman JR (2005) Use of nuclear DNA in stock identification: single-copy and repetitive sequence markers. In: Cadrin SX, Friedland KD, Waldman JR (eds) Stock identification methods. Elsevier Academic Press, San Diego, CA

Worm, B. et al. (2006) Impacts of biodiversity loss on ocean ecosystem services. Science, 314, 787-90 


\section{Chapter IV: General Discussion}

The last few decades have been described as the Golden Age for stock identification (Quinn 2003). The advent of new classes of genetic markers, improved analytical methods, and user-friendly software has fostered novel insight into previously inaccessible aspects of the natural history of marine organisms, and has changed our understanding of connectivity in the marine environment (DeYoung and Honeycutt 2005, Hedgecock et al. 2007). Molecular techniques that were once only accessible to a select few are now readily available to the entire scientific community, and consequently genetics are now becoming an increasingly common avenue by which ecologists explore population structure of marine organisms.

The recent advent of highly variable markers, such as microsatellites, offer a higher resolving power than more traditional genetic techniques such as allozyme or mDNA analysis and have facilitated the detection of fine scale patterns of genetic differentiation that has gone undetected in previous analyses (Lage et al. 2001; Knutsen et al. 2003; Carlsson et al. 2004; Was et al. 2010). This thesis applied polymorphic microsatellite markers to investigate patterns of gene flow between Jasus edwardsii populations, and not only highlights that genetic techniques are an invaluable tool for investigating population connectivity but also that microsatellites are capable of detecting fine-scale spatial variation of highly dispersing marine species.

The appropriate application of genetic techniques, however, requires a comprehensive understanding of their limitations. Extensive dialogue between molecular ecologists and managers is imperative in order to ensure that results from genetic analyses are not misinterpreted (Carvalho and Hauser 1994). Genetic 
connectivity offers an explanation to the evolutionary consequences of dispersal between populations, and to infer contemporary patterns of connectivity based on genetic data without the support of direct measurements of dispersal is inappropriate (Lowe and Allendorf 2010). For example, genetic differentiation between populations could reflect historical fragmentation events that once restricted gene flow, and although these populations may be readily exchanging genes, not enough time has passed for the gene pools to become homogenised. On the other hand, genetic homogeneity does not simply imply high levels of connectivity. It could be the case that populations have recently become isolated, but insufficient time has passed for significant genetic divergence between populations. Genetic assignment tests begin to deal with this problem and can provide a direct measure of connectivity based on genotypes of reference populations. These tests, however, can be unreliable in situations of high levels of gene flow (Lowe and Allendorf 2010).

Therefore, to determine if patterns reflect contemporary ecological processes, genetic results should, whenever possible, be coupled with direct measures of connectivity, such as otolith microchemistry, morphological analysis or oceanographic models. An interdisciplinary approach that incorporates multiple techniques with different perspectives is the most effective at identifying population structure and determining stock boundaries, and as a result has become commonplace in the stock identification process (Abaunza et al. 2004; Hatfield et al. 2005). This discussion is aimed at providing support for the patterns of gene flow observed in Chapter 3 using oceanographic dispersal models.

\subsection{Coupling Genetics with Oceanography}

\subsubsection{Patterns of Recruitment around New Zealand}

Chiswell and Booth (2008) developed a model for J. edwardsii to determine sourcesink relationships between the CRA management zones around New Zealand. This model aimed to track larvae (treated as passive drifting particles) released from each CRA zone, and determined the most likely location of recruitment based on oceanographic surface currents and the pelagic larval duration of J. edwardsii. A 
detailed description of this model was presented in Chapter 2. Results from the model presented patterns of larval dispersal and recruitment that support the results of the genetic study described in Chapter 3 (assuming that the sampled populations are representative of the CRA zones ${ }^{1}$ ), suggesting that the genetic analysis not only reflects historical processes but also contemporary patterns of connectivity around New Zealand.

The results from the model showed a relatively high degree of demographic connectivity between CRA areas 9, 4, 5 and 6 (Table 1 and 2), which support the genetic data that showed high levels of gene flow between the South West Coast (SWC), Wellington (WEL), Kaikoura (KAI) and Chatham Islands (CHI) populations. Results from the model confirm that the transport of larvae from the west coast of the South Island through the Cook Straight, and between centrally located populations along the east coast of the North and South Island, are at sufficient levels to homogenize the gene pool between these populations.

When considering the fate of the phyllosoma released from each CRA zone and the location of metamorphosis for the recruiting puerulus (Table 1), the model showed that more than a third of larvae released from CRA 9 (SWC) travelled through the Cook Straight and metamorphosed in CRA 4 (WEL), and that $30 \%$ of larvae released from CRA 5 (KAI) also metamorphosed in CRA 4 (WEL). Furthermore, 17\% of larvae released from CRA 5 metamorphosed in CRA 6 (CHI) and roughly $40 \%$ of larvae released out at the Chatham Islands are metamorphosing near the mainland. The model also provided evidence that larvae released from CRA 2 (HG) are transported south by the East Cape Current and metamorphosing along the south east coast of the North Island.

\footnotetext{
${ }^{1}$ The SWC population was sampled in the northern boundary of CRA 8, however is more likely to reflect CRA 9 patterns of dispersal and recruitment than those of CRA 8.
} 
Table 1 Sinks: fate of phyllosoma hatched in each quota management area as predicted by Chiswell and Booth (2008) Table should be read as follows: 18\% of phyllosoma released from CRA 1 metamorphosis in CRA 2

\begin{tabular}{|c|c|c|c|c|c|c|c|c|c|}
\hline \multirow[b]{2}{*}{$\begin{array}{l}\text { Source quota } \\
\text { management area }\end{array}$} & \multicolumn{9}{|c|}{ Destination Quota Management Area } \\
\hline & CRA 1 & CRA 2 & CRA 3 & $\begin{array}{l}\text { CRA } \\
4 \\
\end{array}$ & $\begin{array}{l}\text { CRA } \\
5 \\
\end{array}$ & $\begin{array}{l}\text { CRA } \\
6 \\
\end{array}$ & CRA 7 & CRA 8 & CRA 9 \\
\hline CRA 1 & 1 & 18 & 12 & 46 & 1 & 16 & 0 & 0 & 8 \\
\hline CRA 2 & 0 & 23 & 39 & 33 & 0 & 4 & 0 & 0 & 0 \\
\hline CRA 3 & 0 & 0 & 59 & 38 & 1 & 2 & 0 & 0 & 0 \\
\hline CRA 4 & 0 & 0 & 58 & 37 & 0 & 4 & 0 & 0 & 0 \\
\hline CRA 5 & 0 & 0 & 53 & 29 & 2 & 17 & 0 & 0 & 0 \\
\hline CRA 6 & 0 & 0 & 28 & 9 & 0 & 63 & 0 & 0 & 0 \\
\hline CRA 7 & 0 & 0 & 39 & 20 & 1 & 39 & 0 & 0 & 0 \\
\hline CRA 8 & 2 & 0 & 0 & 25 & 21 & 0 & 2 & 30 & 19 \\
\hline CRA 9 & 5 & 5 & 20 & 36 & 4 & 6 & 0 & 6 & 17 \\
\hline
\end{tabular}

Larval recruitment projections (Table 2) followed similar trends and displayed a relatively high degree of connectivity between CRA 9 (SWC), CRA 4 (WEL), CRA 5 (KAI) and CRA $6(\mathrm{CHI})$. The model determined that CRA 4 (WEL) received 11\% of recruits from CRA 9 (SWC) and 15\% from CRA 5 (KAI). Results also showed that CRA 6 (CHI) received roughly $75 \%$ of total recruitment from these populations: $50 \%$ of its recruitment from north-east coast of the South Island (KAI), 13\% from the south-east coast of the North Island (WEL) and 10\% from the south-west coast of the South Island (SWC).

Table 2 Sources of settlement (\% in each quota management area as predicted by Chiswell and Booth (2008). Table should be read as follows: CRA 1 receives $80 \%$ of recruits from CRA 9.

\begin{tabular}{llllllllll}
\hline & \multicolumn{7}{c}{ Source of Recruits } \\
\cline { 2 - 9 } Recruitment & CRA 1 & CRA 2 & CRA 3 & CRA 4 & CRA 5 & CRA 6 & CRA 7 & CRA 8 & CRA 9 \\
\hline CRA 1 & 4 & 1 & 1 & 14 & 0 & 0 & 0 & 0 & 80 \\
CRA 2 & 19 & 20 & 28 & 24 & 7 & 1 & 0 & 0 & 1 \\
CRA 3 & 8 & 10 & 25 & 25 & 25 & 1 & 1 & 0 & 6 \\
CRA 4 & 8 & 12 & 17 & 16 & 15 & 0 & 1 & 21 & 11 \\
CRA 5 & 0 & 1 & 1 & 1 & 4 & 0 & 0 & 87 & 6 \\
CRA 6 & 0 & 1 & 6 & 13 & 51 & 10 & 8 & 2 & 10 \\
CRA 7 & 0 & 0 & 0 & 0 & 0 & 0 & 0 & 95 & 5 \\
CRA 8 & 0 & 0 & 0 & 0 & 0 & 0 & 0 & 93 & 7 \\
CRA 9 & 0 & 0 & 0 & 0 & 0 & 0 & 0 & 74 & 25
\end{tabular}


The model also showed a high degree of isolation of the CRA 8 management area. Chiswell and Booth (2008) suggested that adult populations in CRA 8 may be entirely maintained by local recruitment. Results from the model indicated that approximately a third of the larvae released within CRA 8 (Stewart Island corresponding management area) settled locally (Table 1) and nearly 95\% of the larvae that recruit to CRA 8 are hatched within its boundaries (Table 2). This indicates a high degree of self-recruitment in the area and although CRA 8 is contributing to other populations around New Zealand very few larvae recruiting to CRA 8 originate from CRA areas to the north. This isolation of Stewart Island in the south is consistent with the genetic data from Chapter 3, which, as detailed earlier, showed significant levels of genetic differentiation and reproductive isolation of Stewart Island (CRA 8). The genetic analysis also identified a strong asymmetric pattern of gene flow to the north from Stewart Island and non-significant levels (based on the OMPG rule (Mills and Allendorf 1996)) in the opposite direction (Table $8 b$, Chapter 3 ), suggesting high levels of restriction to larval flow from other areas around New Zealand towards CRA 8.

\subsubsection{Trans-Tasman Dispersal}

An oceanographic model developed by Chiswell et al. (2003) that calculated the path of passive drifting particles across the Tasman Sea determined that dispersal in the west of the Tasman Sea was a likely mechanism maintaining lobster populations in New Zealand. This is supported by the genetic analysis that showed clear asymmetric gene flow across the Tasman Sea from Australia to New Zealand. The results from the model showed that roughly $8-14 \%$ of larvae released from southern Australia successfully arrive in New Zealand within the pelagic larval duration of J. edwardsii.

Based on Bayesian assignment tests, the genetic analysis showed $11 \%$ of individuals sampled in New Zealand to have originated from Australia, a strikingly similar figure to the one predicted by the model. Together, these results provide strong evidence that trans-Tasman gene flow is occurring and contributing substantial amounts of recruits to the New Zealand populations; roughly $10 \%$ of the adult J. edwardsii individuals in New Zealand originate from Australia. This indicates that, although 
some populations in New Zealand may be characterized by higher levels of selfrecruitment than others (e.g. Stewart Island), in general New Zealand lobster populations (particularly those on the south west coast above Fjordland) are dependent on recruitment from Australia. This has large implications for the management of the New Zealand fishery and intensifying collaborative efforts between the management organizations of the two countries should be a top priority for the New Zealand Rock Lobster Industry Council.

The results from the models developed by Chiswell et al. (2003) and Chiswell and Booth (2008) are clearly cohesive with the findings of the genetic analysis in Chapter 3 , indicating that that the genetic results not only reflect historical connectivity patterns but also contemporary patterns of dispersal of J. edwardsii. Furthermore, the consistency between the two techniques suggests that patterns of larval recruitment can potentially be accurately predicted using oceanographic models.

\subsection{Conclusions: Implications for Management}

The results from this analysis indicate that there are fewer genetic stocks then there are CRA management areas in New Zealand and under the current management strategy homogenous populations of lobster are split into different stocks and exploited at different levels. This is not an ideal management scenario. Stock splitting (homogenous populations split into a number of independently managed units) undermines the natural biological structure of a species and can lead to deleterious effects in yield of the fishery (Begg et al. 1999).

Nevertheless, although the genetic analysis has only identified two (possibly three) distinct J. edwardsii populations around New Zealand, the failure to detect additional genetically discrete populations does not imply they do not exist. More extensive sampling, particularly in the Fjordland, North Cape and Otago regions, may reveal additional genetic structure around New Zealand. Furthermore, it may be the case that the sample sizes in this analysis were too small to detect low levels of genetic differentiation between some of the populations, and subsequent studies using 
larger sample sizes may reveal further complexities that were not detected using only 50 individuals (Ward 2000).

Particular emphasis in the future should be placed on the relocation of the CRA 8/CRA 9 boundary. The SWC population was sampled close to the northern boundary of CRA 8 and showed high levels of genetic differentiation to southern CRA 8 populations (Stewart Island). Managing these populations as one stock may lead to an erosion of genetic diversity in the region and ultimately compromise the sustainability of the fishery. It is advised that the boundary separating CRA 8 and CRA 9 be moved south to reflect the bio-geographical break of the coastline. A more suitable boundary would be near Jackson Bay. This appears to be the northern boundary of the Southland Current and any larvae released above this location would likely be dispersed north by the Westland Current. More rigorous genetic sampling in this region, however, is advised before any measures are taken.

\subsection{Literature Cited}

Abaunza, P., Murta, A.G., Campbell, N. et al. (2008) Stock identity of horse mackerel (Trachurus trachurus) in the Northeast Atlantic and Mediterranean Sea: integrating the results from different stock identification approaches. Fisheries Research, 89, 196-209.

Begg, G.A., Friedland, K.D. \& Pearce, J.B. (1999) Stock identification and its role in stock assessment and fisheries management : an overview. Fisheries Research, 43, 1-8.

Cadrin and Secor (2007) Future of Fishery Science in North America, Manuscript submitted for Proceedings of the AIFRB 50th Anniversary Symposium, R.J. Beamish and B.J. Rothschild (eds.), The Future of Fisheries Science in North America.

Carlsson, J., McDowell, J.R., Diaz-Jaimes, P. (2004) Microsatellite and mitochondrial DNA analyses of Atlantic blueWn tuna (Thunnus thynnus thynnus) population structure in the Mediterranean Sea. Molecular Ecology, 13, 3345-3356.

Carvalho, G.R. \& Hauser, L. (1994) Molecular genetics and the stock concept in fisheries. Reviews in Biology and Fisheries, 4, 326-350. 
Chiswell, S.M., Wilkin, J., Booth, JD., Stanton, B. (2003) Trans-Tasman Sea larval transport: Is Australia a source for New Zealand rock lobsters? Marine Ecology Progress Series, 247, 173-182.

Chiswell, S.M. \& Booth, J.D. (2008) Sources and sinks of larval settlement in Jasus edwardsii around New Zealand: Where do larvae come from and where do they go? Marine Ecology Progress Series, 354, 201-217.

DeYoung R.W. and Honeycutt R.L. (2005) The Molecular tool box: Genetic techniques in wildlife ecology and management, Journal of Wildlife Management, 69, 4 1362-1384

Hatfield et al. (2005) WESTHER: A multidisciplinary approach to the identification of herring (Clupea harengus L.) stock components west of the British Isles using biological tags and genetic markers. ICES CM 2005/K.

Hedgecock, D., Barber, P.H. \& Edmands, S. (2007) Genetic approaches to measuring connectivity. Oceanography 20, 70-79.

Knutsen, H. et al. (2011) Are low but statistically significant levels of genetic differentiation in marine fishes "biologically meaningful"? A case of coastal Atlantic cod. Molecular Ecology, 20, 768-783.

Lage, C. et al. (2001) Microsatellite evaluation of haddock (Melanogrammus aeglefinus) stocks in the northwest Atlantic Ocean. Canadia Journal of Fisheries and Aquatic Sciences, 58: 5, 982-990.

Lowe, W.H. \& Allendorf, F.W. (2010) What can genetics tell us about population connectivity? Molecular Ecology,y 19, 3038-3051.

Mills, L.S. \& Allendorf, F.W. (1996) The One-Migrant-per-Generation Rule in Conservation and Management. Conservation Biology, 10, 1509-1518.

Postma, E. \& van Noordwijk, A.J. (2005) Gene flow maintains a large genetic difference in clutch size at a small spatial scale. Nature, 433, 65-68.

Quinn, T.J. (2003) Ruminations on the development of and future of population dynamics and models in fisheries. Natural Resource Modeling, 16, 341-392.

Ruzzante, D.E., Taggart, C.T., Cook, D. (1998) A nuclear DNA basis for shelf- and bankscale population structure in NW Atlantic cod (Gadus morhua): Labrador to Georges Bank. Molecular Ecology, 7: 1663-1680.

Ruzzante, D.E. et al. (2006) Biocomplexity in a highly migratory pelagic marine fish, Atlantic herring. Proceedings. Biological sciences / The Royal Society, 273, 1459-1464. 
Ward, R.D. (2000) Genetics in fisheries management. Hydrobiologia, 420, 191-201.

Was, A., Gosling, E.,Hoarau, G. (2010) Microsatellite analysis of plaice (Pleuronectes platessa L.) in the NE Atlantic: weak genetic structuring in a milieu of high gene flow. Marine Biology, 157:3, 447-462. 